\title{
Conceptualizing International Development Project Sustainability through a Discursive Theory of Institutionalization
}

by

Elizabeth C. Jackson

\author{
A thesis \\ submitted to the Victoria University of Wellington \\ in partial fulfilment of the \\ requirements for the degree of \\ Master of Management Studies
}

49,908 Words

Victoria University of Wellington

2010 


\section{Abstract}

Every year billions of dollars are spent on international development projects. Many of these projects, while initially appearing to be successful, lack the systems and resources that would contribute to their long term success, and collapse once outside assistance is withdrawn; they are unsustainable. This issue of project sustainability is of critical importance to the field of international development. This research uses a case study to explore how international development organizations understand and enact sustainability. Key questions that were asked in approaching this topic were: what makes a project sustainable, and how do international development organizations manage for the sustainability of their projects? This research looks to institutional theory in the attempt to shed light on the process of sustainable development. I endeavour to demonstrate how conceptualizing the process of sustainable development as a process of institutionalization may be of assistance in implementing sustainable development projects. This premise forms the foundation of my thesis.

The theoretical basis of this research can be located in the work of organizational scholar Nelson Phillips, who asserts that institutionalization, the process of institutional formation, should be conceived of as a discursive process. I conjecture that in order for a discourse to produce an institution, it must address three key institutional concerns as described in W. Richard Scott's theory of three institutional pillars. This theory holds that in order for an institution to be stable, it must have foundations in three recognized areas of organizational life: rules, values, and culture. I use critical discourse analysis to examine if and how these institutional concepts feature in organizational texts of sustainable development.

In order to study organizational texts on sustainable development, it was necessary to gain access to a representative development organization. New Zealand's international aid and development programme, NZAID, was identified as the ideal organization for this study, as its formal commitment to internationally recognized development agreements means that its practices should be representative of the practices of other similar organizations. Through interviews, observations and document analysis I have studied its approach to sustainable development, and how that approach continues down the chain of development to 
its partners and stakeholders within two projects in a province of Papua New Guinea (PNG). Data was collected at NZAID in Wellington, as well as at NZAID's office in Port Moresby, PNG, and among two of NZAID's development partners in rural PNG.

The findings of this research demonstrate that while themes of institutionalization are already present to some degree within international development organizations' sustainable development discourse, that discourse and the projects that it informs would benefit from more overt engagement with the principles of institutionalization. My research contributes to development practice by exploring how sustainability goals are formulated and diffused through organizational discourse, specifically between varied environments and organizational actors. It offers practical suggestions for the improvement of the process of sustainable development. This research also contributes theoretically to organization studies through its exploration of how institutional theory can be applied to better understand the process sustainable development. 


\section{Acknowledgements}

There were many people and organizations who were instrumental in making this research possible. I would like to thank NZAID (especially the Pacific Group) for their willingness to participate in my project, and for all that they did to facilitate its development. I would also like to thank Education New Zealand and the Victoria Management School for providing the funds that enabled me to conduct research in Papua New Guinea. It was the experience of a lifetime, and it contributed immeasurably to my ability to understand my theory and its practical application. Sincere thanks go to all of the people in Papua New Guinea who so graciously provided accommodation, transport, meals, and company during my stay. Thank you also to the many research participants who so willingly shared with me such rich information and anecdotes. And my most profound thanks go to my advisor, Dr. Deborah Jones, whose encouragement, insightful questions, and thoughtful comments were invaluable in helping me articulate my ideas and navigate the research process. 


\section{Table of Contents}

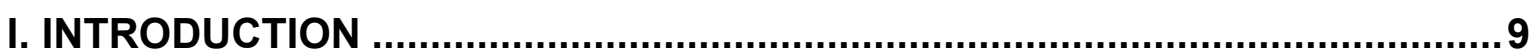

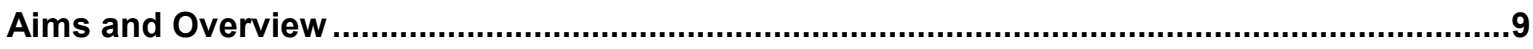

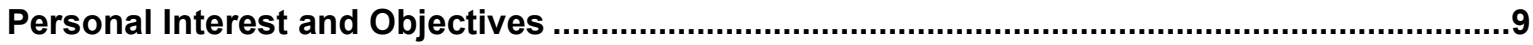

Institutions and Development.........................................................................................

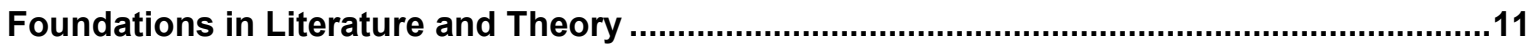

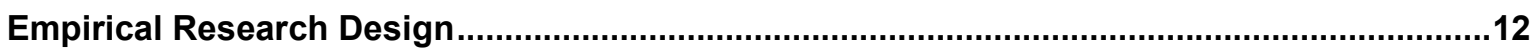

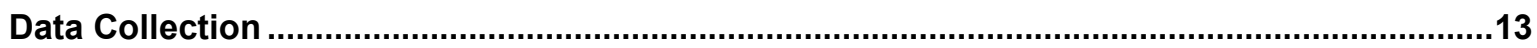

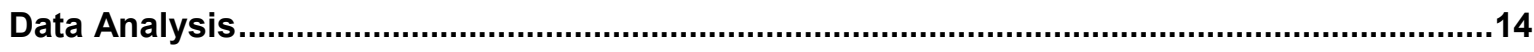

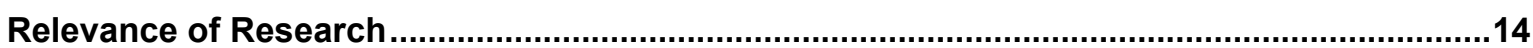

II. LITERATURE REVIEW - INTEGRATING DEVELOPMENT PRACTICE AND INSTITUTIONAL THEORY .........................................................................16

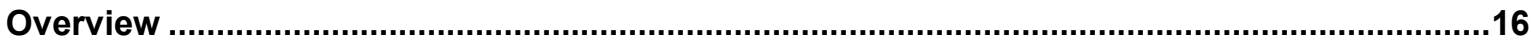

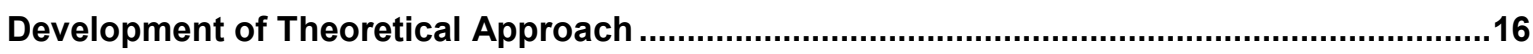

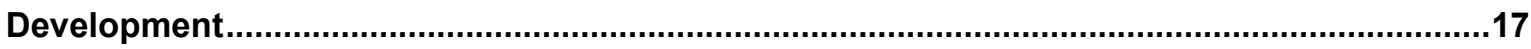

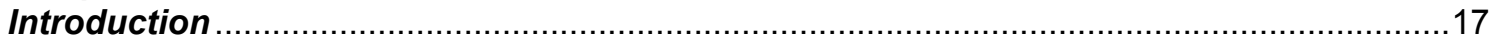

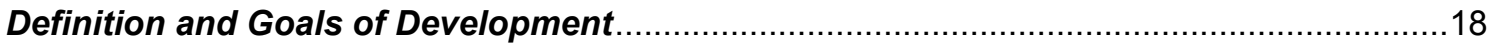

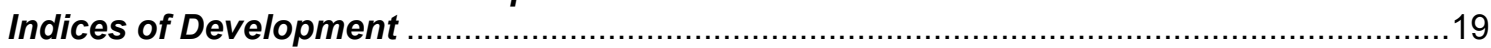

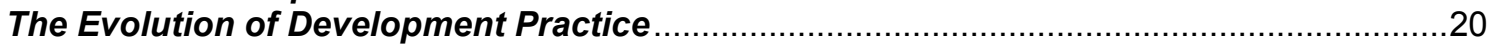

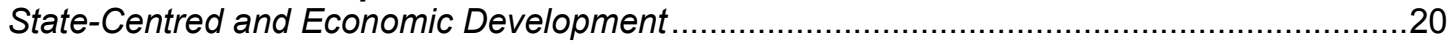

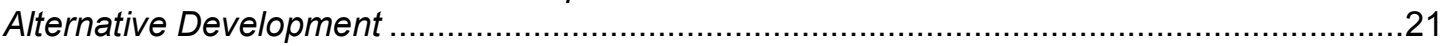

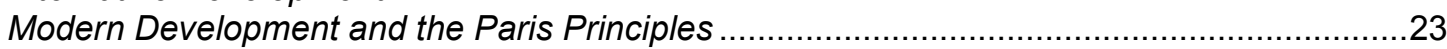

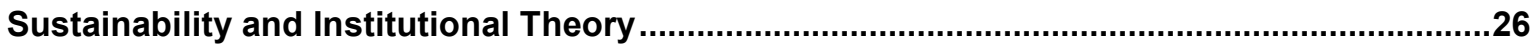

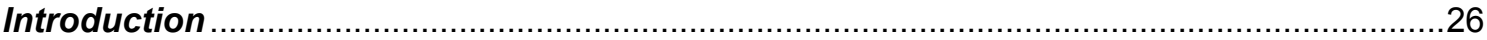

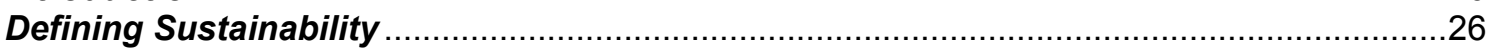

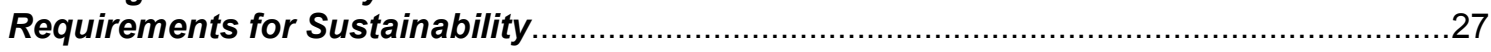

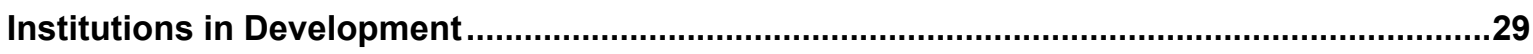

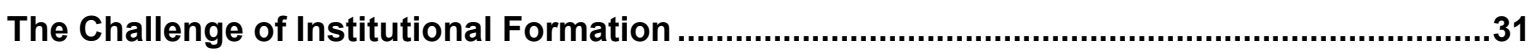

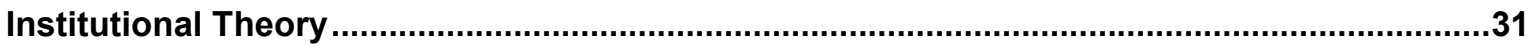

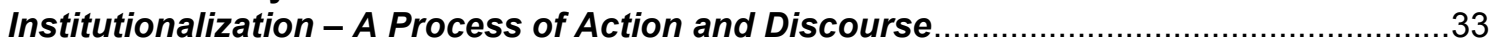

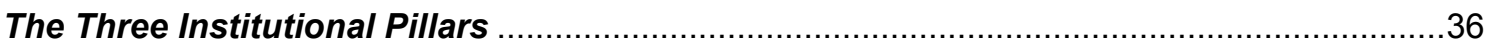

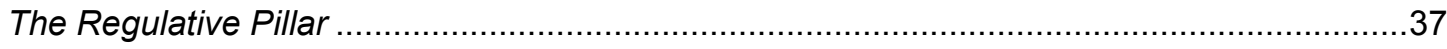

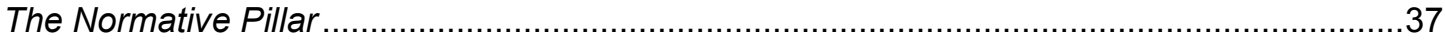

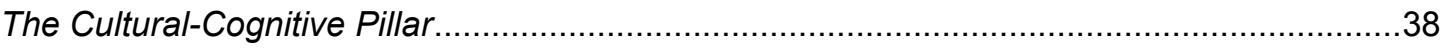

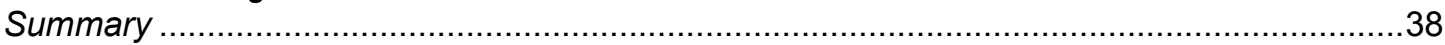

Contributions to Sustainable Development and to Institutional Theory....................................39

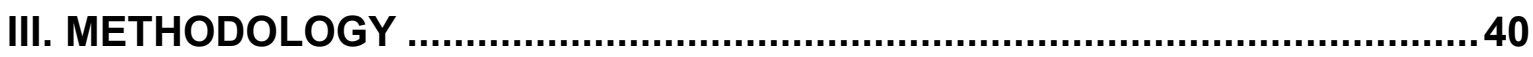

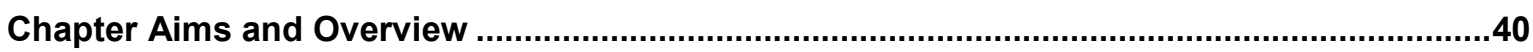




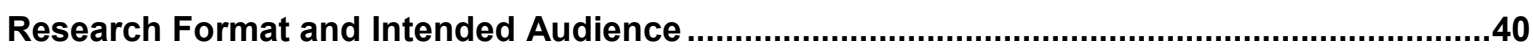

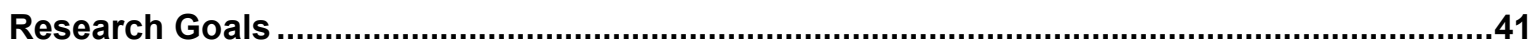

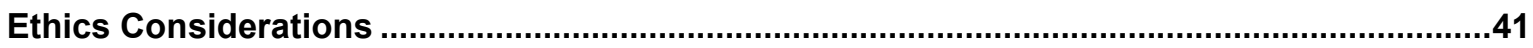

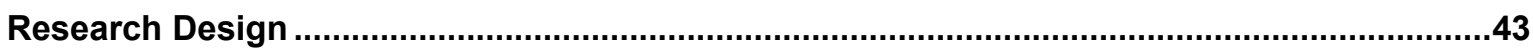

Neo-Institutionalism and Critical Discourse Analysis ..............................................................44

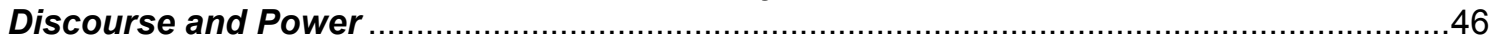

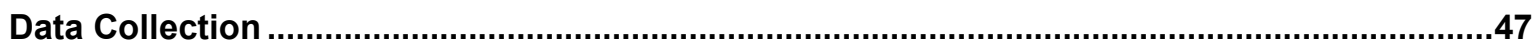

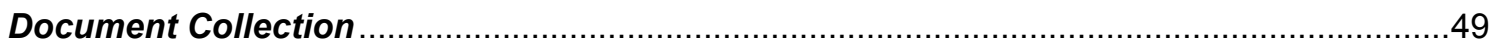

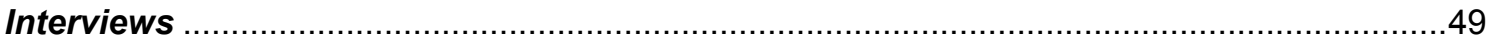

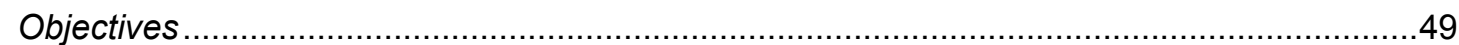

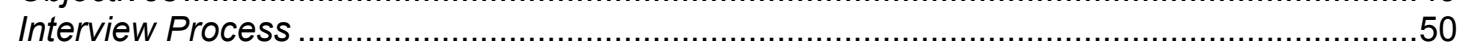

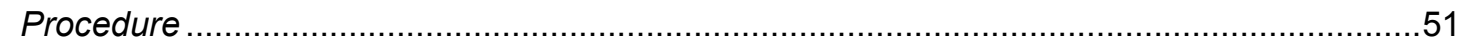

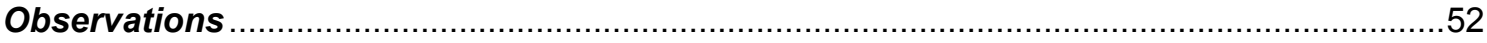

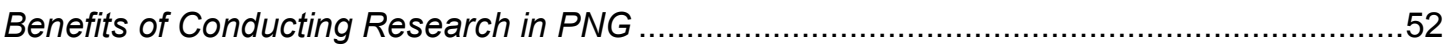

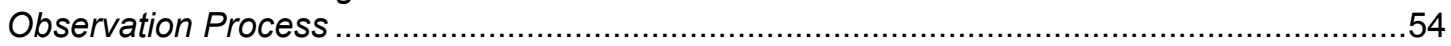

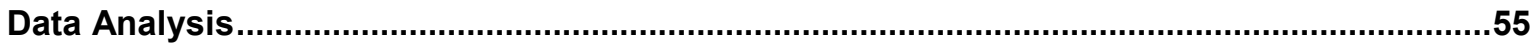

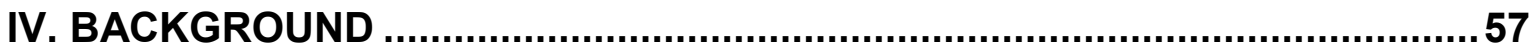

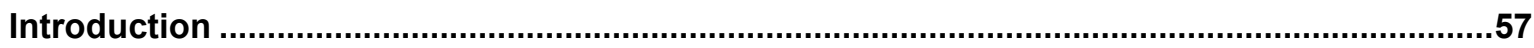

NZAID

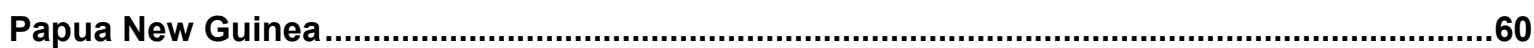

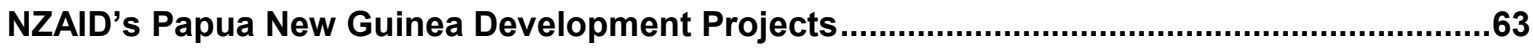

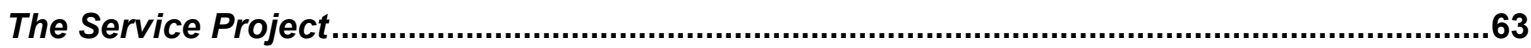

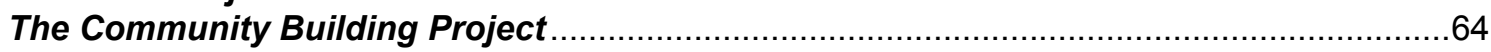

Sustainability Needs of Projects Understood through a Generational Framework.................65

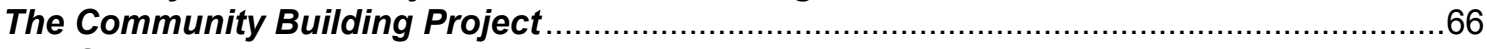

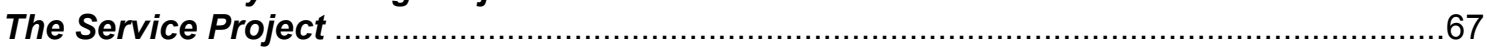

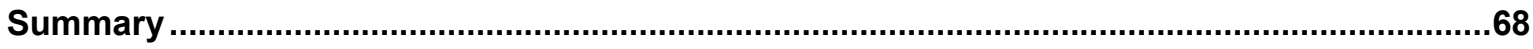

DATA ANALYSIS - SUSTAINABILITY .......................................................69

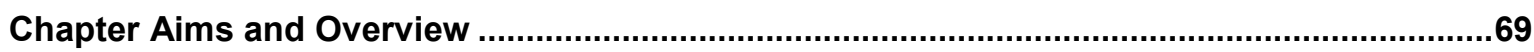

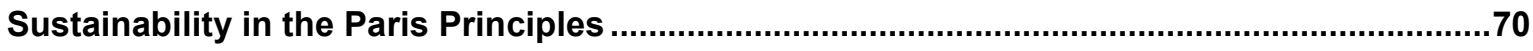

Themes of Sustainability in NZAID Organizational and Project Documents ..........................72

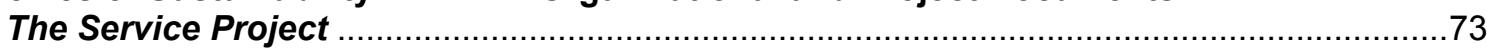

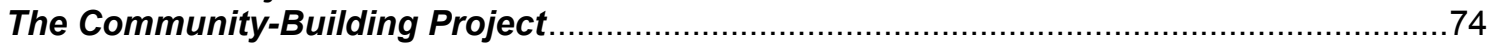

Projects as Representative of the Paris Principles' Focus on Government Primacy .............74

Understandings of Sustainability among NZAID Staff and Project Stakeholders ..................75

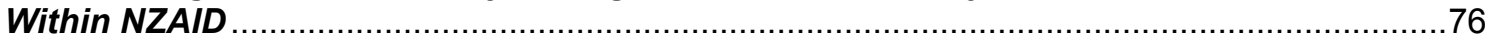

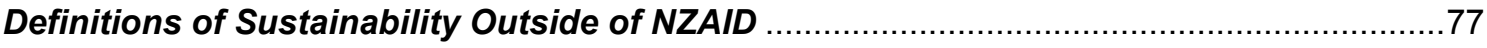

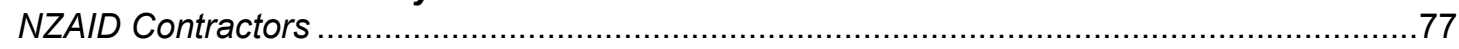

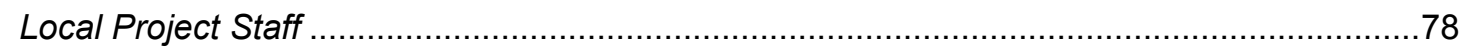

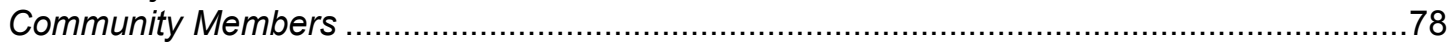


Themes of Sustainability within NZAID and its Projects ..........................................................

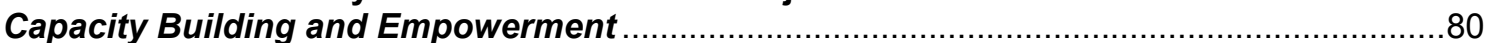

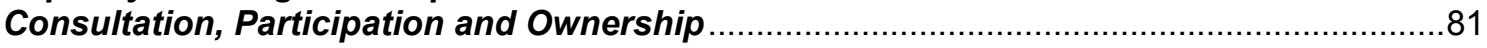

Consistency of Sustainability Dialogue among Stakeholders .................................................. 83

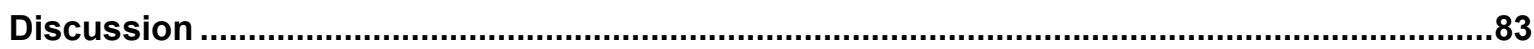

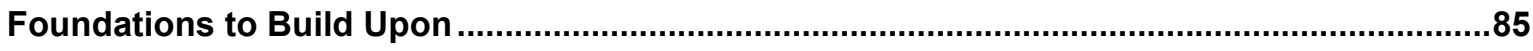

Challenges in Implementing Sustainability, and Potential Benefits of an Infusion of

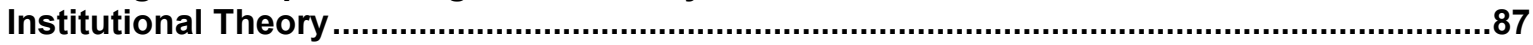

VI. DATA ANALYSIS - INSTITUTIONALIZATION .......................................... 89

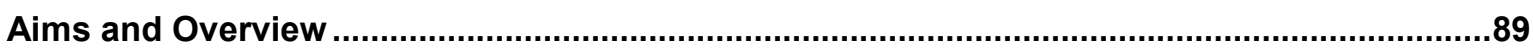

Institutions and Institutionalization as Discussed in NZAID ...................................................91

The Institutional Pillars and their Relationship to Sustainable Development Principles........94

Thematic Links to the Three Pillars within Project Documents .............................................96

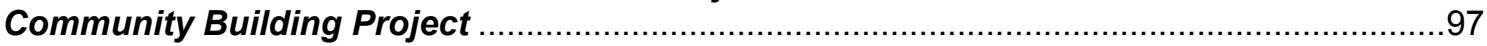

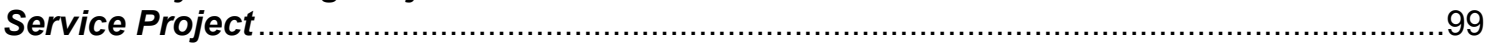

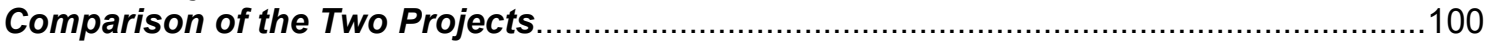

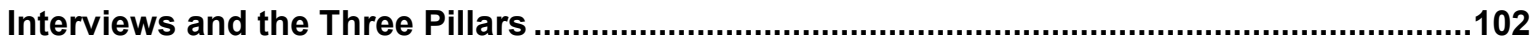

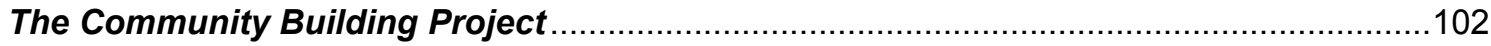

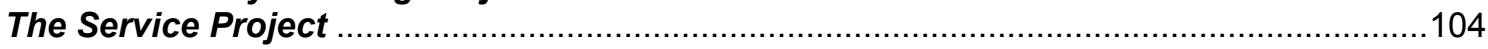

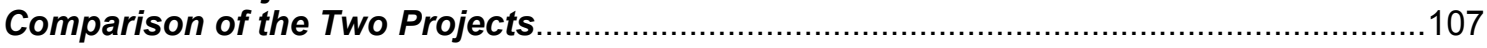

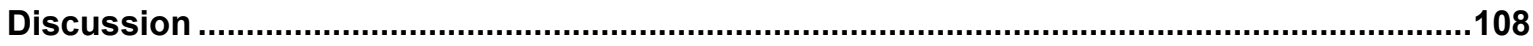

VII. CONCLUSION AND RECOMMENDATIONS .......................................... 111

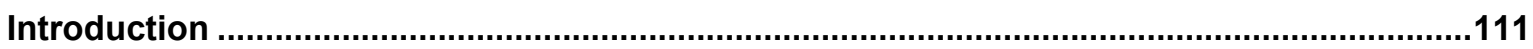

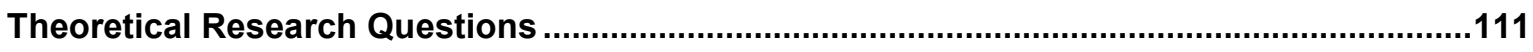

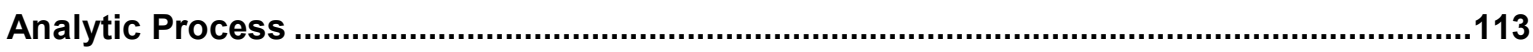

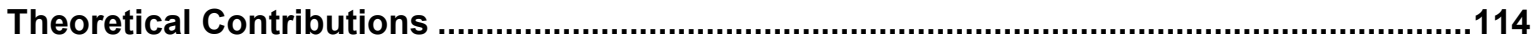

Practical Contributions and Recommendations...............................................................116

Using the Institutional Pillars as an Evaluative Tool .................................................118

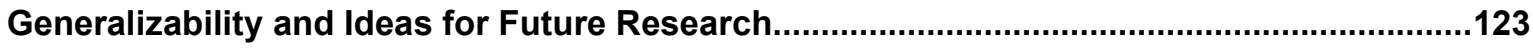

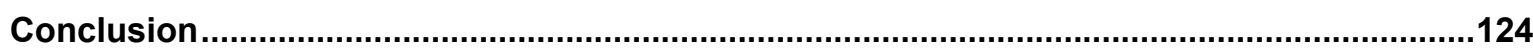

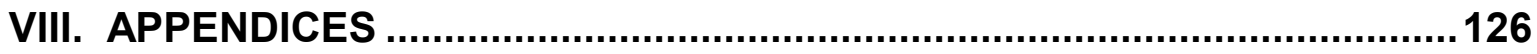

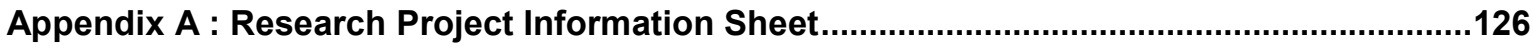

Appendix B : Research Project Participant Consent Form ....................................................128

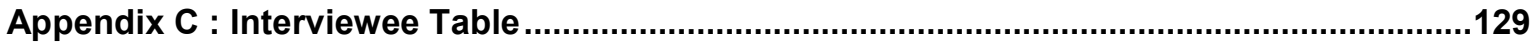

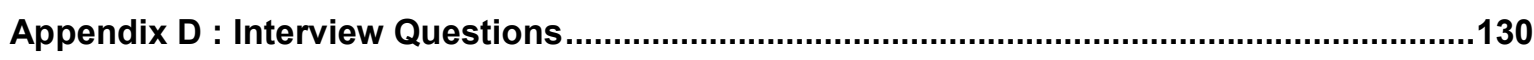


Appendix E : Observation Guide .135

Appendix F : Paris Declaration on Aid Effectiveness .136

IX. WORKS CITED 


\section{Introduction}

\section{Aims and Overview}

In this research I look to integrate aspects of organization studies with the field of international development. I explore how institutional theory may be used to frame and reconceptualize the process by which development organizations design and implement sustainable development projects. I have structured this research as a case study, using institutional theory to explore how the New Zealand Agency for International Development (NZAID) approaches sustainable development. I examine how that approach is manifested in its development discourse, both within the organization and as it extends to partners and stakeholders in two development projects in Papua New Guinea. In this chapter I present the objectives of this thesis and the reasons for which it was undertaken. I identify the key ideas that have informed my research, and introduce my research design and the theoretical foundations that underlie it. Finally, I discuss the relevance of this research, and its proposed contribution to the two fields in question.

\section{Personal Interest and Objectives}

While volunteering with various NGO-operated community based development projects in Peru in 2007, I found myself wondering about the projects' sustainability, and whether or not communities would be capable of maintaining and furthering project objectives once external project funding had ceased and the supply of foreign volunteers had stopped. It seemed unlikely that community members would be able to develop the necessary skills and drum up the required resources, when both skills and resources had been provided for so long by outside organizations. Could community members, who worked so hard simply to make ends meet, assume the responsibility of effectively running their own development projects?

This issue is a concern of the development community at large, from small NGOs to government aid organizations to global institutions such as the World Bank. Much has been written about how best to ensure the long-term sustainability of projects and their outcomes, and how to promote local ownership of development 
projects. Resourcing and long range financial support are critically important considerations in project planning, and have major impacts on projects' long term sustainability. This research does not purport to address resourcing concerns, however, as I perceive international development's financial and resource planning to be beyond the scope of this project. My research objective is to explore how development organizations enact sustainability—how sustainability as an objective is evidenced in project plans, and in the course of implementation on the ground. I pursue this objective from a standpoint within organization studies-specifically within institutional theory. Institutional theory is concerned with the behaviour and effects of institutions, and also with the process by which institutions come to be established: institutionalization. I argue that the process of sustainable development, which seeks to launch robust projects capable of producing lasting results, has much in common with institutionalization, the process of achieving permanence and stability in behaviours or structures. I propose that sustainable development may be productively conceptualized as a process of institutionalization.

My research contributes theoretically to the field of organization studies by combining ideas from different schools of thought within institutional theory, and demonstrating how those combinations may provide new theoretical insights. It also contributes practically to organization studies through its exploration of potential real world applications of institutional theory, in particular theory addressing the process of institutionalization. By applying organizational theories of discourse to the field of development studies, I examine how the sustainability goals of modern development practitioners are formulated and communicated, specifically between multiple and varied environments and organizational actors. This project explores how development discourse, and the subsequent enactment of the modern development principles that it incorporates, contributes to the institutionalization of project practices, and how this institutionalization in turn contributes to outcome sustainability. This research contributes to development practice by using organization studies to explore the practical realities of international development, specifically how best to ensure the long-term viability of projects and project outcomes. 


\section{Institutions and Development}

Within development literature there is a strong focus on institutions: building institutions, fortifying institutions, ensuring projects' integration with existing institutions, etc. (Edwards and Hulme, 1992; Lepenies, 2008). According to institutional theory scholar W. Richard Scott, “...institutions are seen to serve vital social functions, including rule setting and enforcement and the promotion of comprehensibility, legitimacy, and social stability" (1999, p10). Institutions, with their promise of stability, offer steadiness to the unpredictable and volatile project environment, and represent more sound investments for development organizations. Yet despite international development's declared interest in institutions and institution building, there has been little scholarly application of institutional theory to the field of international development. In the course of this research I have observed that within development literature understandings of institutions are narrowly restricted to the formal institutions of government, rarely extending to informal, local level or social institutions. This research seeks to demonstrate how the field of international development may benefit from broadening its understanding of institutions through the incorporation of ideas from institutional theory. I am unaware of institutional theory having yet been applied to the topic of the sustainability of international development projects. Jennings and Zandbergen (1995) have applied it to the topic of ecologically sustainable organizations, but approach their study very differently, and make use of a different theoretical basis within institutional theory. To the best of my knowledge, my use of critical discourse analysis as a tool to analyze international development's discourse of sustainability as it relates to institutionalization represents an original research endeavour.

\section{Foundations in Literature and Theory}

In order to explore institutional theory's relationship to current international development practice, it is necessary to first understand the theoretical and practical foundations of the type of development undertaken by modern development agencies. Development theory as a field evolves continually, and past theory and practice have bearing on how agencies currently develop and

enact policy. How the sustainability of development projects and their outcomes is 
addressed depends on how development agencies currently conceptualize development, and how the philosophies that organizations and their employees subscribe to affect their work. While I will briefly survey traditional development literature, I will draw principally on the literature of modern development, including that of alternative development, as it is that literature that may be demonstrated to currently guide the mainstream practice of international development.

As someone who has always been fascinated by language and its complexities, I was intrigued by scholar Nelson Phillips' theory of institutionalization as a linguistic, discursive process. Phillips defines discourse as collections of communication events related to a given topic. He argues that discourse is the engine that drives the process of institutional formation (Phillips, 2003). As the medium through which ideas are expressed and by which those ideas shape and report on action, discourse has the ability to influence the ideas and behaviours of large groups of people. Phillips argues that if the ideas contained in a discourse reach and are adopted by enough people, an institution will be formed. I put Phillips' discursive theory of institutionalization into dialogue with $\mathrm{W}$. Richard Scott's theory of institutional pillars, which describes how institutions are supported by a combination of governing rules, values, and culturally based traditions and meaning structures (Scott, 2001). I combine Phillips' and Scott's theories in order to argue that for a discourse to produce an institution, it must adequately address each of the institutional pillars. Scott's and Phillips' theories are complemented in my theoretical framework by other institutional theory texts which describe institutions and their characteristics, and how they function. I will examine how both institutional theory and international development address the concept of sustainability, and will bring both fields together by examining how institutional theory can contribute to the achievement of sustainable development outcomes.

\section{Empirical Research Design}

As will be discussed in the Methodology chapter, I chose to study development discourse as it relates to sustainability and institutionalization as evidenced in the discourse of one development organization. I believed that studying a single development organization's discourse (represented by its internal texts and its dialogues with the stakeholders in its projects) would provide sufficient scope for 
my study. Such a design required the participation of a suitable international development organization. NZAID was identified as the ideal organization for my research. Its Wellington location immediately made it an attractive prospect. It also answered the primary qualification of being an international aid organization implementing projects abroad, and active in the design and implementation of those projects. It was also attractive because as an adherent to several important international development agreements, its development practice is fairly representative of the many other agencies conforming to those international standards, thus broadening the audience of this research. I was fortunate to gain research consent from NZAID to carry out document collection and interviews at its Wellington office. I also obtained research consent to travel to Papua New Guinea to conduct research on two of the projects that NZAID funds there. This travel opportunity allowed me to gain a more comprehensive, first-hand understanding of the discourse and processes of sustainable development than research conducted only in NZ could provide.

Wellington-based NZAID interview participants were selected based on 1) their involvement in specific teams within NZAID and 2) their willingness to participate. NZAID employees in Port Moresby were contacted on my behalf by an NZAID staff member in Wellington, who solicited these employees' participation based on their knowledge of the projects that I would be studying. The projects in this case study were selected from a pool of potential projects presented by NZAID (chosen by NZAID for reasons which must remain confidential). Contact was made with representatives of each project prior to my arrival, and those contacts solicited the participation of contractors, project workers and community members based on my descriptions of my research and the ability of each prospective interviewee to provide an informed perspective on the topics in focus.

\section{Data Collection}

Data was collected through interviews with staff at NZAID in both Wellington and Port Moresby, as well as with NZAID contractors, local project workers and community members. Data was also drawn from NZAID project design documents, activity design and evaluation guidelines, and other organization documents. Interviews were conducted on the basis of confidentiality, and thus 
while I may state that data collection occurred in Papua New Guinea, I may not name the region where research took place, nor can I name or describe in any detail either of the two case study projects. My time with each project was spent at the respective projects' headquarters conducting observations, interviews, and collecting project documents, and making site visits in order to conduct interviews and observations. The interview process allowed me to glimpse the informal aspect of NZAID's development discourse and demonstrated how the ideas evident in policy statements and project documents has been assimilated and processed by NZAID employees and their partners and project stakeholders.

\section{Data Analysis}

In that this research seeks to identify and illuminate the relationship between the concepts of sustainability and institutionalization, data analysis has been organized into two chapters, one addressing each concept. In the sustainability chapter, data has been analyzed with a focus on documents' and interviewees' use, and demonstrated understandings, of the word 'sustainability', as well as their incorporation of concepts identified by the development literature as being productive of sustainability, such as empowerment, participation, ownership, etc. The institutionalization chapter examines how those concepts, as well as other themes present in documents' and interviewees' descriptions of project design and implementation can be directly related to the institutionalization process. Through these two analyses I will demonstrate how NZAID's development discourse addresses sustainability, and through sustainability's commonalities with institutionalization, addresses institutionalization as well. I will illustrate how a more intent focus on the 'mechanics' of institutionalization may contribute to the achievement of sustainable project outcomes.

\section{Relevance of Research}

This research has the potential to be valuable to development organizations wishing to effect lasting change in partnership with their stakeholders. For an 'industry' that invests billions each year in development initiatives, lasting success has been highly elusive. For the sake of those organizations' investments, and also for the sake of the millions of people who depend on development to assist 
them in meeting their most basic needs, and for offering the hope of improved livelihoods for them and their children, any research with the potential to illuminate a previously unexplored facet of development should be welcome. While the field of international development may go through fads like any other field, sustainability, regardless of its popularity in literature at any given time, will always be a fundamental goal of development, and thus a topic deserving of attention. And where the field of institutional theory has tended to address issues pertaining more to institutional stability than institutional formation, this research stretches the bounds of the field and demonstrates why further research into institutional formation and change is necessary and relevant. In short, this research seeks to contribute theoretically and practically to two important fields, in the hope that greater understanding and positive results will be the outcome. 


\section{Literature Review - Integrating Development Practice and Institutional Theory}

\section{Overview}

This chapter reviews the literature of international development and institutional theory. I begin by discussing my approach to the literature of these two fields, before moving to examine development practice and theory. As this paper aims to be of use to development practitioners as well as to academics, some of the development literature will be practically oriented, while some will be more theoretical. I briefly survey the history of international development, and then present the principles that currently guide development practice as it seeks to improve its record of sustainability and effectiveness. I then move on to institutional theory, providing a brief overview of institutions and institutional theory before going on to focus on institutional composition and institutionalization. As the chapter progresses, I gradually argue for the commonalities between the process of sustainable development and the process of institutionalization. I argue that these commonalities stem from the shared objective of each process: sustainability.

\section{Development of Theoretical Approach}

To make two different theories talk to each other: ' ... begin with a fairly concrete problem or issue in one or other of the domains, and...seek guidance for understanding in the literature of the other or related domains' (Davis et al., 2005).

The problem that I begin with is the difficulty of achieving sustainability in development projects. I use the literature of institutional theory to address it. This research design can be traced to an article that I read prior to beginning this thesis. Written by Nelson Phillips and entitled 'Discourse or Institution? Institutional Theory and the Challenge of Critical Discourse Analysis' (2003), it presents the author's assertion that the process of institutionalization (by which institutions are formed) is best understood as a discursive process. Phillips' expression of this theory and his use of critical discourse analysis to reveal how discourse is productive of institutions provides the foundations of my research design. Phillips' ideas provided the perfect method by which to explore a topic that 
had long been a personal interest of mine, and which I had been considering for a potential thesis topic: the challenge of achieving project sustainability in international development.

Phillips' article helped me to conceptualize the process of creating and implementing sustainable development projects as a process of institutionalization - that the underlying goal of a sustainable development project is the production of an institution. Phillips' theory of institutionalization and his qualitative, positivist use of critical discourse analysis have informed my theory of development sustainability, and in tandem they produce the foundational framework of this research. This premise of sustainable development as process of institutionalization, developed in the earliest stages of the thesis process, has been refined and reinforced by literature and data as the research process has progressed.

\section{Development}

\section{Introduction}

In my research into development theory and practice, I have read widely in order to develop my understanding and my own point of view. There are many complex political issues and vigorous debates bound up in development. While these issues are important, they require a great deal of attention and space to address adequately. Accordingly, my treatment of the field attempts to avoid those issues entirely, focusing instead on the topic of sustainability. I address development as both a general concept, and as a widely implemented practice. My initial exploratory survey of development literature began with books and articles listed in the syllabi of development courses that I, and acquaintances of mine, had taken. I then focused my reading based on authors' and texts' treatment of issues relating to development project sustainability and effectiveness. Once I began conducting interviews, I also began to draw on literature relevant to several key ideas identified in interviews with NZAID staff. I also chose literature based on its relationship to modern development practice as addressed by such foundational documents as the Paris Declaration on Aid Effectiveness, and initiatives such as the United Nations' Millennium Development Goals. 


\section{Definition and Goals of Development}

While 'development' may seem to be an obvious goal, its definition is nuanced and subtle. The ideas it encapsulates and the outcomes it seeks to generate have changed over time. While development is a widely used term presumed to be clearly understood, it is very rarely clearly defined. Neither the United Nations, NZAID, nor the World Bank offers definitions on their websites. The OECD provides no definition for development, offering instead what I view as a profoundly accurate definition of human development, which identifies what development means to people on an individual level. Human development is defined as '...the process of enlarging people's choices. Their three essential choices are to lead a long and healthy life, to acquire knowledge and to have access to the resources needed for a decent standard of living' ('Glossary', 2003, n.p.) (the definition goes on to more finely elaborate those fundamental choices). This definition cuts through the trappings of more common definitions of development with their basis in economics and Western understandings of modernity (Calás and Smircich, 2003; Peet with Hartwick, 1999; Tsoukas, 2003; 'Modernity', 2009), in order to identify what development proceeds from and amounts to: freedom from poverty and the hardships it implies, stemming from access to good education and health care, and the ability to support oneself through one's chosen living. Development as a goal can thus be defined as the ability of individual nations to ensure each citizen's right to ably make and pursue these essential choices in the way that seems best to them. This definition also firmly identifies development as a social endeavour, implying that while politics and economics will be involved in ensuring development, it is ultimately about people.

Each of these fundamental 'choices' requires the provision of essential services to make them possible. The provision of those services-health care, personal security, education, and the protection of property rights (among others)-is typically the province of national governments (Edwards and Hulme, 1992). Countries whose governments are not in the position to ensure the provision of these services can be said to be 'developing'. International development organizations, both government funded and independent, have made it their goal 
to assist the governments and citizens of these developing nations to reach the point where service provision independent of foreign assistance may be guaranteed.

\section{Indices of Development}

Development has been, and is still considered by many development theorists and practitioners as primarily an economic achievement, and has thus been measured using GDP and other economic indicators. This understanding '... essentially identifies development with economic growth or increasing the Gross National Product (GNP), i.e. development is best stimulated by doing whatever will most increase production for sale, investment, exports, trade, etc. It is assumed that economic growth will in time lead to the improvement of all other important aspects of society' (Trainer, 2001, p30). Economic development is undeniably a driver of multiple types of social development, and many development organizations make economic development the primary goal of their work (Peet with Hartwick, 1999). But economic indicators like GDP do not measure the degree to which a country's economic prosperity is distributed throughout its population, or how that economic prosperity is manifested. This concern with the deficiencies of economic development is reflected in many of today's more holistic understandings of, and approaches to development (The World Bank Group, 2001).

Newer measures of development, as exemplified by the UN Millennium Development Goals and the Human Development Index, seek to reconceptualize development through measures of quality of life, and the accessibility of basic human necessities and services (Peet with Hartwick, 1999; UN Millennium Project, 2005). The Millennium Development Goals (MDGs), which seek to halve the number of people living in poverty around the world by 2015 ('Goal 1', 2008), have as their rationale the belief that all people ought to be able to enjoy baseline standards of living, principally those pertaining to health, nutrition, education and life expectancy. The MDGs represent a holistic measure of development, in that they seek to determine the degree to which economic development is experienced by a population as a whole, and how that economic development has manifested itself. While the practice of development has been subject to critiques of its being based on colonialist philosophies (Kothari, 2005) - a modern incarnation of the 
'white man's burden'-the MDGs represent an unambiguously altruistic objective, and presume that objective's uncontested universal desirability.

\section{The Evolution of Development Practice}

\section{State-Centred and Economic Development}

In order to achieve development goals like the MDGs, modern development (exemplified by the Paris Declaration on Aid Effectiveness, discussed in the coming pages) unites a focus on the primacy of the state with an interest in grassroots participatory development approaches. This emphasis on using partner systems and following state strategic plans is a relatively new tactic, emerging in the 90s after two decades of distrust of the state (Kothari, 2005), where development organizations instead entrusted NGOs with the task of carrying out their development programmes. In fact, modern state-centred development strategies, emerging toward the end of the $90 \mathrm{~s}$, constitute a return to the state (Zaidi, 1999). Modern development's genesis can be located in the postcolonization period following WWII, when foreign nations (many of them former colonial powers) sought to empower nascent states and former colonies to manage their own affairs and their own development. Harriss explains that the goal of development was growth: the agent of development was the state and the means of development were national economic planning... These were the takenfor-granted presumptions of 'development theory' as it evolved from the 1950s onwards' (Harriss, 2005, p19). In this model, development would begin with government and economic institutions, and would trickle down to the masses.

Despite the billions disbursed through this model, development did not function as planned in most countries, with government and economic institutions not being sufficiently resourced or stable to meet the varied demands of countries in the process of political and social change. Developers and stakeholders were eager to point fingers. Third World governments were labelled as corrupt, and blame was also placed on Third World peoples, accused by some of being intractable and fundamentally ill suited to modernity (Calás and Smircich, 2003; Oakley and Marsden, 1984). In many cases though, First World nations and development institutions simply failed to recognize the inappropriateness of cutting and pasting 
Western systems and institutions into countries whose demographic, geographic, and political realities were so different from those of the First World (Clegg, 2003), and which demanded uniquely tailored solutions (Sachs, 2005).

\section{Alternative Development}

The beginning of the alternative development/non-governmental organization (NGO) movement, with its focus on addressing poverty, inequality, and poor service provision by governments perceived to be corrupt and ineffective, can be located here (Peet with Hartwick, 1999). Rejecting the failed orthodox approaches to development, development organizations and NGOs cut government out, working instead in tandem with target populations to bring services directly to people in need (Mdee, 2008; Parnwell, 2008; Robb, 2004). Alternative development is based on the principle that sustainable development can be achieved by other means than through the state. Proponents of alternative development argue that by focusing on the people through initiatives involving community participation and grassroots political mobilization, they can produce development from the ground up (Bebbington, 1997; Goldsmith, 1992). Adherents to alternative development also point out that an educated and switched on citizenry is better placed to hold governments to their responsibilities (Parnwell, 2008; Bebbington and Farrington, 1992). Driven by these principles, for over two decades in the 70 s through the 90 s, NGOs set themselves up as alternatives to the state (Bebbington, 1997; Brett, 2003).

In addition to offering an alternative to state development policies, theories of alternative development call attention to the human aspect of development, perceived to be missing from orthodox approaches. Alternative development 'privileges local and grassroots autonomy' by using participatory development techniques (Nederveen Pieterse, 2000, p181). It seeks to address aspects of social and sustainable development (such as the perspectives of affected communities) that have bearing on the outcomes of development initiatives, but which themselves are often unaddressed by those initiatives. As communities have historically been excluded from development discourse (Briggs, 2008), proponents of alternative development seek to consult with and empower them to 
generate dialogues more favourable to their own interests and needs (Cornwall, 2002).

Projects responding to community needs using methods acceptable to those communities are much more likely to be embraced and willingly maintained upon their completion. Participatory techniques, involving target groups in the planning, decision-making, and management and implementation of projects, can thus be seen to contribute to ownership and sustainability (White, 1996). Ownership, the responsibility that people feel for a project, is a key principle in alternative development (Berner and Phillips, 2005). If beneficiaries take a proprietary interest in the project being implemented, they will be more likely to do all they can to see that it succeeds and carries on producing the outputs and outcomes that they value. Participation and ownership are two concepts that have become ubiquitous in development literature, as described in the following quote:

\footnotetext{
There is a growing recognition in developing countries that community participation...is a necessary strategy in sustainable development. The main advantage of following such an approach is that, if participation can encourage a sense of ownership of the projects, the benefits of the project are more likely to extend over the long term (Robles-Morua et al., 2009, p197).
}

Ownership, resulting from participatory techniques and supported by capacity building to enable project stakeholders to independently perform and manage project activities, is a valuable commodity for development organizations seeking to create effective and sustainable projects.

Ultimately, alternative development was insufficient as a viable long-term development strategy. While it had its share of successes, this approach to development also had many flaws: difficulty in scaling up and replicating projects, absolute dependence on foreign donors, lack of collaboration among NGOs resulting in duplication of efforts, etc. (Bebbington and Farrington, 1992). The experiment of development without the state proved to be equally difficult and unreliable. Zaidi suggests that 'Because of their limited scope and reach, NGOs are no alternative to state failure. The only alternative to state failure, which is indeed endemic, is not privatization, the market, or any new or alternate paradigm, but the state itself' (Zaidi, 1999, p270). The state needed to be brought back in. 
Not only are most NGOs unable to commit to indefinite service provision, such a setup would weaken citizens' relationship with the state, and would weaken the state's accountability to its citizens, as Edwards describes:

\footnotetext{
If...you are increasingly dependent on NGOs for access to health, education, even finance and telephone connections, you may gain more entitlements to these things...but lose them as rights, especially if the NGOs are only weakly accountable to a weak state. The danger is that countries...end up with aid-dependent social sectors, a patchwork quilt of welfare provision, eroding government authority, and quiescent NGOs... (2000, p85).
}

Ideally services will be provided by the state, with NGOs filling the role of advocates and supplementary service providers.

\section{Modern Development and the Paris Principles}

Many international development organizations, such as the World Bank and USAID, have accordingly refocused their policies to incorporate an emphasis on the state and its cooperation with NGOs and its incorporation of successful NGO development principles and techniques, working to combine the best aspects of both the traditional and alternative development models (USAID, 1995). Policies now include provisions to improve governance by rehabilitating and bolstering the state and its formal institutions such that rather than the state being a hurdle to effective development, it is an asset (Edwards and Hulme, 1992). Development organizations' agendas are (optimally) aligned with state strategy and approved by the state, and wherever possible are implemented through state channels, rather than through NGOs (Groves and Hinton, 2004).

Modern development's focus on partnership with developing country governments, and its commitment to some of the key principles of alternative development, are enshrined in the Paris Declaration on Aid Effectiveness (and the subsequently signed Accra Agenda for Action). Signed on March $2^{\text {nd }}, 2005$ by representatives of over 100 countries (OECD, 2005) including all of the OECD countries, the Paris Declaration (commonly referred to as the 'Paris Principles') identifies the principles and strategies contributing to positive outcomes in international development (see Appendix F). Its signatories commit themselves to implementing sustainable 
development policy within the bounds of a well-defined philosophy. Sustainability is encapsulated in the term 'effectiveness', as the OECD describes aid effectiveness as 'making aid more effective at supporting poverty reduction and sustainable development' ('Glossary', n.d.), and as increasing both the quantity and the quality of aid to developing nations (Herfkens and Bains, 2009). The declaration sets out a series of specific targets for signatory nations, dealing primarily with achieving greater involvement of partner country governments and distribution systems in the disbursement of aid, ultimately aligning more closely with, and reinforcing partner government strategies.

While the Paris Declaration signals the international development community's reorientation towards the state, it has not necessitated the abandonment of all alternative development principles. Indeed, alternative development principles such as consultation, participation, empowerment and ownership are key features of the Paris Principles (OECD, 2005). The Paris Principles simply relocate the application of these principles, with development organizations encouraged to apply them in their dealings with the state, and the state and their donor partners encouraged to apply them in their dealings with the people. The Paris Principles exemplify the shift in practice that Brett describes, observing that 'The search for participatory solutions began with the leading non-governmental organisations, but has now been taken on by the major donors and many national governments' (Brett, 2003, p2).

In outlining the methods and objectives of its state-centred tactics, the Paris Principles incorporate alternative development principles of consultation, participation, capacity building and donor partner empowerment in their request to partner countries to 'Take the lead in co-ordinating aid at all levels in conjunction with other development resources in dialogue with donors and encouraging the participation of civil society and the private sector' (OECD, 2005, p3). Donors are encouraged to consult with partner governments and stakeholders, and to 'encourage broad participation of a range of national actors' in the formulation of aid strategies - this in order to encourage donor alignment with partner government strategies, and also to encourage partner government ownership of the development process (OECD, 2005, p6). The Paris Principles also identify capacity building as a key component of producing sustainable outcomes, stating 
that growing partners' 'capacity to plan, manage, implement, and account for results of policies and programmes, is critical for achieving development objectives' (OECD, 2005, p4). Through its emphasis on the integration of multiple levels of stakeholders in its recommended approach to development practice, the Paris Declaration exemplifies the changes in international development that confirm Brett's observation that participation '...now dominates the theory and practice of most service delivery agencies' (2003, p4). Even in 1984, at the time of the publication of their book Approaches to Participation in Rural Development, Oakley and Marsden suggested that it was rare to find a development document that did not advocate for participatory processes. This is even more true today, with participation being ubiquitous in development literature and practice, and advocated by some of the most prominent actors in international development (The World Bank, the United Nations Development Programme, etc.) (The World Bank Group, 2010; UNDP, 2006). It is proving to be a fruitful strategy, as World Bank studies have identified a 'strong correlation' between grassroots participation in World Bank funded projects, and project success (USAID, 1995). Through its emphasis on these empowering features of alternative development, the Paris Principles validate their contribution to sustainability and effectiveness.

While the Paris-advocated approach to development has become doctrine for most international development organizations, many (including NZAID) still make some use of alternative channels for the disbursement of their aid. Until government channels are reliably and effectively able to reach all populations in need, development organizations will continue to directly aid those people as yet cut off from state assistance. Their commitment to the Paris Principles ensures that even when implementing development projects outside of partner government systems, development organizations still seek state approval and link their projects to state strategies. Linking local level initiatives into state structures ultimately reinforces and builds state networks and credibility, and contributes to state strategic goals, as well as improving chances of sustainability (Mackie, 1992). Indeed, as Constantino-David warns, 'NGO work would be relegated to "gapfilling" if NGOs did not try to link their activities to the larger issues of social structure' (1992, p146). 


\section{Sustainability and Institutional Theory}

\section{Introduction}

As illustrated in the previous section, the field of international development is currently very strongly focused on achieving sustainability in development projects. In this section, I explore how sustainability is achieved. My contention is that sustainability is the outcome of a successful process of institutionalization. As such, I examine the links between sustainable development and the institutionalization process. The primary outcome of institutionalization is, of course, the formation of an institution, and so I review various understandings and definitions of institutions in order to draw parallels between institutions and the outcomes of successful development projects. One theory of institutions that I explore is Scott's theory of institutional pillars (Scott, 2001). In the coming paragraphs I review this theory and relate it to the field of development. Critical to the process of institutionalization (some scholars argue) is the phenomenon of discourse (Phillips, Lawrence and Hardy, 2004). I thus examine the concept of discourse and its relationship to institutionalization and sustainability. Overall, the coming pages explore the link between institutional theory and development theory, and how a dialogue between the two may contribute to the success of sustainable development projects.

\section{Defining Sustainability}

The very fact that it is necessary to use the term 'sustainable development' indicates that sustainability has not been a regular feature of development up to this point, and it is thus necessary to specify sustainability as a desired quality of development. But whether explicitly stated or not, sustainability is critical to every donor-funded development project, because at some point donor funding is withdrawn and project beneficiaries are left to maintain project outputs and outcomes as best they can. No organization wishes for the outcomes of its investment to collapse upon their withdrawal, and thus all organizations attempt to design their projects and equip their stakeholders to carry on for the long term. Unfortunately, it tends to be the exception rather than the rule that they succeed. In 2005 the United Nations Development Program warned that ' there is a growing 
danger that the next 10 years-like the past 10 -will go down in history not as a decade of accelerated human development, but as a decade of lost opportunity, half-hearted endeavour and failed international cooperation' (Watkins et al., 2005, p18).

Sustainability is a concept that does not pertain only to international development. As a general rule, it is more frequently used to denote environmental sustainability. While the concept of sustainable development may encompass aspects of environmental sustainability (Newman, 2007), it is not a requirement. The type of sustainability that I address in this research is concerned with the longevity of development projects. Klinmahorn and Ireland define sustainability as '...the ability to maintain services in the longer run without significant external support' (1992, p60). They go on to say that 'Clearly, there is little point in demonstrating that a model of intervention or service development can achieve results... if these circumstances require continuing high levels of external support' (ibid, p60). Projects may be unsustainable due to a lack of human, physical or financial resources required to operate the project or maintain its outcomes (again, this research does not discuss resourcing issues). Other projects may be surrounded by available resources, and yet still be unsustainable due to a general perception that the effort of maintaining them isn't justified by their outcomes. Thus, as important as it is to design and implement a viable and successful development project, this counts for little if within a few years of a project's conclusion the target community has reverted to old ways, or project outputs and outcomes have deteriorated and become unusable.

\section{Requirements for Sustainability}

The sustainability of development projects has historically been very poor. While hundreds of billions in aid dollars have been disbursed globally since the mid- $20^{\text {th }}$ century, the effectiveness of that aid, and the sustainability of its outcomes is consistently questioned. One prominent article by Peter Boone, written in the mid$90 \mathrm{~s}$, claimed through rigorous statistical tests that "aid had no significant effect on growth" (as cited in Collier and Dollar, 2004, p244), specifically that "...in a sample of 96 recipient countries, foreign aid did not significantly contribute to investment or economic growth rates, or to an improvement in human development indicators" 
(Ovaska, 2003, p176). Such bold and authoritative claims have prompted such development scholars and practitioners as Jeffrey Sachs, Paul Collier, David Dollar and William Easterly to debate if and by what means aid can be effective and sustainable-and this debate continues today (Sachs, 2005; Collier, 2007; Collier and Dollar, 2004; Easterly, 2006). Consequently, development organizations have identified aid effectiveness and sustainability as a major objective for projects going forward. The Paris Principles represent such a commitment to sustainable development.

Sustainable projects demand more than adequate funding and infrastructure. In addition to ensuring the financial and resource security of a project (most often accomplished by linking into permanent, government-funded institutions of the state), it is also necessary to make provision for the target population to learn and assimilate the practical and administrative skills required to support a project's operation (McAdam and Scott, 2005). Once outside support has been withdrawn, local stakeholders must be able to perform the tasks necessary to operate the service themselves (Brinkerhoff, 2002). Also, stakeholders must want to keep the project going, either because the consequences of project abandonment or failure are undesirable, or because they value project outcomes. Indeed, project beneficiaries must value project outputs enough to wish to support them for the foreseeable future. Here sustainable development's links to institutional theory become very clear: 'Institutional sustainability is defined as the ability of an institution to produce outputs that are sufficiently in demand so enough inputs are supplied to continue production at a steady or growing rate, leading to long-term positive results' (Goldsmith, 1992, p585; see also North, 1990). If there is no perceived incentive to invest time, energy and resources in the maintenance of a project whose outcomes are perceived as being poorly aligned with local values, or of little value themselves, projects stand no chance of continuing without outside support and initiative (Edwards, 2000; Tolbert and Zucker, 1996). In order to ensure that projects and their outcomes are of value to communities, development organizations must actively consult with and involve communities in the project process.

This concept of value is vital to the achievement of sustainability (Goldsmith, 1992). If people become accustomed to having a service that they value, they 
come to depend on it. And when people depend on something, they will take reasonable measures to ensure that that service will always be available to them-so that service will be a permanent fixture of their environment. This degree of permanence necessitates the regular availability of the resources required to produce that service, including the knowledge of how to reliably provide it, a system of distribution, and a demand regular enough to justify both (Goldsmith, 1992; McAdam and Scott, 2005). Depending on demand, services may be operated at community levels, using locally available resources, or at regional or national levels, drawing upon greater resources. For these services to be scaled up to a regional or national scale (or assimilated into a pre-existing regional or national service) they must be replicable-specific enough to a community to adequately address its particular needs, but not so specific that its template may not be used elsewhere (Mackie, 1992). It is my assertion that what has just been described-a service relevant to, and valued by a wide range of users, possessed of sufficient resources to be maintained so long as there is demand for it, upon which people come to depend but whose existence they take for granted-can be described as an institution.

\section{Institutions in Development}

Institutions are the building blocks of society, providing the assurance of security, ease of social transactions, and a sense of established order. As such, they feature strongly in the literature of many diverse fields: organization theory, political and economic theory, development theory, etc. Douglass North, a prominent institutional theory scholar, defines institutions thus: 'Institutions are the rules of the game in a society, or more formally, are the humanly devised constraints that shape human interaction. ... Institutions reduce uncertainty by providing a structure to everyday life' (1990, p3). At their simplest, institutions are sedimentations of specific behaviours and supporting structures that make possible or simplify the accomplishment of a given task or set of tasks. By identifying and defining accepted behaviours and imposing 'penalties' for behaviours located outside of those boundaries, institutions make it possible for desirable actions to occur more frequently, and the outcomes of those desirable behaviours are the result (Scott, 2001; Reed, 2003). After sufficient time and repetition, those desirable actions become the norm (Green et al., 2009). People 
don't even think about the rules in the course of carrying out their actionsbehaviours sanctioned by the institution simply become taken for granted (Scott, 1991). Institutions vary in size, complexity and formality, from basic rules of driving etiquette, to institutions of government such as tax departments and the behaviours they demand (DiMaggio and Powell, 1991). Once the rules of those institutions are learned, they are taken for granted-just the way things are-and it is difficult to conceive of acting outside of those institutional boundaries. In this way, institutions can be understood as the patterns of behaviour and accompanying ideological structures that govern the performance of specific activities or groups of activities (Barley and Tolbert, 1997).

Many development texts, regardless of the type of development advocated by their authors, emphasize the need for strong institutions as prerequisites for sustainable growth in developing nations (Waisbord, 2006; UN Millennium Project, 2005). (It is to be noted that the incorporation of institutions in development literature has pertained largely to formal institutions and institutions of the state, rather than social and informal institutions.) Edwards and Hulme sum it up by saying, 'One clear conclusion... is that institution-building is the critical task facing all NGOs in their search for sustainable development' (1992, p214) (original italics). I would broaden the quote to say that institution building is the critical task facing all development organizations in their search for sustainable development. Lepenies goes on to say that 'institution-building itself has become the raison d'être of many development projects since the late 1990s' (2008, p22). These quotes support the thesis of this project: that institutionalization (the process of institutional creation and formation) is the foundation of sustainable development projects.

Scott asserts that institutions '...serve vital social functions, including rule setting and enforcement and the promotion of comprehensibility, legitimacy, and social stability (Scott, 1999, p10).' It is this stability in various social, political and economic sectors that provides the foundation for growth and development. Thus, a fundamental goal of development, at all levels of society from government to the grassroots, is the establishment of effective institutions. It is clear from aid disbursement figures that donors are aware of the importance of good institutions to the sustainability of their development projects. The UNDP's 2005 Human Development Report states that '....a measure of the correlation between aid and 
the quality of institutions in aid recipient countries, suggests that development assistance flows are increasingly sensitive to the quality of institutions' (Watkins et al., 2005, p92). Those nations with more stable institutional environments are perceived to be safer investments for aid, as their stability is more likely to support the achievement of sustainable results.

\title{
The Challenge of Institutional Formation
}

Within the field of international development

\begin{abstract}
[s]cholarly research and concern with institutions is not new, but a strong interest in institutions re-emerged in the 1990s, largely because the stronger macroeconomic policies of the 1980s had not achieved more rapid progress in development... Interest moved from 'getting the policies right' to 'getting the institutions right'...' (Zagha, 2005, p280).
\end{abstract}

Although billions of dollars have been spent over the past several decades in order to design, diagnose, re-design, and strengthen formal government institutions in developing nations, it is broadly conceded that this money has produced little in the way of permanent results (Harriss, 2005; Trainer, 2001). This indicates that understandings of institution building, development, and the realities of working to develop Third World countries have not yet been practically integrated. Understanding institutions, and not solely formal government institutions, is critical to sustainable development. Institutional theory helps to illuminate understandings of institutions, and the processes by which they are created.

\section{Institutional Theory}

\begin{abstract}
Institutional theory examines the processes and mechanisms by which structures, schemas, rules, and routines become established as authoritative guidelines for social behaviour. It asks how such systems come into existence, how they diffuse, and what role they play in supplying stability and meaning to social behaviour (Scott, 2004, p1).
\end{abstract}

Institutional theory is a predominant theoretical tool within the field of organization studies (Suddaby, 2010). Institutional theory has its roots in the scholarly understanding of institutions as monolithic, permanent structures invested with socio-cultural meaning, and governing social behaviours. It was initially used in 
the 1970s to study what were perceived by scholars as the institutional qualities of organizations: their stability, and the rule-like structures they exhibit which shape and constrain members' behaviours (Scott, 2008). Institutional theory was subsequently used to examine how organizations and their behaviours acquired myths and meanings which contribute to formal organizational structure, but which are not able to be understood as the products of organizations' practical demands (ibid). The scope of institutional theory has steadily expanded to include its application to the study of how, through institutional pressures, organizations come to resemble each other, how individuals exercise power within institutional environments, and how institutions change. Institutional theorist Roy Suddaby even goes so far as to say that institutional theory has become ubiquitous within organization studies, being applied by default to any and all questions within the field (Suddaby, 2010). Suddaby describes this knee-jerk reliance as organization scholars' 'obsession with, and simultaneous trivialization of' institutional theory (Suddaby, 2010, p15). Nonetheless, institutional theory offers a powerful way to understand organizations, and there are still aspects of institutional theory which are comparatively unexplored, as I will soon discuss.

Institutional theory is a very broad field, and within it there are many different schools of thought, not all of which are compatible. There is debate about how best to study and understand institutions, how they function, and how they come into being, change and dissolve. I have not engaged with all of the institutional theory literature available, but have selected that literature which I feel best aligns with my research: that pertaining to institutional formation, or institutionalization (drawn from such sources as Barley and Tolbert, 1997; DiMaggio and Powell, 1983; North, 1990). Tolbert and Zucker identify the processes of institutional formation as being relatively poorly addressed in institutional theory (1996). In contrast to many other theories of institutions, which focus primarily on the characteristics of institutions, how they work, and how they maintain their equilibrium (Lounsbury, 2003; Scott, 2004; Tolbert and Zucker, 1996), newer institutional theories (in specific neo-institutionalism) are concerned with institutional change and institutional formation (Fernández-Alles and ValleCabrera, 2006; Phillips, 2003; Schneiberg and Soule, 2005). This process of institutional formation-institutionalization—struck me as being particularly 
relevant to the field of international development in its focus on institution building and sustainability.

It is my contention that the process of sustainable development may be fruitfully theorized as a process of institutionalization. The institutionalization of behaviours leads to their adoption and long-term maintenance within a social group (Schneiberg and Soule, 2005). This is the goal of sustainable development-to foster the permanent establishment of behaviours that contribute to a group's wellbeing. And while international development frequently refers to the importance of institutions, it very rarely does so by making reference to institutionalization. Thus the study of institutionalization may provide useful insights for those development practitioners focusing on sustainable development. If development initiatives can be translated into the language of institutionalization, and analyzed for how they match up to different facets of the institutionalization process, light may be shed on a process that is both difficult to predict and manage, and vital to get right. As a goal of development is the building of sturdy institutions, addressing the process of development in the language of institutions may help to clarify it.

\section{Institutionalization - A Process of Action and Discourse}

Institutionalization, the process by which institutions come into being, is based on a combination of action and discourse. It is perhaps easier to understand institutional formation through action, so I will begin there. One way in which institutionalization is understood is through the process of structuration, whereby 'action reproduces structures' (Lawrence, 1999, p166). Structuration, a sociological theory elaborated by Anthony Giddens, is a well-established concept within institutional theory, identifying repeated action as being a key to the rationalization and adoption of practices and structures, at both the individual and the broader organizational level (Cohen, 2004; Hardy and Phillips, 1999). DiMaggio and Powell define structuration as 'the process of institutional definition' (1983, p148). As behaviours are repetitively performed, they take on meaning.

These meanings may slot into existing value and belief structures, or may spur the creation of new ones. An action's relationship with these structures is solidified with each performance of the action in question (Lawrence, 1999). Actions performed in accordance with values serve to reiterate and reinforce those values 
and other normative structures, eventually becoming intimately linked to those values, and a part of those structures (Rao et al., 2000). Structuration, occurring on a scale involving many people, whole communities, or larger social groups, can be understood as a process of institutionalization, wherein many people come to ascribe the same meanings to regularly practiced actions (Phillips, Lawrence and Hardy, 2004). Eventually, institutionalized behaviours may become so ingrained as to be performed automatically, without conscious thought of reason or meaning.

Structuration is certainly an important component of institutional formation. But it is not the action, so much as the communication of the action that defines the institutionalization process (Phillips, Lawrence and Hardy, 2004). Neoinstitutionalist scholars such as Nelson Phillips, Cynthia Hardy, Thomas Lawrence and David Grant maintain that institutions are formed through the production and dissemination of discursive texts. Outside of certain academic circles, institutions are not generally conceptualized as discursive or verbal constructions. The institution is popularly perceived as a permanent, unchanging presence generating very tangible effects in the real world. The Oxford English Dictionary lists as one of its definitions of 'institution', 'An established law, custom, usage, practice, organization, or other element in the political or social life of a people' ('Institution', 1989, n.p.). In his description of institutions, however, prominent sociolinguistic scholar and pioneer of critical discourse analysis Norman Fairclough states that 'A social institution is an apparatus of verbal interaction or an "order of discourse". . . Each institution has its own set of speech events, its own differentiated settings and scenes, its cast of participants, and its own norms for their combination' (Fairclough, 1995, p38). Phillips echoes Fairclough's idea that 'institutions depend on sets of texts that bring them into being, [and] that maintain them' (Phillips, 2003, p221). Operating on the idea of institutions consisting of 'verbal interaction', it is logical to study institutions using a linguistically-based approach.

Such an approach is based on the principle that language constructs and structures reality by serving as the mediator between reality and our experience of it (Mumby, 2004). Actions are prompted by communication, and actions also generate communication, which generates texts, which in turn generate discourses. Discourse has been described in many ways by many theorists, but 
for the purposes of this research, I use Nelson Phillips' definition. He defines discourse as '....both a collection of texts and the social practices through which they were produced, distributed, and interpreted' (Phillips et al., 2008, p772). Based on Phillips' definition, discourse can thus be understood in two ways. A discourse can be a collection of communication events recorded in audio, visual or written forms (texts), with multiple texts related to a given topic constituting a discourse (Ainsworth and Hardy, 2004). And discourse can also be understood as the process by which those texts are produced, disseminated and consumed (Grant et al., 2004; Hardy and Phillips, 2004; Phillips and Jørgensen, 2002). It is the former understanding that I use most in this research.

In his discursive theory of institutionalization, Phillips puts forward the idea that 'it is not the practices or understandings themselves that propagate, but descriptions of the practice or understanding' (Phillips, 2003, p228). Actions are only ever observable by a limited audience (even in this age of media saturation). The texts created in the wake of those actions, and the discourses they go on to inform, are much more durable and readily communicable, and serve to frame the actions themselves (Phillips and Hardy, 2004).

\footnotetext{
...[A]ctions may form the basis of institutionalized processes, but in being observed and interpreted, written or talked about, or depicted in some other way, actions generate texts, which mediate the relationship between action and discourse (Phillips, Lawrence and Hardy, 2004, p638).
}

It is the interaction of action and the discourses that inform and interpret that action that produces reality and makes it meaningful.

The phenomenon of discourse is thus a window into the study of institutionalization (Maguire and Hardy, 2009). While structuration is a critical part in the institutionalization process, it is dependent upon the processes of text production and dissemination, which stimulate and situate action. Those organizations wishing to establish institutions in developing nations must thus be concerned not only with their actions, but also with the discourses surrounding those actions, both produced by the organizations themselves and by their partners, as well as those discourses already at work in the areas they are 
targeting. My research design is an attempt to study some of the multiple texts informing sustainable development discourse.

\section{The Three Institutional Pillars}

If institutionalization is to be understood as a discursive process, it is necessary to know what things a discourse must address in order to produce an institution. In his essay 'Power and Institutions', Nelson Phillips (2003, p228) presents the idea that 'When a sufficient number of texts have been produced by actors who can make those texts stick, then an institution comes into being. The greater the number of texts and the more well structured the discourse, the more "institutionalized" the institution becomes.' Phillips' idea of 'texts that stick' is somewhat ambiguous, and he does not elaborate further on what exactly makes them stick. My argument is that texts that stick are those that address W. Richard Scott's institutional pillars. While my decision to use Phillips' theory of institutionalization to look at the process of international development came early in the thesis process, my incorporation of Scott's theory of institutional pillars came later on, as a result of further research into institutional theory. If institutionalization describes how institutions are formed, the three institutional pillars describe what supports and maintains them. By putting the three pillars in dialogue with institutionalization, I hope to demonstrate which behaviours, values, and structures need to be addressed in a discourse in order to set those pillars in place, creating a viable and sustainable institution.

Scott conceives of institutions as being dependent upon a foundation of regulative, normative and cultural-cognitive pillars. Each pillar, composed of a particular set of structures and behaviours, provides support crucial to the achievement of institutional stability. Scott proposes that an idea or behaviour will have become institutionalized and achieved legitimacy within a community or group when it is aligned with and supported by all three pillars: rules and governance, values, and culture. 
The regulative pillar pertains to governance and the enforcement of rules. These rules dictate the actions that may or may not be performed within the boundaries of the institution, thus helping to define institutional functions. The regulative pillar provides incentives and penalties for actions depending on the degree of their alignment with the other two pillars and with institutional objectives (Maguire and Hardy, 2009). Desirable actions that reinforce the purpose of the institution and complement its values will be incentivized (Grindle, 2000; Scott, 2001). Actions that endanger or do not contribute to the institution's goals will be discouraged through the application of penalties or punishments. Such incentives and disincentives serve to increase the likelihood of desired behaviours, and reduce the likelihood of unwanted behaviour. By incentivizing compliance, this pillar supports the institution by increasing the frequency of the performance of desirable behaviours contributing to its purpose. Because these rules are expressly designed and enforced by institutional entrepreneurs, rather than internalized, they require authoritative governance structures to make them possible. Thus the regulative pillar is most frequently addressed through discussions of governing bodies and authority structures.

\section{The Normative Pillar}

The normative pillar '...introduce[s] a prescriptive, evaluative, and obligatory dimension into social life. ... Normative systems define goals or objectives but also designate appropriate ways to pursue them' (Scott, 2001, p54). Morals and values are at the centre of the normative pillar, shaping behaviour according to widely accepted obligations, and standards of right and wrong behaviour (Maguire and Hardy, 2009). In contrast to the purpose-designed penalties and incentives of the regulative pillar, the normative pillar's incentives and penalties are internalized by organization or group members, and often pre-date the institutional project. Alignment with these morals and values allows an institution to take advantage of their power to shape behaviour; the normative pillar's morals and values act, in effect, as an institutional conscience. An action will either resonate with existing morals and values, or will not. Those that do not are unlikely to be maintained. It is possible, however, that if the outputs of the institution are sufficiently valued, 
institutional proponents will undertake a process of change to realign the values of the greater institutional environment to those of the institution itself.

\section{The Cultural-Cognitive Pillar}

The cultural-cognitive pillar establishes how institutional behaviours are to be carried out, according to the cultural frames and customs of a given group. Those frames locate actions within a web of cultural meaning, through which people understand their environment and their position in it. As described by Scott, the cultural-cognitive pillar represents the deepest level of institutional meaning '... because it rests on preconscious, taken-for-granted understandings' (2001, p60). If behaviours can be easily slotted into existing cultural frameworks, and rationales for those behaviours situated within existing cultural paradigms, they may become adopted into communities' culture. This type of cognitive alignment makes it possible for behaviours to become taken for granted-performed without the need for continual reassessment of value alignment and potential worth (Clemens and Cook, 1999). When actions no longer require justification, but are 'just the way we do things around here', they will have achieved cultural-cognitive alignment (Green et al., 2009). If a behaviour blends well with, and makes sense within, a cultural paradigm, it is more likely to be institutionalized.

\section{Summary}

By combining Phillips' and Scott's institutional theories, I argue that if a project is to be institutionalized, its discourse must address each of the three pillars described above. (It should be noted though that some institutions will lean more heavily on some pillars than on others (Maguire and Hardy, 2009)). By consciously directing their development discourse to each of the three pillars, and ensuring the discourse's (and resulting actions') consonance with the dictates of each pillar, development organizations will increase the chances of their projects' behaviours and outcomes being institutionalized. Such alignment requires intimate knowledge of the institutional environment, which it is likely that only people living in that environment can provide. Thus institutionalization is more likely if those stakeholders have had a guiding hand in project design and have been involved in the implementation of project activities. 


\section{Contributions to Sustainable Development and to Institutional Theory}

Neo-institutionalist theories of discourse's relationship to institutions, and Scott's pillars assume institutions to be social constructions whose stability is dependent on their fit with the values and culture of given groups, and their ability to maintain their relevance by adapting to changes in their institutional environments. The combination of these two different ways of looking at institutions provides a valuable insight to organizations wishing to achieve institutionalization and sustainability. By mapping out the inner workings of institutions, these two theories give development organizations a better understanding of what they are trying to achieve and how they might go about achieving it. Organizations must ensure that the discourse informing their actions aligns with target groups' normative and cultural-cognitive values, and that new and pre-existing regulative structures are complementary. While not a guarantee of institutionalization, such an approach would at least improve the chances of projects lasting into the long term.

Using institutional theory as a lens through which to examine development theory is also a good theoretical exercise. Institutional theory usually examines institutions already in existence, typically in developed nations, with wellestablished regulative and normative structures. Its primary focus is on how these structures determine the behaviour of organization members. Where institutional theory focuses largely on formal, established organizations, in contrast international development aims to produce such institutions where there currently are none, or where they are insufficiently established or resourced to meet demand for their outputs. Development focuses on the growth and establishment of institutions, an area of institutional theory that is less well understood (Phillips, 2003). Applying institutional theory to development is thus a good exercise of institutional principles and ideas, expanding its scope beyond its traditional areas of application. By studying what current development practices have in common with the process of institutionalization, it should be possible to point out parallels as well as identify areas where development processes could improve to increase the likelihood of sustainability. 


\section{Methodology}

\section{Chapter Aims and Overview}

This chapter describes the process by which this research was undertaken. It presents the research design and explores some of the key concepts that have guided its formulation. Data collection and the reporting of data have involved the navigation of fairly complex ethical considerations, which are presented in detail. This project involved the use of three methods of data collection: interviews, document collection, and observations. The procedures and contributions of each of these methods are therefore reviewed. Finally, I review the method by which I have undertaken my data analysis. Overall, this chapter provides a comprehensive picture of the way in which I pursued this research and its objectives.

\section{Research Format and Intended Audience}

This research takes the form of a qualitative case study, exploring how NZAID and its partners within two NZAID-funded projects conceive of and address sustainability. As this case study demonstrates, the concept of sustainability is ubiquitous in NZAID and its partners' development discourse. The case study delves into that discourse and the everyday realities of the two projects in order to provide evidence of how my theory of sustainability as institutionalization may be conceptualized and glimpsed in real life (O'Leary, 2004). It provides a worthwhile example of how sustainability is implemented and why it is important. Data analysis looks at how sustainability may be fruitfully conceptualized in terms of institutionalization. While not intended to be statistically representative, this research aims to be theoretically generalizable through its demonstration of the functionality of the theorization of sustainability as process of institutionalization.

While most directly relevant to NZAID, this research is pertinent to any international development organization. Indeed, I argue that research outcomes and suggestions will be of use to any development organization seeking to plan and implement sustainable development projects, from small community-based development organizations to large, well-funded organizations undertaking 
multiple development projects at once. Because the principles of development are not region-specific, this research includes in its intended audience not only development organizations operating in foreign countries, but also organizations operating within their own communities, regions and nations. As will be explained in the Background chapter, the development goals and practices of NZAID are broadly representative of the processes and goals of any number and variety of development organizations committed to participatory methods of sustainable development. This research thus looks to contribute to any organization looking to achieve sustainable development project outcomes and objectives.

\section{Research Goals}

My objective is not to evaluate the quality or effectiveness of NZAID's planning processes or implementation techniques. I use NZAID's development discourse, taken to be an exemplar of international development discourse in general, as a site to analyze development practice using institutional theory. I do this by drawing parallels between the sustainable development process and the process of institutionalization. By demonstrating the similarity of these two processes, and addressing sustainability in the language of institutionalization, I hope to be able to illustrate how an understanding of the workings of the institutionalization process, and the incorporation of texts productive of institutionalization, may be beneficial to those individuals and organizations working towards the creation of sustainable development objectives and outcomes. In addition to contributing practically and theoretically to the field of development, this research constitutes a new application of institutional theory, and thus also contributes practically and theoretically to the field of organization studies.

\section{Ethics Considerations}

This research was conducted in two phases. The first phase consisted of data collection at NZAID's Wellington office. Ethics approval was initially obtained for this phase only, with the expectation that a second phase of research would follow if NZAID's research consent, and independent funding for data collection abroad, were secured. Ethics approval was obtained for the second phase after research consent from NZAID in Wellington and PNG was given, and funding was 
confirmed. The second phase consisted of data collection abroad in Papua New Guinea, conducted both at NZAID's Port Moresby office, and at NZAID-funded project sites in rural Papua New Guinea. Of concern in the ethics application was the recruitment of Papua New Guinean participants. Due to the somewhat privileged status of Westerners in PNG, and the high regard in which aid workers are held, it was important to emphasize with potential interviewees that, despite my temporary affiliation with NZAID, they were under no obligations to talk to metheir participation was completely discretionary and they were free to decline to answer any questions they wished, or end their interviews at any time.

Also of concern in ethics applications was the confidentiality of research participants, and also of the region in Papua New Guinea where project research was conducted. Because of the limited nature of NZAID's activities in Papua New Guinea, naming the province in question would permit the easy identification of projects and potentially of project participants. Participants were advised that although they would not be named and their positions would not be identified, within NZAID they would likely be identifiable by people familiar with PNG projects. Outside of the organization in focus, however, confidentiality was more easily guaranteed.

Maintaining the confidentiality of research locations and projects has been difficult, and has required the omission of valuable detail in the presentation of my results. Because of the great diversity of Papua New Guinea, each province has unique, and thus easily identifiable, social and cultural practices. Descriptions of the project environment were correspondingly muted in order to maintain confidentiality. Information which would have served to more evocatively situate data was omitted. Anecdotes and examples expressive of concepts key to this paper were also left out as they were too specific to the region in focus, and too difficult to alter. I have also been unable to name and cite project documents whose titles are indicative of the region or projects in question. Concerns for confidentiality have also required a painstaking writing process. I have been meticulous about omitting identifying names and terminology from all project references included in this paper (including in my Works Cited), and creating pseudonyms. Furthermore, all identifying descriptive details have been scrupulously removed from project descriptions, quotes from interviewees, and 
project documents. Being unable to provide details of the projects has meant that the richness of collected data has been forcibly dulled. I do believe, however, that the data that I have been able to use is suitably rich and illustrative of this study's key concepts.

This project has also involved overlapping accountabilities. I have been accountable in my research to both NZAID and its two projects as regards the maintenance of projects' and participants' confidentiality, as well as formally agreed ethical obligations. As the research has progressed, however, I have felt increasingly accountable to NZAID, and especially to its partner projects and stakeholders, in a capacity beyond that stipulated by ethics agreements. I have felt the obligation to produce research and recommendations that they find to be of practical use and import. Project stakeholders were unfailingly generous of their time, knowledge and assistance, and were very interested in my research and how it might help them and their projects achieve their development goals. All participants in PNG expressed the hope that I would be able to offer concrete suggestions on how to better go about their work. Since my time in PNG I have felt increasingly obligated to meet their expectations and answer their generosity with an insightful and useful product.

\section{Research Design}

The focus of the project is on the written and spoken texts of NZAID and its development partners, and how these texts and associated social practices are productive of institutions. The goal of this research is to identify, by putting development texts in dialogue with institutional theory, what concepts a development strategy must address in order to produce a successful and sustainable outcome. It will demonstrate how NZAID's development discourse, as glimpsed through NZAID's organizational texts on development practice, as well as through NZAID and its partners' texts addressing two NZAID-funded development projects, currently touches on these required strategic concepts, and how that body of texts might grow to address those concepts more comprehensively. In undertaking this research endeavour, I have adopted the following approach: 
1. To identify the concepts that a discourse must address in order to produce an institution.

2. To identify the concepts within the discourses of sustainable and alternative development that can be seen to contribute to and pertain to institutionalization.

3. To identify how NZAID and its partners' development discourse addresses sustainability. Examine how (or how not) that discourse carries through to NZAID's partners in PNG.

4. To explore how NZAID and its partners' sustainable development discourse contains concepts also understood to contribute to institutionalization.

5. To examine how NZAID and its partners' development discourse is set up to achieve their institutionalization/sustainability goals, and what else that discourse might productively incorporate.

As this research combines institutional theory and development practice in a way not previously done, it was difficult to slot into any pre-established methodological framework; so I have effectively created my own. As can be seen above, this framework approaches the study of a phenomenon-institutionalization - through the study of discourse, namely the discourse of a development organization and its partners as they attempt to produce sustainable development outcomes.

\section{Neo-Institutionalism and Critical Discourse Analysis}

As discussed in the Literature Review, institutional scholar Roy Suddaby describes institutional theory as being the all-purpose, go-to theory of organizational scholars (Suddaby, 2010). While certain aspects of institutional theory have been well mapped, there are other aspects that have been little explored. Nelson Phillips suggests that institutional theory has yet failed to tackle issues of institutional development and 'the processes of social construction' at work during institutional formation (Phillips, 2003, p200). Phillips describes neoinstitutionalism as an emerging and promising form of institutional theory-a 'best of' compilation that combines some of the most important aspects of old institutionalism and new institutionalism: respectively, their focus on institutions shaping behaviour, and on institutions as a forum for change through individual 
entrepreneurial behaviour and agency (Phillips, 2003). While neo-institutionalism is identified as the most promising new form of institutional thought, Phillips finds that it nonetheless fails to provide a satisfactory description of institutional formation processes. Phillips accuses both neo-institutionalism and its parent, new institutionalism, of having 'concentrated on the effects of institutions while not exploring their constitution in social practice' (ibid, p221).

Phillips' proposed remedy is for neo-institutionalism to team with critical discourse analysis (CDA) in order to approach the topic of institutional formation and describe the process of institutionalization. CDA, which '....aims to reveal the role of language as it relates to ideology, power and socio-cultural change' (Grant et al., 2004, p11), is a well-established analytical technique in the field of organization studies. Phillips recommends the use of CDA because it examines the links between texts and the social structures that have affected their production, their dissemination, and their consumption and interpretation. Phillips and other institutional theory scholars assert that CDA, with its focus on discourse as productive of concepts and objects, is the proper tool to employ alongside neoinstitutionalism in exploring the social and discursive processes that construct institutions (Kramer, 2000; Phillips, 2003). This idea provides the theoretical justification for the methodological design of this research.

CDA serves a dual purpose in this paper, both as method and as theory. It is the primary method of analysis that I employ in exploring my data. It is also a way of understanding language and social construction (Burman and Parker, 1993). As a method of analysis, it involves looking at a) the language content of a given text, b) the ways in which that text is created and distributed and consumed, and c) how that text is illustrative of the social relationships from which it emerges (Broadfoot et al., 2004). These analytical steps require the analyst to be in sympathy with the philosophical underpinnings of CDA. CDA understands language as a medium for and a driver of social construction (ibid). By identifying language as a tool of social construction, CDA informs my understanding of the social construction process of institutionalization and dictates my focus on language as the window to understanding that process (Hardy and Phillips, 1999). Because CDA understands 'what people say' as being productive of 'what people do', documents and interviews, as records of what people say, are fundamentally linked to 
observations, which identify what people do. CDA has thus been influential in determining my research design.

As described in the Literature Review, to complement this theory of language as the engine of institutionalization, I use Scott's theory of institutional pillars. By fusing Phillips' institutionalization theory with Scott's theory of institutional pillars, I established my research design: I maintain that in order for a discourse to drive a process of institutionalization, it must discursively address and establish the support of the three pillars. I thus examine NZAID and its partners' discourse for elements that can be categorized in terms of their relationship to Scott's institutional pillars, and for principles identified as contributing to the process of institutionalization. As discussed in the Literature Review, both modern development practice and institutionalization share an emphasis on common principles, such as participation and consultation, etc. It has thus been my assumption from early on in the research process that development organizations' development discourse likely contains many themes understood to be productive of institutionalization.

\section{Discourse and Power}

Many discursive theorists are interested in the concept of power, and how power influences how discourses are created, and limits or encourages those discourses' distribution and consumption. Critical discourse analysis (CDA) in particular is interested in exposing how power issues influence the process of discourse production. Some CDA techniques are concerned with highlighting power discrepancies in the hopes of those discrepancies being recognized and levelled. Phillips and Jørgensen conceptualize CDA as being '..."critical" in the sense that it aims to reveal the role of discursive practice in the maintenance of the social world, including those social relations that involve unequal relations of power' (2002, p63). It is this strength of CDA that has made it a preferred analytical technique of alternative development scholars (Kothari, 2005), as well as of neoinstitutionalist scholars. Both of these fields advocate critical discourse analysis because of its ability to interrogate the effects of power on a discourse and its outcomes. 
While power is not a focus of this research, it is important to address its presence in the topic being studied, and its effects on the empirical subjects of this study. I have elected to study NZAID and its development discourse as it affects development outcomes with its partners and project stakeholders. Power is an important aspect of NZAID's influence over the development discourse of its projects. Because of NZAID's financial resources and its privileged status as a Western development programme, the texts it produces have the ability to influence the development discourse of its projects, and thus project design, implementation and outcomes-more so than the texts of its partners in developing nations who may lack NZAID's distributive power and the influence. This research operates on the assumption that because of NZAID's power, its texts will be most influential in determining the content of the development discourse it elaborates with its partners (Hardy and Phillips, 2004). However, this research does not address power inequalities, but rather focuses on the content of NZAID's development discourse itself. Power is an important consideration in discursive processes, in development, and in the process of institutionalization, and would be a worthwhile avenue to explore for future study.

\section{Data Collection}

I have conceptualized my research design as the exploration of the perspectives of the multiple participants in the development process. While I began my data collection at NZAID, it is to be noted that the genesis of the development process need not be located with the funding organization. There are many different discursive strands that combine to produce project discourse. These strands originate within target communities, local development organizations, development partners, etc. While studying the origins of stakeholders' development discourse would be worthwhile, it is NZAID's development discourse that is the focus of this study, and so I study that discourse as it originates there.

It is important to note that while NZAID is studied as the origin of development discourse as related to its projects, some of the origins of its own discourse can be located within the broader international development community, of which it forms a part. NZAID's development discourse and actions are influenced by that community's development discourse. As described in the Literature Review, this 
discourse is strongly rooted in the Paris Principles, with its focus on alignment with partner governments and their strategies. It is also influenced by alternative development texts, which encourage the inclusion of multiple levels of stakeholders in decision-making processes, as well as the integration of indigenous perspectives, and the participation of target populations, etc. All of this external discourse is reflected within NZAID's organizational discourse, and within its project documents.

As it is NZAID's development discourse that is at the centre of this research, I began my study there. As this research is concerned with how sustainable development discourse flows through NZAID and on to other project stakeholders, I followed the path of development discourse from NZAID through to stakeholder communities. Beginning at NZAID's Wellington office, my data collection proceeded to NZAID's office in Port Moresby, Papua New Guinea, to NZcontracted project workers in country, to local project workers, and finally to beneficiaries and community members.

Data collection consisted of a combination of document collection, interviews and observations. Each data collection method was chosen according to its ability to reveal different aspects of NZAID's development discourse. Project documents reveal how NZAID as an organization conceives of its task as a developer, and by what principles its methods are guided, as well as how it communicates with its stakeholders. Interviews reveal how development discourse has been received, internalized and interpreted by project stakeholders. And observations reveal how ideas within development discourse are enacted by project stakeholders, how they affect the project environment, and how projects are currently placed to achieve the goals expressed in project texts. The texts resulting from these data collection techniques form the 'corpus' of the discourse I am studying. The 'corpus' has been described by Fairclough as 'a series of discourse samples which can give adequate information about the "archive"-in other words, the corpus consists of a sampling of texts understood to be representative of the discourse as a whole (Prichard et al., 2004, p227). This corpus is in no way the complete discourse, but provides information sufficient to represent the discourse in question. 


\section{Document Collection}

One method of data collection employed throughout the research process was document collection. Studying NZAID's organizational and project documents permitted me to glimpse the organization's formally recorded development procedures, allowing direct textual comparisons between NZAID's own guiding documents and such external documents as the Paris Principles. It also illustrated the language used to discuss sustainability and development, indicating the terminology I should look for in my study of texts produced through other data collection methods. My access to NZAID documents was limited to nonconfidential project documents.

In selecting the documents for studying NZAID's sustainable development discourse, I chose texts that I deemed would have the greatest influence on project practices and goals: NZAID's Project Design Documents and the like, as well as documents describing NZAID's recommended approach to project design. Selecting documents originating beyond NZAID was more difficult, in that development is a broad field influenced by multiple actors, organizations and literatures. Ultimately, the documents chosen were those most regularly referred to in interviews, and those identified by NZAID staff as being most influential. It must be emphasized that the discursive samples that I have studied are merely aspects of a discourse of which they form a part, but which is much larger than themselves.

\section{Interviews}

\section{Objectives}

As Phillips and Hardy (2004) maintain, a discourse can only be studied through its texts, both formal and informal. While formal texts are easily obtained through document collection, informal texts are less frequently recorded. In addition to obtaining NZAID's formal position on sustainability through document collection, I was also interested in informal understandings of sustainability, demonstrating how NZAID's development concepts are consumed and digested. This suggested an interview process. (Furthermore, in these projects' process of development, it 
is primarily only NZAID that produces documents, and thus interviews were the only way available to study the development texts of stakeholders farther removed from NZAID.) Discourse is a process in which people interact with texts, interpreting and digesting them before putting their own spin on them and rereleasing them in new communicative events. Interviews, which draw out subjects' views on and experiences of a subject, were thus an obvious choice. I wanted to draw out interviewees' personal understandings and experiences of sustainable development. The expectation was not that interviewees would parrot NZAID's definitions of sustainability and its supporting principles, but rather that interviewees would demonstrate how, through those concepts' interactions with their social and cultural environments (Phillips and Jørgensen, 2002), they made these concepts their own.

Interview Process

I began my interviews at NZAID's Wellington office, speaking with members of the Papua New Guinea team. I conducted one focus group interview with three members of the PNG team in order to obtain a baseline understanding of how project planning was undertaken, who project stakeholders were understood to be, and how sustainability was understood by NZAID as an organization. I also conducted two individual interviews with members of NZAID's Strategy, Advisory and Evaluation Group (SAEG) in order to develop a better understanding of NZAID's development strategy. Once my travel to PNG had been confirmed, I conducted one further interview within the PNG team with the individual best acquainted with the area to which I would be travelling, and the projects that I would study. In addition to addressing my interest in the organization's approach to sustainability, these interviews, as well as those conducted at NZAID's office in Port Moresby, served to illustrate how NZAID functions as an organization-which teams are responsible for which things, to whom they answer, whose work informs whose-these interviews enabled me to understand the nuts and bolts of NZAID's operations, and how NZAID is organized in order to best go about 'doing' development. In PNG I conducted interviews with two NZAID staff members familiar with the projects that I would be studying. In addition to interviewing NZAID workers in Port Moresby, I interviewed stakeholders at two communitybased projects in the area of PNG chosen (for confidential reasons) by NZAID. 
The sample size of participants in this project is relatively small. This reflects the limitations of the time and scope of the project. Sampling was purposive. I hoped to speak with approximately 4 interviewees within NZAID in Wellington, and 3 within NZAID in Port Moresby. I hoped to speak with approximately 5 stakeholders within each of the two projects in rural PNG (see Appendix $C$ for interviewee table). Interviewees were selected based on their positions within their organizations, and their degree of knowledge about the projects and processes in focus. Within NZAID's Wellington office, participants were recruited via e-mails written by me describing my research and its purpose (see Appendix A). These e-mails were distributed by contacts within the PNG team and the Strategic Advisory and Evaluation Group to members of their teams. Participants were volunteers knowledgeable about project planning and implementation, and the political and social environments of projects. In PNG, there was a more limited pool of potential participants, simply due to the smaller number of NZAID workers on the ground. Participants in Port Moresby were thus recruited via e-mail, by an NZAID employee familiar with potential participants' knowledge of programmes in PNG. Projects in PNG were chosen from a pool of potential projects in the region proposed by NZAID. Of the three projects presented as options for study, only two responded to my introductory e-mails indicating their willingness to participate. Within those projects, participants were chosen in consultation with employees of NZAID, and with employees of the two projects in focus. As opposed to NZAID participants, who indicated their willingness to participate via e-mail weeks before data collection began, interviewees in rural PNG were recruited in person by project workers often less than a day before being interviewed. Signed research consent was obtained from all interviewees (see Appendix B).

As opposed to the unidirectional engagement of document analysis, the conversational nature of interviews permits the subjects and the researcher to interact to construct the process and the end result (Holstein and Gubrium, 2004). It was thus crucial that I constructed interviews to elicit personal responses from participants. This entailed tailoring each semi-structured interview to suit each interviewee's position and specific area of expertise, enabling them to speak 
authoritatively and anecdotally about concepts familiar to them. While interviews were personalized for each participant, several questions carried through all of the interviews I conducted: how do you define sustainability, how do you describe a successful/unsuccessful project, how are development plans created/where do development plans come from?, etc. (see Appendix D). Other questions arose over the course of individual interviews. All interviews were recorded digitally, and transcribed by me. Each interview lasted approximately one hour and was digitally recorded and later transcribed. Interviews were conducted at the office of the organization in question (and in the case of the community member interview in the Community Building Project, under a tree in the village).

Interviewees were not informed of specific questions before the interviews, although participants were all acquainted with the purpose of the project. All interviews were conducted in English, with one exception in the Community Building Project. This was an interview conducted through an interpreter. While English is spoken by some Papua New Guineans, most people are more fluent in Tok Pisin (Pidgin). This particular interviewee, while capable of understanding my questions in English, preferred to give his answers in Pidgin. While the language barrier was in no way an issue at the Service project, at the Community Building Project it became clear (from the brevity and comprehensibility of some interviewees' responses to some questions, as compared to the length and fluidity of their responses to other, perhaps simpler, questions) that due to varying degrees of English comprehension and speaking ability, some of my questions may not have been fully understood. Nor was I able to fully understand some of the answers that I received. While the data from these interviews is slightly more limited, I was still able to obtain comprehensible answers to the majority of my questions.

\section{Observations}

Benefits of Conducting Research in PNG

Conducting research at a number of locations has enabled me to follow sustainable development discourse as it extends through the development system - from the head office where plans are designed and assessed for their 
overall fit with the PNG country strategy, to the PNG office where face to face interactions with local people and organizations begin, to the communities where development plans come to fruition and begin to act upon, and are acted upon by, the project environment. Visiting all of these locations gave me a good feel for the varied project environments and the way in which project work is conducted. My research would have suffered had I not been able to visit all of these sites and conduct interviews and observations in person, because, as Fairclough and Wodak state, 'Discourse is not produced without context and cannot be understood without taking context into consideration...' (as cited in Phillips, 2003, p223).

My travel to PNG was motivated by the need to collect data from those parties involved in the NZAID development process. In addition to data collection though, my time spent in PNG permitted me to engage with the contexts of each development projects. I was in PNG for a total of 16 days, and in addition to conducting formal research, I was also able to absorb a great deal just by being in country. I was able to witness some of the challenges that make effective and sustainable development, and daily life, a challenge for Papua New Guineans. I was also able to learn about, and engage with the culture of the particular region in which I carried out my data collection. Everyday interactions with people, and observations of behaviours and customs were useful in filling out my understanding of the project environment. It was a fascinating couple of weeks.

While I read extensively about Papua New Guinea prior to my departure, I was able to obtain little information about the two projects prior to my departure, largely due to the difficulty of communication in developing areas of PNG, and also as NZAID was reluctant to provide me with too much information about partner organizations without those partners' prior knowledge and consent. I was told that required information could be obtained upon gaining the consent of partner organizations once I had arrived at my destinations. This was indeed the case. The learning curve upon arrival in PNG was steep-it was necessary to take in a great deal of information about each project as quickly as possible in order to ask the most appropriate questions in the limited time allotted for data collection. 


\section{Observation Process}

Observations were conducted for the purpose of examining how the project plans about which I had been interviewing development workers about were actually being implemented-how people's statements about the sustainable development process informed and produced their actions, and how those statements were products of the project environment. They were conducted as permitted by conditions on the ground, and as dictated by workers familiar with the projects and their environments. The observation stage of my research was quite exciting, as it represented the first time I was able to bring together both the development theory and institutional theory parts of my research in practice. Over the course of my observations I was able to observe to what degree development practice conformed to scholarly theories of the institutionalization process. It was my chance to see what project realities were after having read and heard so much about them.

Rather than collecting previously specified data, observations were conducted in order to 'get a feel' for the project environment. At each of the projects I made one rural site visit where I conducted observations and interviews. The rest of my data collection consisted of interviews and observations at the projects' headquarters. Observations were conducted informally, and while informed by a pre-written observation guide (see Appendix E), varied greatly according to site conditions and time constraints. For example, while one observation lasted approximately 4 hours, another was cut short by the threat of a potential natural disaster (which fortunately did not eventuate). In another case, due to the time required to travel from a rural site back to organization headquarters, my observation lasted less than an hour. While one Service Project observation took place in a public meeting place, a Community Building Project observation was conducted while being taken on a project site walk through. I did take infrequent notes while carrying out the observations, but the large part of my observations were written up after they were concluded, as it was difficult for me to take notes unobtrusively and without interrupting my observations. I also wrote reflections on my data collection and daily experiences in general. 
Observations lent credence to NZAID's assertions of the centrality of consultation and participation to their development process. I was able to observe the close consultative working relationships between NZAID contractors and Service Project workers. I was able to witness community members' level of comfort with NZAID and local Service Project staff, and how community members interacted with and owned Service Project activities and outcomes. Observations enabled me to see the local outcomes of the values professed within NZAID back in New Zealand, and demonstrated that those values were not merely talking points, but were actually carrying through to influence actions and results on the ground. Also, observing how community members interacted with the project site and with project workers (and vice versa) allowed me to see to what extent projects were fitting in with communities and meeting their service needs, as well as their social needs. Observations served to demonstrate how projects were on their way to achieving their objectives, and if and how project behaviours and activities were becoming institutionalized within the community.

\section{Data Analysis}

I have treated the selected organizational documents and interview texts in two different ways: first as sources of factual, framing data, and second as examples of development discourse. (It is to be noted that interview data have been treated as texts, not as a special kind of data. They have been analyzed in the same manner as other textual data.) Based on the understanding that individual understandings flow on from individuals' consumption and processing of formally recorded texts, I begin each section of analysis by first examining relevant documents and identifying key ideas and themes. From there I move on to analyze interview texts for the presence of those identified themes, as well as others that may have emerged. The analysis of these two types of texts (formal documents and informal speech events) serves to present the development discourse produced by NZAID, and the ways in which that discourse is or is not altered over the course of its distribution, consumption, and interpretation by stakeholders.

As described earlier, I have used critical discourse analysis to analyze collected data-specifically interview data and document data. There are many types of 
CDA, some involving painstakingly close readings of texts and coding of all words used (Potter, 2004). My analysis has not been quite so arduous. By identifying the presence of key words and direct references to key concepts, I have coded texts according to prominent themes in development literature (such as participation and empowerment). Some texts have required more interpretive analysis than others. Where direct conceptual references are few or absent, I identify key terms and explain their links to principles of sustainability and institutionalization. But where texts contain direct references to concepts pertaining to sustainability or institutionalization, subsequent identification of key words that can be interpretively linked to those concepts is redundant, and thus omitted. Important thematic passages from different texts have then been grouped together, and where possible, linked to observation data. Observations are used to support my interpretations of data, but, not being examples of discourse, but rather my own records of action and descriptions of settings, observations have not been analyzed using CDA. Rather, they have been coded for key themes and linked to those key themes appearing in interview and document data, where appropriate. Observation data has also been used anecdotally and as a source of background information in order to more evocatively situate textual data.

In that only a small number of people were spoken to in each organizational setting, I have weighed how representative their texts are likely to be of broader discourse, taking into consideration the regularity of organizational communication, the comprehensiveness of social networks, subjects' positions and degrees of influence within those networks, and subjects' degree of similarity with other members of their organization or environment. Through these analytical considerations I hope to present data that is both illustrative as well as representative, accurately presenting organizational and project realities. 


\section{Background}

\section{Introduction}

This chapter provides important background information for the organization and projects studied in this research. It begins by reviewing the history and the ethos of the case study organization, NZAID. It presents NZAID's relationship with the broader international development community, and its commitment to internationally recognized standards of development best practice. It then provides information for each of the two NZAID projects studied in Papua New Guinea. The specificity of the information provided for these projects is limited by concerns for maintaining the confidentiality of projects' identities and locations. Finally, this section examines where each project is currently situated in terms of achieving its objectives. It uses David Korten's generational framework of development projects to illustrate how each project's design dictates the path that must be followed in order to achieve sustainability (Korten, 1990). This chapter provides information sufficient to understand NZAID and its approach to development, as well as its involvement with each project, and the challenges they face.

\section{NZAID}

The development organization studied in this research is NZAID (New Zealand Agency for International Development). NZAID is the arm of New Zealand's Ministry of Foreign Affairs and Trade (MFAT) that delivers the country's overseas development assistance ('FAQs: About NZAID', 2009). Based in Wellington (where it employs approximately 180 staff), it also maintains overseas posts in several nations (employing over 100 New Zealanders and local staff) (ibid). NZAID will spend $\$ 500$ million on overseas aid in the 2009-10 financial year (ibid). The majority of its funds are devoted to development programmes in the nations of the South Pacific, with some programmes also being run in Southeast Asia and other parts of Oceania. A small portion of NZAID's budget also goes to programmes in Africa and South America. NZAID's mission is to 'Support sustainable development in developing countries in order to reduce poverty and to 
contribute to a more secure, equitable, and prosperous world' ('About NZAID', n.d., n.p.).

New Zealand is a member of the OECD DAC (Organization for Economic Cooperation and Development Development Assistance Committee) and a signatory to the Paris Declaration on Aid Effectiveness and the Accra Agenda for Action. Further to Paris and Accra, Papua New Guinea created its own aid effectiveness agreement in 2008, the Kavieng Declaration on Aid Effectiveness ('Kavieng Declaration', 2008, p1). This agreement, to which New Zealand is a signatory, aims to localize the Paris Declaration and situate it within the PNG development context. By this proliferation of aid effectiveness agreements it can be seen that aid effectiveness (and thus sustainability) is one of the more important issues in development today. NZAID's alignment with its peers in the international development community, and its commitment to agreements outlining best practice signal that its own approach to development is shaped by international standards and practices.

NZAID was created in 2002 as a semi-autonomous agency within MFAT. Until the 2008 election of the National Party, NZAID had existed solely under Labour Party leadership. The National Party's coming into control of the government has meant changes for NZAID. Its semi-autonomous status has been revoked and it has been fully subsumed into MFAT. No longer a semi-independent agency, under this new arrangement NZAID will continue to administer New Zealand's development assistance programmes, but will be managed by and answerable to MFAT ('FAQs: Recent', 2009). NZAID has not changed its name in this re-shuffle, but is no longer considered to be an 'agency', so much as a 'programme', or business unit within MFAT.

With this change in structure also comes a new focus for NZAID's funding. Previously NZAID's development mandate was based on a strategy of poverty reduction. NZAID's new aid policy will be based on a strategy of sustainable economic development ('FAQs: Recent', 2009, n.p.). This shift in focus has been controversial and has provoked public debate (with many opponents of change questioning whether aid will be used as leverage to reinforce government foreign policy) ('NZAID review', 2009; 'Stop McCully's Cull', 2009; Twyford, 2010), and it is 
not yet known what effect this switch will have on NZAID's long-standing programmes. NZAID's website addresses this concern by stating that 'The changes strengthen the alignment of New Zealand 's foreign policy and development goals, by ensuring that New Zealand agencies working abroad are doing so in an effective and coordinated manner as part of 'NZ Inc.' ('FAQs: Recent', 2009, n.p.). Interviewees within NZAID did not consider themselves at liberty to comment on the issue, as their ideas would have been speculative.

Within NZAID are multiple groups with responsibilities to specific geographic or operational areas: the Executive Director's Group, the Global Group, the Pacific Group, the Strategy, Advisory and Evaluation Group (SAEG), and the Management Services Group ('Organisational Structure', n.d.). The group within which I conducted the majority of my research was the Pacific Group, responsible for Pacific region development programmes, including overall regional strategy formulation, implementation, and monitoring and evaluation. Pacific Group staff members may be stationed at NZAID's Wellington head office, or in any of NZAID's Pacific overseas posts. Serving as a resource to the other groups is the SAEG, within which I conducted two interviews. The SAEG provides strategic and policy advice (upon request) to NZAID's development initiatives, having within it a number of specialists in specific areas of development (such as agriculture, fisheries, etc). It was stressed by interviewees that consultation between regionspecific teams, and between groups was regular.

Like any international development organization, NZAID has had varying degrees of success with the long-term viability of their development initiatives. In NZAID's current PNG strategic plan is an NZODA (New Zealand Overseas Development Assistance) critique of prior development initiatives, stating that previous projects suffered from 'A lack of an exit (sustainability) strategy for programmes highlight[ing] the need for planning for the conclusion of assistance with a phased hand-over of responsibility to the government, or other local partner agency' (NZAID, 2008, p16). NZAID has responded constructively to this critique with the following statement of intent: '... programmes to be phased out will be subject to reviews and sustainability assessments and/or subsumed under longer term programmatic approaches (ibid, p16).' With those two previous quotations in mind, I chose to look at NZAID's PNG projects in order to analyse and understand 
how the organization goes about developing sustainability strategies critical to long-term project viability. NZAID's PNG programme struck me as being eminently suited to a study on sustainability management as, subsequent to the identification of sustainability as a shortcoming of the programme, language pertinent to sustainability would likely be abundant and rich.

\section{Papua New Guinea}

The nation of Papua New Guinea (PNG) occupies the eastern half of the island of New Guinea (the world's second largest island), and also comprises hundreds of outlying islands. PNG is a nation of tremendous diversity. Situated only 6 degrees south of the equator, the highest mountains in the country $(4500+\mathrm{m})$ experience snow ('Papua New Guinea', 2009), while low lying areas experience tropical temperatures throughout the year with little seasonal variation. Rugged forested mountains cover the majority of the country, with coastal lowlands and swamps making up the rest (Flannery, 1998). Due to the extent of the country's mountains, populations are extremely fragmented and social heterogeneity is very high. With communities being isolated and sparsely distributed across rugged terrain, over 800 distinct languages are spoken in an area the size of California ('Papua New Guinea', 2009). Many of those languages, though spoken by tribal groups living only miles apart, are mutually unintelligible (McKinnon, 2008). While local languages are spoken within communities, Tok Pisin (Pidgin English) is used as the lingua franca throughout the country, but is not universally understood.

PNG was colonized by both the British and the Germans in the late $19^{\text {th }}$ century, with the Germans claiming the north-eastern quadrant of the island of New Guinea, and the British the south-eastern quadrant ('Papua New Guinea', 2010). The western half of the island was claimed by the Dutch (eventually becoming part of Indonesia). Throughout the $20^{\text {th }}$ century, as the fortunes of its colonial powers changed, administration of the eastern half of New Guinea changed hands as the Germans and then the British withdrew, ending ultimately when Australia granted Papua New Guinea its independence in 1975 (ibid). Throughout the colonial period, plantation agriculture in the coastal lowlands was the primary means of economic development, though mineral deposits were discovered throughout the country in the early $20^{\text {th }}$ century. Exploitation of those minerals has intensified 
since the 1970s, producing no small amount of conflict over land rights, distribution of benefits, environmental degradation, etc. (ibid).

Although rich in natural resources (gold, silver, copper, oil, natural gas, timber, etc.), PNG is very poor, with some $37 \%$ of its population living under the poverty line ('Papua New Guinea', 2009). The United Nations Development Program puts its Human Development Index at 121 of 135 countries ('Human Development', 2009). Of PNG's 6.1 million people, approximately $85 \%$ live in rural areas (Newson, n.d.). Transportation and communication infrastructure being minimal and unreliable, services are largely unavailable in rural areas, and so literacy rates are low and health services are very poor. Accordingly, life expectancy is only 60 years, and maternal and child mortality rates are very high ('Human Development', 2009). Most Papua New Guineans practice subsistence farming, and other forms of employment are few and far between.

PNG's rugged topography and the resulting barriers to infrastructure and intercommunity networks also inhibit effective and sustainable development. In answer to the question 'what are some of the obstacles to sustainable development in PNG?', interviewees at NZAID replied

In terms of [political engagement and] participation, the geography imposes communication difficulties. Less than half the households in PNG have a radio. The telephone network - though it is expanding, there are a few areas that are out of reach. People can't even get information about what's going on in their polity, let alone involve themselves in it.

Another employee elaborated, saying

The topography of PNG is just a ridiculous barrier, because people live in geographical pockets... and people still exist culturally in that kind of tribal dynamic, even when they move to the cities, there still are those sort of cultural mores that they bring with them.

While social networks within community groups may be quite strong, the isolated nature of villages has limited the growth of inter-community networks, often resulting in hostility and conflict. Violent conflict between tribal groups is still exceedingly common, especially in the highland provinces, and security is poor 
(McKinnon, 2008). Communities are governed by chiefs and councils of elders, and in areas where national justice systems are virtually absent, these traditional authority structures are still highly relevant and effective. Holding communities together is the wantok system, wherein groups of people speaking the same language or living in the same area are loyal to, and look after each other, sharing possessions if any of the wantok is in need (ibid). The strength of kinship networks has proven to be both a blessing and a curse for Papua New Guinea, particularly in the post-independence period. As described by NZAID interviewees, politicians' loyalties tend to be to their own tribal groups, rather than to the whole of their constituency, and policies, contracts, and government funding disbursements reflect this bias. Thus for many Papua New Guineans, political representation is ineffective at best, and may often be detrimental to their livelihoods. Corruption is rampant, and this presents an additional hurdle to the effective and egalitarian distribution of state services and resources.

Governance in PNG is an obstacle to development, and to effective aid. Since 1975 only one administration has managed to serve out its full term (McKinnon, 2008). With political loyalties so fragmented, many politicians spend much of their time in office just trying to keep their seats. Many officials also take advantage of their positions to secure as many benefits for their wantoks as possible. Of 180 countries evaluated in 2009 by Transparency International for perceptions of corruption in the public sector, PNG ranked $154^{\text {th }}$ (New Zealand is currently ranked $1^{\text {st }}$ ) ('Corruption Perceptions', 2009). This statistic cannot be a welcome one for PNG's aid partners. Currently over $20 \%$ of Papua New Guinea's total budget is derived from foreign aid ('Papua New Guinea', 2009). Effective aid distribution is hampered by PNG's persistent corruption, which makes it difficult for aid organizations to have faith in their funding being equitably and effectively distributed. While alignment with the Paris Principles prompts aid partners to channel their funds through government networks, in the face of such pervasive corruption many organizations choose to use alternative distribution networks until such a time as the integrity of government distribution policies and channels can be relied upon. As a result the majority of international aid is distributed outside of government channels ('Kavieng Declaration', 2008, p10). 
After the Solomon Islands, Papua New Guinea is the recipient of NZAID's second largest portion of aid funding. NZAID will spend \$27 million in PNG in 2009-10 (Newson, n.d.), to be dispensed in accordance with a ten year strategic agreement signed with the government of PNG (GoPNG) in July 2008. This strategy focuses mainly on improving the capacity and delivery of health and education services, and on the empowerment of PNG's rural populations through increased 'livelihood opportunities' (Newson, n.d., p2).

\section{NZAID’s Papua New Guinea Development Projects}

While many aid organizations provide money to partner governments in the form of budget support for governments themselves to use in order to implement preagreed strategic plans within their budgets, aid organizations also finance projects to which they give funding directly, and which they often take a direct hand in designing and running. I studied two such projects while in Papua New Guinea, both funded directly by NZAID. (Due to confidentiality concerns, I will be unable to elaborate on any distinguishing attributes of the projects or the region in which they were based.) Each project was based in a large town in the same remote region, separated by a journey of several hours by car over a rough road. All of the hurdles to development described in the preceding paragraphs are present in the rural province in which I conducted my research: poor infrastructure, inadequate state institutions, high socio-cultural and linguistic diversity, etc.

\section{The Service Project}

One of NZAID's PNG projects (to be referred to as the 'Service Project') is being implemented under the guidance of a staff of several NZAID-contracted foreign technical advisors. These advisors are assisting local people to set up a service that will expand the capabilities of, and be eventually subsumed into, an existing provincial government-run service. The project was initiated at the request of the provincial government, who wished NZAID to assist in the permanent establishment of a service reaching not just the province's semi-urban populations, 
but also rural populations in remote areas (NZAID project document ${ }^{1}$ ). In collaboration with the provincial government, NZAID elaborated the project design and objectives, in accordance with which the project activities have been implemented. Early stages of the project focused on the selection and capacitation of community members to perform the service in question, and reinforced community networks to support the service and its providers. In its current stage, the project is focusing on developing the service's provincial provider, which will eventually take over operation of the community-based service and run both the community and provincial services going forward.

At the time of my research, the project had been funded and operated by NZAID for several years, and was due to be moved into its final phase of implementation in the following year (though this plan was due to be reviewed shortly after the conclusion of my visit). The project's current phase, nearing its scheduled end date, is designed to conclude with the handover of the project to the provincial service provider. The community-based service capacitation and rollout is deemed by all involved to be progressing very well and is highly regarded by community members, local staff, and the provincial government. The capacitation of the provincial service provider, as is described later in this research, is proving to be a more complicated task.

\section{The Community Building Project}

The second project that I studied is a community development organization that had been founded and operated by an international NGO until being handed over to local ownership in 2004. NZAID has been its primary source of funding since the handover. The main task of the project (to be called the 'Community Building Project') is to provide skills training for local communities in order for them to implement and operate income generating schemes to improve standards of living and the overall economic health of the region and its population. Its mission statement is 'To improve people's living standards...through indigenous empowerment for sustainable social and economic development' (NZAID project document). To this end, it also runs a business skills school, from which it expects

\footnotetext{
${ }^{1}$ Due to confidentiality concerns, I regret that I am unable to explicitly cite any of the specific NZAID project documents collected and used in this research. Where I have drawn information from such documents, I indicate it thus: (NZAID project document).
} 
to graduate approximately 100 pupils in 2010 . Unlike the Service Project, the Community Building Project (CBP) is staffed entirely by local workers, and its relationship with NZAID is essentially that of funding recipient. The organization sets development priorities, and NZAID monitors and evaluates their performance based on targets aligned with these priorities. Within NZAID's monitoring and evaluation priorities, mainly addressing the CBP's community-based initiatives, are also targets addressing the management and financial sustainability of the organization.

Once a community has been identified by the Project as being a good candidate for skills training, needs assessments are undertaken to determine what type of training is required, and what type of project would best suit the village, its environment, and its people, as well as what type of project each community is interested in undertaking. As technical training is minimal, projects tend to capitalize on skills or resources that community members already possess. The community that I visited had begun a brick-making project, taking advantage of the community's proximity to an unused, gravelly piece of village land. Other projects currently in operation in other villages were sewing projects, poultry projects, and peanut-growing projects. By initiating relatively simple projects that employ knowledge and skills already available within target communities, the CBP helps to promote the independence of communities in the operation of their projects, such that they are not dependent upon outside advisors to carry out the basic functions of their projects.

\section{Sustainability Needs of Projects Understood through a Generational Framework}

Helping to understand the nature of these development projects, development theorist David Korten situates development projects within a generational spectrum (Korten, 1990). Locating projects within this spectrum is helpful in understanding each project's goals and how each project proposes to address sustainability. First generation projects are those that address immediate (often emergency) needs of developing populations. They are designed to provide services to afflicted populations until such time as a given crisis has passed, and need for the service has substantially diminished (ibid). According to Korten, 
generation two projects tend to have community empowerment as their goal. Such projects attempt to equip communities to provide for themselves and be selfreliant going forward. As communities become more skilled and capable, the development agency can withdraw while the community drives its own continuing development (ibid). The goal of third generation strategies is the growth and establishment of sustainable service provider institutions responsive to, and equipped to meet the needs of their target populations (ibid). Finally, the fourth generation of development strategies seeks to change the environment in which development is practiced. This is to be accomplished through alliances between development organizations and social movements (ibid).

\section{The Community Building Project}

The community-based nature of the CBP locates it strongly within generation two:

Second generation strategies focus the energies of the NGO on developing the capacities of the people to better meet their own needs through self-reliant local action. Because of their attention to sustainability, true second generation strategies are developmental in concept and are often referred to as community development strategies (Korten, 1990, p118).

A board member for the CBP stated that 'the objective is to help the people of the community so they can help themselves.' Essentially the CBP is attempting to metaphorically teach communities 'how to fish'. This illustrates the CBP's status as a second generation development project, as Korten describes generation two projects as 'an attempt to 'empower' the village people" (Korten, 1990, p118). Interestingly, Korten warns that generation two projects may resemble handouts rather than programmes of empowerment, and may result in dependence on the organization in question. The CBP has confronted this issue itself. Several staff members discussed how before the organization was handed over to local operation, community projects and resources were given to communities, but communities were not trained to run them. With communities lacking the necessary skills to run them, projects deteriorated rapidly.

The CBP has addressed this problem by providing skills training rather than physical resources or funding to communities. This training is designed to make 
communities capable of developing and managing their own projects independent of the CBP. The success of generation two projects, designed to stimulate longterm sustained growth, depends on the degree to which training is suited to communities, and the degree to which those communities take that training on board. Korten warns that unless the initiatives of generation two projects are reinforced by proactive and supportive government policies, they will be unlikely to have any impact on their overall environments. Development scholar Norman Uphoff echoes Korten's opinion, saying that '....while isolated instances of local institutional development can be impressive their cumulative effect is negligible.... what counts are systems of networks of organisations, both vertically and horizontally' (as cited in Edwards and Hulme, 1992, p24). Analysis will examine how the CBP addresses these needs.

\section{The Service Project}

Providing a contrast to the CBP, which is firmly situated in generation two, the Service Project is bi-generational in nature. The Service Project's origins are in generation two, as until recently its activities have been focused on capacity building at community levels, enabling communities to effectively provide a service for themselves in the absence of a capable provincial provider. With the success of this initial phase of the project, it has now moved into the third generation, working towards the capacitation of the provincial provider to effectively and sustainably run the community-based service in addition to its existing service based largely in provincial population centres. As Korten describes them, 'third generation strategies focus on creating a policy and institutional setting that facilitates, rather than constraining, just, sustainable and inclusive local development action' (Korten, 1990, p121). As evidenced by the following statement from a recent Service Project review, the project currently straddles generations two and three: 'The Review recommended that the project needs to shift focus to strengthening the [system] under which [community service providers] operate, including by providing broader support to the [provincial service provider]' (NZAID project document).

The sustainability of the project as a whole thus involves two separate development endeavours: 1) the continued capacitation of community service 
providers, and the further integration of that service into community networks and culture, and 2) the incorporation of the community-based service into the regular operations of the provincial service provider, and the integration of those operations and their motivating ideology with the provincial service provider's culture and its staff-who will require extensive capacity building and skills training. Because of its bi-generational nature, the Service Project's task is doubly complicated, and as was emphasized by programme managers and project workers (and reinforced by Korten's conceptualization of development generations), the successes of the project's community level efforts will only be sustainable if the provincial level institution is brought up to speed. This is the project's current challenge, and one that will place significant demands on all project stakeholders if it is to be met.

\section{Summary}

The two projects that I observed are thus very different, both in the nature of their involvement with NZAID, and in their approach to their development goals. Where the CBP seeks to encourage community development and self-sufficiency in the absence of government institutions, the Service Project seeks to build the capacity of government institutions to support a specific community service. Their situation in Korten's generational paradigm also indicates that they have two different approaches to, and means of achieving, sustainability. The sustainability of the CBP's community initiatives is dependent on the quality of the training provided, the nature of the broader project environment, its suitability for each community and its environment, and those communities' drive to implement that training. The Service Project however, is dependent on the integrity of the institution that will take over service provision in the near future. In the following chapters I will present in detail how each organization conceives of and approaches its development tasks. 


\section{Data Analysis - Sustainability}

\section{Discursive Manifestations of Sustainability in the Development Strategies of NZAID and its Partners}

\section{Chapter Aims and Overview}

As discussed in the Methodology chapter, data collection was conducted for the purpose of assembling representative samples of NZAID and its partners' formal and informal development discourse. This chapter, and the chapter following demonstrate how that discourse, represented by a selection of organizational documents, project documents, and interviews with NZAID staff and project stakeholders, addresses two related and interweaving concepts: sustainability and institutionalization. This chapter and the next are concerned respectively with how NZAID's development discourse gives evidence of addressing the objective of sustainability, and then how those concepts relating to sustainability may also be understood to address and fuel the process of institutionalization. NZAID's treatment of sustainability, as shaped by its commitments to international development best practice guidelines and philosophies, is the focus of this chapter, which lays the necessary groundwork for the interpretive work of the next chapter.

The conceptual presence of sustainability is signalled both by direct references to sustainability and to sustainable outcomes, and also by the use of themes and vocabulary (such as participation, consultation, etc.) identified as being linked to the production of sustainable outcomes. Following on from the Literature Review, where I examined how sustainability features in such foundational texts as the Paris Declaration on Aid Effectiveness and the Millennium Development Goals, I begin this chapter's analysis by demonstrating how vocabulary within the Paris Declaration signals and supports its objective of development project sustainability. I then briefly explore how identical thematic and conceptual markers are present in the language of NZAID's organizational documents, and echoed in individual project documents. Finally, based on Phillips' and other scholars' theories of discourse stimulating, shaping, and situating the thoughts and actions of those who engage with it, I examine how the concept of sustainability is 
evident in the spoken texts of project stakeholders, both within NZAID and without. Overall, this chapter looks to demonstrate how discourse is the site of much of the work of producing sustainable development, and how themes and methods of addressing sustainability carry through multiple levels and sites of development texts.

\section{Sustainability in the Paris Principles}

As described in the Literature Review, the Paris Principles identify the capacitation of the developing nation state, and coordination and cooperation with that state to achieve its national strategies, as key factors in producing effective and sustainable development. In order to facilitate donor cooperation with developing nation states, the Paris Principles present a template for action for international development organizations, encompassing several principles of alternative development identified as contributing to sustainable development outcomes. As described by several interviewees, NZAID's approach to development is closely aligned with this template. In the coming paragraphs I examine how concepts and key words related to sustainability are evidenced within the Paris Principles text, which plays a critical part in shaping NZAID's development discourse. I present excerpts from the Paris Principles document that pertain to concepts contributing to sustainability. While the Paris Principles text signals its alignment with alternative development concepts through explicit reference to those concepts themselves (such as participation, ownership, capacity building, etc.), it also signals its alignment with these principles through the use of key words. These key words, italicized below, allude to other concepts such as partnership, consultation, alignment, etc. considered as contributing to participation and ownership, and thus to sustainability. Through the presence of these concepts and key terms in the Paris Principles, the document lays out its commitment and recommended approach to sustainable development.

Within the Paris Principles are provisions encouraging partner countries to 'Exercise leadership in developing and implementing their national development strategies through broad consultative processes' (OECD, 2005, p3) and to 'Take the lead in co-ordinating aid at all levels in conjunction with other development resources in dialogue with donors and encouraging the participation of civil society 
and the private sector' (ibid). Donors likewise are encouraged to 'Respect partner country leadership and help strengthen their capacity to exercise it' (ibid). The above strategies are specifically identified by the Paris Principles as contributing to partner government ownership of projects. There is a strong emphasis on partner governments assuming a leadership role in their partnerships with donors.

In a section of the Paris Principles' labelled 'alignment' is the proposal that 'Donors base their overall support on partner countries' national development strategies, institutions and procedures' (ibid), to be achieved by partner countries and donors agreeing to 'Work together to establish mutually agreed frameworks' (OECD, 2005, p4). These frameworks must address the donor country's 'capacity to plan, manage, implement, and account for results of policies and programmes' which must be 'responsive to the broader social, political and economic environment' (ibid). To this end, donors agree to 'Align their analytic and financial support with partners' capacity development objectives and strategies, make effective use of existing capacities and harmonise support for capacity development accordingly' (OECD, 2005, p5). Partner countries are also exhorted to 'Make progress towards building institutions and establishing governance structures that deliver effective governance, public safety, security, and equitable access to basic social services for their citizens' (OECD, 2005, p6) and to 'encourage broad participation of a range of national actors in setting development priorities' (ibid). Donors are also encouraged to 'Align to the maximum extent possible behind central governmentled strategies or, if that is not possible, donors should make maximum use of country, regional, sector or non-government systems' (OECD, 2005, p7). By its emphasis on consultative strategic alignment and building the capacity of partner systems, the Paris Declaration details its approach to development, working to partner-established objectives and building partner capacity in order to enable partner governments and stakeholders to take ownership of their projects and their development.

Through this brief interpretive survey of the Paris Principles, it can be seen that donor alignment with partner government strategies is central to the Paris Principles strategy to achieve sustainable development, and that techniques emphasized in alternative development texts, such as alignment, partnership, consultation, participation, ownership, and capacity building are the identified 
tactics to achieve this. Through direct conceptual references, as well as indicative terminology, the Paris Principles encourage behaviours in line with those identified desirable concepts. As NZAID interviewees identified the Paris Declaration as being a major influence on NZAID's development policy, it is to be presumed that NZAID's own development discourse also contains the same conceptual foundations and references. I seek to confirm this deduction in the following paragraphs.

\section{Themes of Sustainability in NZAID Organizational and Project Documents}

Turning to NZAID's documents, it is evident that the principles of alternative development present in the Paris Principles (discussed in the preceding paragraph) are very much present and influential in NZAID's development strategy. Within the organization's Activity Design Guideline are several Activity Design Principles, among them 'involving key stakeholders throughout the design process' and 'building on existing partner institutions and processes' (NZAID, 2006, p5). These principles closely mirror the foundational principles of consultation and alignment presented in the Paris Declaration. The document also lists several 'common elements of success in Activity design', including the requirement for a participatory design process, 'clear demand for, and ownership of, the project' and 'informed agreement between major stakeholders' (NZAID, 2006, p6). The document also states that 'Particular attention should be given to the design of Activity management arrangements. These should be integrated as closely as possible with local management processes and structures' (NZAID, 2006, p7). Thus it can be seen that the principles of ownership, participation and alignment present in the Paris Declaration feature strongly in NZAID's own guiding principles of sustainable development.

The Activity Design Guideline illustrates NZAID's approach to activity design and its intentions for project implementation. It is thus to be expected that the principles that it outlines are encapsulated in its Project Design Documents and Work Plans. Here it is necessary to identify a key point of difference between the two projects in focus. The Service Project was, at the request of the provincial government, instigated and designed by NZAID, whose contractors are currently managing its implementation. The Service Project is thus guided by both a Project 
Design Document (PDD—a comprehensive document elaborating project background and rationale in addition to project activities) and a Work Plan (outlining project activities and objectives). In contrast, the Community Building Project, founded by another donor organization and local stakeholders, was already in existence when NZAID stepped in and began providing financial and mentoring support. Requiring no project charter from NZAID, it functions with only an NZAID Work Plan, and its outcomes are guided by an NZAID Monitoring and Evaluation Framework.

\section{The Service Project}

Within NZAID's Project Design Document for the Service Project, concern for sustainability is evident from the first page of text, in which the goals 'to develop and manage, in line with the NZAID Policy, a programme of sustainable activities...' and 'to develop and support implementation of a [project] sustainability strategy' are outlined. This strategy of sustainability is to be enacted through such objectives as 'To build the capacity of the [Provincial Service Provider] to effectively train and manage [community service providers], using systems that include COE [Councils of Elders] and local stakeholder participation', and 'to further develop operational... competencies among [Provincial Service Providers] and support active application of the [Provincial Service Provider] community [service] philosophy...' (ibid). These objectives, and indeed the whole project are to be achieved through the implementation of several 'Guiding Principles', among them the provisions that 'Support should be consistent with the [provincial governance] system', 'Aid interventions must support the development of sustainable, local systems, rather than establishing parallel and unsustainable systems' and that ' $N Z$ will implement the project in partnership with local stakeholders and national agencies'. These partnerships are to be encouraged through the NZAID's emphasis of the following: 'Government and other leaders need to fully participate and have ownership of any [Service Project] initiatives' and 'Community-based bodies such as COEs, NGOs and community groups need to be consulted, supported and involved' (ibid). Clearly the same development principles identified in the Paris Declaration and in NZAID's Activity Design Guidelines are present in the Service Project's design document. 


\section{The Community-Building Project}

As mentioned above, the CBP has no Project Design Document, but within its Work Plan and Monitoring and Evaluation Framework are ideas which exemplify the principles so clearly present in the Service Project's design. Within its Monitoring and Evaluation Framework are listed the objectives 'To build cohesive and connected communities who can identify their needs and have skills and networks to develop new livelihood options' and 'The capacities of approximately 10 communities and or [sic] community groups to plan and manage their own livelihood activities will be enhanced'. These objectives are meant to contribute to the overall goal, identified as 'To improve people's living standards...through indigenous empowerment for sustainable Social and Economic Development' (ibid). And, as the CBP organization is an NGO and thus unable to rely on government financial support, NZAID also outlines its objective 'To ensure effective governance, management, administration, financial systems to guide, maintain and sustain [the CBP organization] and its programs in the delivery of services to the communities'. In order to achieve its objectives of effective and sustainable community development, NZAID and the CBP organization outline a programme logic which consists of community empowerment, capacity building, and large scale community mobilization and participation, in which communities consult and partner with the organization in the assessment of their needs, and gain the skills required to design and implement a programme of activities to adequately address those needs.

\section{Projects as Representative of the Paris Principles' Focus on Government Primacy}

The examples above illustrate the projects' commitment to the principles of consultation, participation, empowerment and capacity building outlined in the Paris Principles. Interestingly, NZAID's involvement with these two projects embodies another facet of the Paris Principles as well: preferential partnerships with government, with a secondary reliance on alternative partner systems where required. NZAID's involvement in the Service Project is illustrative of the Parisadvocated tie-in with government strategies and systems, as NZAID is successfully partnered with the provincial government, and is presently scaling up 
provincial service providers and their systems for eventual management of the project. NZAID's partnership with the CBP is representative of organizations working through local and NGO systems to implement development in the absence of suitable government networks. Within the CBP, it is also important to note that although it is an NGO, NZAID encourages it to both 'Prepare relevant research reports... on issues for presentation to [the provincial government]' and to 'Attend [provincial government law-making] sessions and talk to [provincial government] members on issues being discussed by [the provincial government]' (NZAID project document). Thus, even NZAID's NGO partners are encouraged to align their strategies with those of the government, streamlining approaches to development and increasing the chances of effectiveness and sustainability. This addresses a concern expressed in the Background chapter, that generation two projects on their own are unlikely to generate lasting or profound impacts on the greater environment unless propped up by supportive government policy (Edwards and Hulme, 1992). Building relationships with government assists the generation two CBP in engendering goodwill that could result in policy helpful in deepening the impacts of its projects.

The examples given above provide evidence that the sustainable development principles and practices outlined in the Paris Declaration have been fully taken on board by NZAID and have been well-integrated into its guiding documents and project documents. What must be proven is whether these texts, which have clearly influenced organizational ethos, have also have influenced individual organization members' ways of thinking about and approaching their work. This will be indicated by the presence of the same themes in organization members' spoken texts, as well as by their presence in the interview texts of other project stakeholders.

\section{Understandings of Sustainability among NZAID Staff and Project Stakeholders}

It is clear from the examples given above that the approach to development sanctioned by the Paris Principles has been thoroughly integrated into NZAID's own development strategies. Before going on to look at how this approach is manifested in NZAID and its partners' implementation of their projects, I first 
examine how NZAID and its partners understand the concept of sustainability itself. NZAID provides the following definition of sustainability on its website: 'The continuation of benefits from a development intervention after major development assistance has been completed' ('Glossary', n.d.). Furthermore, NZAID understands sustainability as being an integral aspect of project success: employees in a focus group interview stated that 'a successful development project is one where it achieves the outcomes that it was intended to achieve, and those outcomes are sustained over a prolonged period, beyond the life of the project itself.' Focus group participants were in consensus that a project could not be called successful unless it was sustainable. As project success is contingent upon the achievement of sustainability, it is important that project stakeholders share NZAID's understanding of the concept and how it is to be implemented.

\section{Within NZAID}

Within NZAID, definitions of sustainability were relatively uniform, even across teams. This was not unexpected, given the centralized nature of NZAID's project planning guidelines and other organizational documents, and its correspondingly well-entrenched development philosophy. Furthermore, NZAID is guided in its development practice by its commitment to the Millennium Development Goals, the Paris Principles, and the Accra Agenda-all documents in which there is a strong emphasis on effectiveness and sustainability. Within the PNG team, there is the further guideline of PNG's Kavieng Declaration.

NZAID employees defined sustainability in the following ways in interviews:

Sustainability is the ability to achieve the outcomes and the outputs that people want to achieve even after the programme is long gone. It's things happening even after the external systems have pulled out of whatever activity or project, and leaving a lasting, positive impact on the beneficiaries of whatever the activity is.

... at NZAID it does tend to come down to the longevity of the benefits and whether they're likely to continue.

I would define it this way: how an organization is able to sustain the benefits after its general support comes to an end. It's a great challenge. But if their capacity issue 
is addressed, if the planning and governance is addressed, and good support from the beneficiaries and the key stakeholders, I am pretty sure [they will be successful].

Although the NZAID employees represented in the quotes above (drawn from employees within different teams and in different locations) all make use of different vocabulary in describing sustainability, all definitions are structured around a central premise of project longevity and the continuation of project outcomes after the projects and support for the projects have concluded. Thus, within NZAID this understanding of sustainability is well entrenched.

\section{Definitions of Sustainability Outside of NZAID}

In this section I present definitions of sustainability gathered through interviews with multiple project stakeholders outside of NZAID. This section illustrates to what degree and in what form NZAID's focus on sustainability has reached beyond its organizational boundaries. As project stakeholders represented in this section for the most part experience only infrequent and indirect contact with NZAID (mostly in the form of interactions with project documents and other project stakeholders), their understandings of sustainability give evidence of the penetration of NZAID's sustainable development discourse, despite the hurdles of poor communication, and the distance it would have travelled to reach project stakeholders.

\section{NZAID Contractors}

The Team Leader of the Service Project defined project sustainability by saying 'To be sustainable it needs to be achievable, it needs to be funded, managed, led... It needs to be able to operate under its own steam.' Another NZAID contractor defined sustainability as 'Being able to keep something going forever.' In these two definitions it can be seen that in this first degree of removal from NZAID, definitions of sustainability have become greatly simplified and more practically oriented, but nonetheless maintain a central thread of project longevity. This indicates that while project stakeholders may not possess the profound and multi-faceted understanding of sustainability resulting from constant exposure to the strong conceptual presence of sustainability in NZAID's organizational 
documents, themes of sustainability are still sufficiently present in project documents and dialogue to guide stakeholder understandings.

\section{Local Project Staff}

CBP staff members demonstrated their understanding of sustainability by defining the concept in the following ways:

It means that whatever project or activity that we're doing in a community or in small groups, it must last a long time, and it must be environmentally friendly. It must be something like an income generating activity, and also it must be socially just. It must be something that will help us to earn income. It must be a good project that will last a long time. Even when the funders or whoever is supporting you leaves you, that project must still continue.

It means to me the project can look after itself after being given or started. It doesn't really have to depend on the person who is giving money to start the project. The project will continue by itself, supporting itself, motivating itself, and propagating itself.

Sustainability for us is like total ownership. The people from the place they must take part in the programme. The other one is self-sustaining in terms of funds. There must come a time when the project is self-sustaining in terms of funds, not getting funds from outside in terms of aid. ... I guess it's total ownership on whatever we want to do for a project or for the people... within that programme.

Though relatively different, the definitions above share a common theme of 'lasting a long time', as well as of independence, particularly from outside funding. It should also be noted that whereas other definitions of sustainability have been objective and impersonal, project staff used the terms 'me', 'us' and 'we', indicating that they are directly implicated in, and affected by projects and their sustainability.

\section{Community Members}

While no direct definitions of sustainability were provided by the community members involved with the Service Project, discussion turned several times to sustainability issues, and community members' concern for the ability of the provincial service providers to manage the NZAID service, and what would happen 
to all of the work that had been done in the communities in earlier stages of the project. Within the CBP, the community project leader being assisted by the CBP organization initially defined sustainability in terms relative to the environment. Upon rephrasing my question to ask what he believed would happen to the project once the CBP organization withdrew, the community project leader discussed his plans for the longevity of the project, and what he and his community would require to continue the project.

Within all community member and community worker interviews it was noticeable that while such vocabulary as 'capacity building', 'community mobilization' and 'participatory techniques' were used (and in the case of the CBP community project leader, used in English in an otherwise Tok Pisin interview), sustainability as a term relative to project longevity was not used. This would signify that it is not a term used regularly by those carrying out community level project work. However, the longevity of projects is something that project stakeholders are aware of and concerned about. This indicates that while sustainability is not regularly used term, the unique requirements for each project's longevity are certainly discussed. This variation in understandings and definitions of sustainability among project stakeholders demonstrates that once outside of the bounds of NZAID's immediate influence, definitions of sustainability become more varied, and comprehend a broader range of qualities. Still, the overall similarity of definitions and understandings of sustainability show that it is indeed a concept that is well understood and taken seriously, even by people in remote areas far removed from NZAID.

\section{Themes of Sustainability within NZAID and its Projects}

From the discursive samples presented above, it is evident that NZAID and its project partners share very similar understandings of sustainability. And from NZAID's organizational and project documents it is clear that NZAID incorporates principles of sustainability outlined in the Paris Principles into its development practice. However, this research is not concerned with the presence of these principles in NZAID alone, but also with how NZAID's discourse of sustainable development is manifested amongst its partners. Thus in this section I examine how concepts such as participation, consultation and capacity building are 
evidenced in NZAID's partners' spoken texts. The presence of these themes in samples of stakeholders' discourse provides evidence of texts containing these concepts being adequately distributed to, and consumed by stakeholders, who then incorporate them into their thinking and the texts that they themselves produce.

\section{Capacity Building and Empowerment}

Capacity building and empowerment are central elements of NZAID's development practice. If a project is to be left to local stakeholders to run after the departure of their donor partners, those groups must have the skills required to perform project tasks, and understand how those tasks contribute to the whole. Following on from NZAID's organizational focus on capacity building, it featured prominently in interviews with stakeholders in both projects:

...if we're doing our job properly, we're giving more and more of that responsibility to the likes of [local stakeholders] anyway. Because if we're heading towards devolving and sustainability by the [provincial service provider] of the [community-based programme] programme, then it's my job to give more and more and more responsibility to [local staff] to a point when [they don't] need me... (NZAID Contractor, Service Project)

I have seen and do see other advisors run around and do a lot of stuff, and I think no, because it's not our job to do that, our job is to feed the line out a little more all the time. (NZAID Contractor, Service Project)

To sustain the project it depends on people who are now having the project, running the project. They train them as they want in the things that they want. (CBP Organization Staff Member)

The first thing they do is give them training. The Community Development Facilitation training. They teach them the basic things dealing with projects. Have to understand effective communication, mobilization skills, leadership skills, conflict resolution. (CBP Organization Staff Member)

One is like what I was saying, preparing the communities, and later coming to a stage where they are empowered, build their capacity and access projects to meet those whatever, their economic needs and social needs for their communities. (CBP Organization Staff Member) 
NZAID's commitment to capacity building in both projects was very evident. With the CBP, NZAID staff were absent from the project almost entirely, consulted only occasionally and involved largely as funders, with a secondary role as mentor to the CBP organization. The CBP organization also used a very hands-off approach in its involvement with its community projects. Aside from initial training periods for skills development in target communities, CBP staff are only rarely present at project sites, leaving projects entirely in the hands of target communities to operate according to the skills that they have acquired. Similarly with the Service Project, aside from once monthly training visits from NZAID contractors and provincial service providers, community service providers are left to themselves to carry out their duties as they see fit, and as required by their villages. From reports of services performed by community service providers (reported by NZAID contractors and community members alike), community service providers have fully taken on board the skills learned in their training, and have made them their own.

\section{Consultation, Participation and Ownership}

In order for projects to adequately address the needs of the target populations, the Paris Principles and alternative development texts identify the need for consultation with end users. Following on from consultation is the task of ensuring end users' participation in the planning and implementation of the project. These principles, consultation and participation, have been identified as contributing to stakeholder ownership of projects, which has in turn been identified as crucial to achieving long term sustainability. All of these principles were regularly referred to in interviews with stakeholders of both projects as being central to project implementation.

\footnotetext{
Mostly it's based on the needs of the people here. Do most of the guided points from the communities surrounding them. The leaders, stakeholder NGOs, government...to workshops. Got a series of workshops. Not only when the time comes to assess what needs to be done, but ongoing. It's from the communities surrounding them and the people. Not from [our organization]. They just facilitate the assessment of needs. Guide them with guidelines for funders. (CBP)
} 
At [rural sites] we get at least three outsiders coming to the trainings. We get a couple of the elders [and others] coming along to all the trainings and things like that. [At another rural site] we usually get some of the villagers, the elder men and women coming along and sitting in on the trainings. (Service Project)

Consult with the community a lot. We encourage the bottom-up approach. We don't want to make plans that do not benefit the community. So that at the end of the day we meet their needs. (CBP)

Ownership is what we really look at. As much as possible, training from the beginning tries to develop that thinking. (CBP)

One of the CBP's board members stated that successful projects were those where communities

\footnotetext{
...see them as their own. They take ownership. ... Those people who have seen the projects as theirs, they are now succeeding. We only give you advice and also other technical information we can find to help you, but the job is yours. Make sure you look after it. We want people to see that whatever training we give them or knowledge, it is theirs, it is not [ours].
}

The quotes above, extracted from interviews with stakeholders at various levels of each project, from team leaders to local staff, give evidence of consultation and participation being well-integrated into each project's ethos. Their effects were visible in the observations I conducted at the Service Project. While observing a community service provider training at a rural location, while NZAID project staff were present, over the course of the several hour training they spoke only at the very beginning and at the very end. The training itself was run entirely by community service providers (and I was informed later that training manuals are written by provincial service providers with minimal input from NZAID staff). It was amply evident that local stakeholders were heavily involved in project implementation. The Community Building Project was the same. As described by the village project leader, it was he who initiated the project with the CBP organization. Planning was undertaken in tandem, working to the self-identified strengths and available resources of the village. The result was a project whose community stakeholders took a proprietary interest in ensuring its success. 


\section{Consistency of Sustainability Dialogue among Stakeholders}

NZAID interviewees consistently described sustainability as being something that should be discussed with partners from day one, yet it was evident that among their development partners this may not have been standard procedure. While the Team Leader of the Service project described sustainability as being a major topic in his discussions with NZAID, it appeared that this practice was not continued at the community level. One NZAID contractor in the Service Project described a meeting with some of the higher ups among the community service providers wherein one of the attendees asked what would happen when NZAID left, and when the contractors described the handover to the provincial government's service provider, the community service providers became panicked and expressed their worry that the provincial government's service provider would 'never be in a position to run them.' The Team Leader described their reaction as 'they just flew into a panic.'

Such an occurrence provides a stark contrast to the NZAID intention of discussing exit and sustainability strategies at the outset of a project. While these topics had been addressed with stakeholders in government, community stakeholders had been left out of the loop. NZAID may be conscientious about discussing these things with their partners, but perhaps these partners aren't as conscientious about discussing them with stakeholders further down the line. Partner governments and target communities must understand the full extent of the project/intervention that they are signing up for, and the long term demands that it will place on their resources. It is important that this dialogue include not only higher level stakeholders, but all project participants.

\section{Discussion}

All NZAID employees that I spoke with strongly emphasized the importance of consultation and continuous dialogue with stakeholders. The Team Leader of the Service Project stated that communication with NZAID occurred every three to four days, 'From high level strategic stuff through to nuts and bolts, but the contact is regular.' In turn, NZAID contractors on the Service Project were in daily contact with various stakeholders in the project, from higher-ups in the provincial service to 
community service providers. It was demonstrated that this contact was not unidirectional, but that stakeholders at all levels were consulted. Community members described the incorporation of local networks and traditional systems into the service, and were pleased with how Councils of Elders and chiefs were consulted in the course of service provision or planning. In fact, it is the Council of Elders and village chiefs who choose their community service providers who then go on to be trained by NZAID contractors and provincial service providers. Such involvement has increased the stake that community members and people with local political power feel that they have in the success of the service. They feel that they own the project.

Ownership was identified by project workers on the CBP as being the single biggest factor in a project's success and sustainability: 'Ownership is what we really look at. As much as possible, training from the beginning tries to develop that thinking. As much as possible the ownership is what we really expect.' In fact, all of the other principles emphasized in development literature and within NZAID go toward building ownership. Consultation with communities is important in order to incorporate community concerns and values such that those communities feel that the project is truly serving their interests, and who will then have an interest in maintaining those projects and their outcomes. Capacity building also serves to increase the ownership that stakeholders feel, enabling them to take charge of projects and direct them as they wish, without needing to defer to the expertise of others. This will help to ensure that development partnerships are equal partnerships, rather than partnerships in name only.

Hand in hand with capacity building, empowerment encourages the development partner to speak up to ensure that projects go in the direction that they wish them to, and meet the needs that they deem to be most important, while addressing and safeguarding their values. 'It is about empowering the partner as much as possible. It is about attempting to go at partner pace and ensuring they have ownership as much as possible in the work that we're doing.' Along these lines, one NZAID employee stated that 'The critical thing, whenever we're contracting in support, is to make sure it's got a capacity building function rather than an in-line function. So we've always got to have an eye on when that person or when those people go, will this be able to continue.' Empowerment is a key part of the 
alternative development canon, lauded by development scholars such as Dr. Jeffrey Sachs, who advocates empowerment by saying that 'Just as experience with group lending in microfinance has been highly successful, projects that empower village-based community organizations to oversee village services have also been highly successful' (Sachs, 2005, p238).

All of the above principles require the participation of project stakeholders. Development scholar E.A. Brett defines participation by saying that

it is "a process by which people, especially disadvantaged people, influence decisions that affect them", as opposed to one where decisions are imposed on them by hierarchical outside agencies (Brett, 2003, p5).

In keeping with this idea of participation as empowering people to take an interest in, and seek to influence those decisions that affect them and their livelihoods, one NZAID employee described participation as being a goal in and of itself, and not just a tool to employ in the pursuit of success and sustainability:

...[P]robably the most important thing (it is a key issue around sustainability) is that level of participation. And to be honest, a lot of our programmes, what we're trying to do is actually build participation. I'd argue that's what we mean fundamentally by 'governance', is building that participation of citizens into health and education, livelihoods or whatever, farmers. So it's not just a way we look at it, a methodology, it is a, a major development outcome. ... I get very frustrated that participation is now used...or seen primarily as a possible project management tool. Me, personally, the key to participation is the key to development and that is engagement of citizens in their political/economic/ social activities.

Thus by encouraging participation, development organizations and their stakeholders can both contribute to project ownership, and also the ownership of the political decisions that affect those people that are the targets of development.

\section{Foundations to Build Upon}

Previous phases of the Service Project focused primarily on building the operational capacity of communities (and in particular those individuals selected by village councils to provide services) to carry out the service in question, and establishing necessary support networks. These phases have been concluded 
successfully, with the development of community services progressing very well, and with community networks very strong. As described by one community member, 'The [community service provider] is good because it's at the level in the village where people can see [results] happen swiftly. It doesn't take lots of time like the [provincial] system.' Another community member stated that people 'trust the [community service providers] because they work to the level of the community. They are doing the good work.' NZAID's focus on consultation and participation has evidently paid off, in that community members feel that the project is working for them and meeting their individual needs. NZAID may now move forward from this broadly supported and strong foundation and work to address the provincial service provider's capacity to manage this service going forward.

It is the CBP's goal to build the capacity of multiple communities each year so that they may better 'manage their own livelihood activities' (NZAID project document). A board member stated that the Project's 'main objective is capacity building. We train people to look after themselves.' Within the rural community that I visited, the local project leader attributed much of the project's success to the participatory methods of decision-making learned from the training provided by the CBP. Accordingly, once skills training has been delivered, it is expected that communities will build upon this foundation and continue to grow and develop their income generating potential through increasingly varied activities. Some communities (such as the one that I visited) are further assisted to develop specific income generating projects. Because the CBP hopes to contribute to the social and economic development of the province as a whole, growth is not expected to end with skills development or with just one project. As described by one staff member, 'I'm telling this group here that this is not the end, you can still develop further.' From the trust and goodwill that the CBP has built up in communities, and from the skills that communities are incorporating into their projects, the CBP organization and its partners are well placed to move forward. 


\section{Challenges in Implementing Sustainability, and Potential Benefits of an Infusion of Institutional Theory}

It was emphasized in several NZAID interviews that although employees begin thinking about project sustainability from day one, and think of it constantly from then on, it is something that is difficult to implement formulaically, or with any degree of predictability. Said one NZAID employee: 'You come back to the sustainability thing. It's not like...it's a no brainer at the start, but like a lot of things in development, how you actually do it, really how do you do it...'. NZAID interviewees stated that even while sustainability is a major priority, and something that they try to address from the inception of a project, implementation challenges in widely varying environments make it difficult to be able to do it consistently or with any certainty. 'Hopefully the discussion would start right from the beginning, but sometimes it doesn't, because sometimes we don't really know what the future holds. I'm not sure that happens all the time. Even though our attention is there.'

Clearly even though sustainability is emphasized within NZAID, and within critiques of NZAID programmes, it is something that is difficult to implement. One NZAID employee describes this difficulty, explaining

\footnotetext{
You can't predict-it's a social science, nothing is predictable. But there are indications that will give you more confidence that it's more likely to stick in the end if you follow these sorts of principles. It also can be quite hard to assess when you're busy doing something (busy designing a project), it's quite difficult to step away from it [to evaluate the process toward sustainability].
}

While progress toward sustainability may be difficult to judge, understanding the sustainable development process as a process of institutionalization may clarify the mechanism by which it occurs, and may make it easier to assess. By situating sustainability within a framework composed from Phillips' theory of institutionalization and Scott's theory of institutional pillars, it may be possible to assess progress through key concepts' presence in stakeholder discourse, and those concepts' subsequent manifestations in stakeholder actions and behaviours. The combination of Scott's and Phillips' theories may be used to illuminate what sustainable development concepts such as ownership and participation go to produce: normative and cultural-cognitive alignment. By exposing the nuts and 
bolts of these pillars, as well as of the regulative pillar, institutionalization may clarify the constructive mechanisms of the sustainable development process and make them easier to implement with consistency. This concept is explored in the next chapter. 


\title{
VI. Data Analysis - Institutionalization
}

\section{Locating Themes of institutionalization within NZAID and its Partners' Development Discourse}

\author{
When a project is completed, the institutional capacity to sustain programs and \\ benefits is left behind...(Brinkerhoff, 2002, p6).
}

\section{Aims and Overview}

The quote above from Brinkerhoff describes the idea driving this chapter, as I attempt to learn, through examples in discourse, how NZAID goes about building the institutional capacity critical to producing sustainability. Not every discourse takes the shape of a process of institutionalization and produces an institution. What differentiates institutionalizing discourses from other discourses are the concepts that they address. It is my theoretical premise that for a discourse to produce an institution, it must generate ideas and actions that establish the supports upon which institutions rest. As described by Scott, stable institutions rest upon three pillars, one regulative, one normative, and one cultural-cognitive (Scott, 2001). Thus I argue that institutionalizing discourses are those that adequately address each of those pillars. As I also assert that sustainability is contingent upon successful processes of institutionalization, it follows that organizations hoping to implement sustainable development projects must ensure that their texts contain concepts that build the support of the three institutional pillars.

In the previous chapter I demonstrated how NZAID and its partners address sustainability by employing terminology and concepts identified in development literature as contributing to the production of sustainable project outcomes. In this chapter I discuss how this focus on sustainability indicates that NZAID's development discourse is well set up to contribute to institutionalization. As I have discussed, sustainability demands many of the same conditions as institutionalization. Thus, I argue that NZAID and its partners, having integrated sustainability into their development discourse, already address many of the principles required to establish the three pillars upon which stable institutions are based. I support this argument using samples from NZAID documents and 
interview transcripts. In addition to addressing institutionalization through its focus on sustainability, I examine how NZAID and its partners address institutions and institutionalization directly, thereby establishing the present role of institutional theory in NZAID's development discourse.

The previous chapter's discursive analysis of NZAID and its partners' texts for the presence of sustainability terminology and concepts was a relatively straightforward exercise. As demonstrated, project stakeholders at all levels frequently refer directly to sustainability, and to concepts identified by development literature as being productive of sustainability. As will be demonstrated in the coming pages, while development discourse does address several aspects of the institutionalization process, it does so obliquely, with the terms 'institution' or 'institutionalization' used extremely rarely. This has necessitated a more complex interpretation, examining texts for theoretical and linguistic links to institutionalization, rather than identifying direct references. The discursive analysis of organizational and project texts for thematic links to institutional concepts has required a multi-layered interpretive process. Where possible, I begin by identifying direct references to institutions and institutionalization. I then examine texts for the presence of ideas and objectives that may be linked to institutional concepts. Finally, I identify language and key words that, through their association with and allusion to concepts and principles, may be related to institutional theory.

I use critical discourse analysis to examine how themes of institutionalization and sustainability interweave in NZAID and its partners' development discourse, as glimpsed through NZAID's project documents and transcripts of interviews conducted with project stakeholders. I attempt to illustrate how those themes within development discourse work to produce institutionalization and sustainability in the project environment. I begin by examining NZAID's organizational documents and also interview transcripts for indications of how NZAID understands institutions and the institution building process. I then examine how features of development discourse can be categorized using the three pillars that Scott identifies as being required to establish and maintain an institution. I do this by first examining project documents for conceptual links to institutionalization and the institutional pillars. I then apply the same analytical 
procedures to transcripts of interviews obtained at each of the two project sites. Comparisons of each project follow each of these two sections. I then discuss the implications of the interpretive links to the institutional pillars in each project's discourse, before concluding with a brief discussion of the contributions of institutional theory to the development process, and to each project's potential outcomes.

\section{Institutions and Institutionalization as Discussed in NZAID}

Before employing more interpretive data analysis techniques in my study of how NZAID and its partners address institutionalization, I first examine how NZAID and its partners explicitly address institutions and institutionalization. Although many development scholars and practitioners describe institution building as being the primary task of development (e.g. Edwards and Hulme, 1992; Lepenies, 2008), institutions were very seldom referred to in either organizational or project documents, or in interviews with project stakeholders. This presents a marked contrast to the concept of sustainability, which featured strongly in NZAID's organizational and project documents. Project stakeholders, from NZAID staff members right through to community members, frequently mentioned sustainability by name, and discussions of the concept were thematically uniform. As demonstrated in the coming paragraphs however, discussions of institutions and institutionalization lacked consistency, and were nowhere near as fluently discussed, when they were mentioned at all; outside of NZAID, institutions and institutionalization were never referred to by name. Even within NZAID, institutions and institutionalization were brought up in so many words in just a few instances during interviews with Wellington-based staff members.

The following quotes are representative of the ways in which institutions and institutionalization were discussed by NZAID employees and within organization documents: 
We're primarily funding the [community service providers], but it is now in that stage of going out...that's what [this phase] is talking about is institutionalizing that into [the provincial service provider].

I'm absolutely drilling down on sustainability. For me, I mean in fact it is the key issue now for this whole programme. This is actually sustainability of the whole initiative, which requires institutional analysis.

These quotes were all spoken by Wellington staff members in reference to the Service Project, and they pertain to the scaling up of the regional government's provincial service provider to take over operation of the community based service. It is clear that the speakers recognize the importance of institutional support to project success. However, within NZAID's development discourse, as exemplified by the quotes above, the only references to institutions were those relating to formal institutions: institutions of national government, and institutions such as the provincial service provider. There was no reference to social institutions, or any institution not formally chartered, governed or funded. Considering that a considerable amount of NZAID's work is done in communities, and in arenas outside of national or regional government involvement, I was surprised to observe that references to informal institutions were entirely absent from discourse. While formal institutions may be the most widely recognized type of institution (addressed prominently in the Paris Principles), they are by no means the only type, with informal social institutions performing vital roles at all levels of society.

Mirroring the scarcity of direct references to institutions, institutionalization was mentioned by only one NZAID staff member (in the course of discussing the development of formal partner government institutions). This staff member equated institutionalization to behavioural change, and identified it as being indicative of a project's proceeding well. When asked to elaborate on how he would describe institutionalization, he replied,

\footnotetext{
Ummmm, I don't know, I'm not an expert in that. I know it when I see it. It's seeing a new-something new-embedded and, let's just say part of the wallpaper. I guess there's none of the characteristics that you would see, depending on which sort of institution you're talking about. But, certainly some of the things that it would involve is [a task] being a normal part of people's jobs rather than being a one-off thing...just accepted and an ongoing thing. Sorts of the things which have moved from being seen as a special project, and even worse a special project forced on us by the New
} 
Zealanders, to just being the way that we do things around here. Yeah... people just expect that it'll happen all the time, whatever that thing is.

This employee seems to have a good idea of what institutionalization looks like as a finished result. It is not clear, however, whether the process of institutionalization is well understood, or if this employee is merely unsure of how to express it. What is clear is that where NZAID and its development partners regularly gave highly consistent definitions of sustainability, with the concept featuring regularly in their discourse, institutionalization did not elicit expressions of similarly uniform understanding (when it was mentioned at all).

In a final example of how institutional themes featured by name in NZAID's development discourse, one employee linked the achievement of sustainability to the setup of 'institutional functions':

I think that to actually break it down to more sort of institutional functions of an activity... I think there's areas of governance. After governance is the area of management. So there we're talking about capability, capacity of management to manage that project, that activity, that programme. Next would be just the skill-the operational side. Is there the logistics, is there support, the people in the field, have they got the necessary training? And then, for the last one of those which I think's right across those which is the resources to keep it going. I think if you start looking at sustainability in that way, at a programme or a project, then I think we can actually move it forward.

This employee touches on the importance of institutional capacity (governance, support, etc.) in producing sustainability, echoing Brinkerhoff in this chapter's opening quote. Furthermore, the interviewee goes so far as to explicitly link sustainability to institutions. This employee's ideas and the ideas expressed in the previous quote regarding institutionalization, while incomplete, do touch briefly on important themes that will be addressed and elaborated upon in this chapter, which explores the link between sustainability and institutions. I hope to identify how, through this link, components of NZAID and its partners' development discourse may be conceptualized in terms of institutionalization. 


\section{The Institutional Pillars and their Relationship to Sustainable Development Principles}

As demonstrated in the preceding paragraphs, institutions and institutionalization are rarely addressed in stakeholders' development discourse. Where they are addressed, their scope is limited to formal institutions. Part of the aim of this project is to identify how, without project stakeholders' conscious inclusion of institutional themes, their development discourse intrinsically contains elements that address aspects of institutionalization. To this end, I examine how NZAID and its partners' discourse of sustainability contains elements that can be seen to contribute to the establishment of Scott's institutional pillars. Although sustainability discourse does not overtly address institutionalization or the three pillars, it contains many similar discursive elements. For example, participation, ubiquitous within sustainable development discourse, is directly pertinent to the normative and cultural-cognitive pillars (as is discussed in the next section). As illustrated in the previous chapter, NZAID and its partners' development discourse is full of direct references to sustainability, and also thoroughly incorporates principles proven to contribute to it. I thus expect that regardless of the degree to which NZAID directly addresses institutional concepts, themes within NZAID's development discourse will be readily interpretable as relating to institutionalization. In the coming paragraphs I attempt to show how each of Scott's institutional pillars is addressed by common features of sustainability discourse.

As described in my discussion of Scott's institutional pillars in the Literature Review, the regulative pillar pertains to governance and the enforcement of rules (Scott, 2001). It supports institutions by enabling them to shape adherents' behaviours such that they are consistently and predictably productive of valued institutional outputs. In the process of institutionalization, the capacitation of, or alignment with a recognized regulative authority signals the nascent institution's ability to credibly communicate and enforce incentives and penalties in order to bring members' behaviours in line with institutional requirements. Within development discourse, two concepts related to the regulative pillar, and productive of regulative support, are 'governance' and 'management' (examples given in the next section). By supporting the establishment and capacitation of 
governance and management structures, and by integrating projects with these authority structures, developers equip their projects with the means to shape behaviours and produce desired outcomes.

Normative support is also critical to the establishment and maintenance of institutions. It differs from the regulative pillar in that rather than using externally enforced rules to promote select behaviours, it makes use of internalized moral and value systems to produce alignment with desired behaviours (Scott, 2001). Normative support is derived from an activity's alignment and association with the morals and values adhered to within a given population. This is achieved through the design and implementation of activities that produce outcomes valued by target groups, and which align with those groups' morals and values. I suggest that in development discourse, prevalent concepts such as consultation, participation, and ownership, contribute to the establishment of the normative pillar. Each concept promotes the engagement of stakeholders with project activities, thereby cultivating and securing their support.

Consultation ensures that the perspectives and wishes of a target group are heard and (ideally) incorporated into project design. If the members of the target group perceive that a project addresses their identified needs, and in ways that align with and reinforce their values and their moral sensibilities, they will be more inclined to support and become invested in that project. In turn, their participation in project implementation encourages group members to personally engage with and shape project activities. Group members' participation in projects signals that they understand the value of project activities and wish to contribute to their outcomes. Participation also encourages group members to develop the skills necessary for project continuation. If projects can count on the participation of target groups whose interests and values oblige them to support projects, they are likely to build project ownership, wherein target groups perceive projects as being theirs, and take a vested interest in maintaining those projects and their outcomes. Each of these concepts is strongly emphasized within the Paris Principles, and as identified in the previous chapter, each forms part of the approach to development to which NZAID has committed itself. 
Cultural-cognitive support is derived from the alignment of an activity or behaviour with the beliefs, understandings and foundational stories of a given group (Scott, 2001). I argue that common concepts within development discourse, such as participation, ownership, and indigenous perspectives and knowledge, are productive of cultural-cognitive support. The cultural-cognitive pillar, as described in the Literature Review, is the most difficult pillar to establish, as it requires alignment with deep, taken for granted cultural practices and understandings. Once alignment with these cultural understandings has been achieved, however, institutional behaviours will likely become part of taken for granted routines, with group members not even questioning why they are performing the activities they are performing. While consultation may assist project designers pursuing cultural alignment, much cultural information is seldom articulated (Scott, 2001) - it's 'just the way we do things around here' (Green et al., 2009). Projects' alignment with, and incorporation of, this cultural knowledge is thus dependent on intimate understanding of the target group, best developed through time spent in situ working alongside the target group, permitting the gradual integration of the project with the cultural practices observed and engaged with. The incorporation of such indigenous knowledge should assist developers in making their projects more cognitively relevant to their target populations (Briggs, 2005), and more likely to slot in with existing behaviours. Group members will be more likely to participate in given projects if project activities are perceived as resonating with their culture and their ways of perceiving the world.

\section{Thematic Links to the Three Pillars within Project Documents}

As evidenced in the previous chapter, NZAID's organizational documents and its project documents are saturated with terminology and themes relating to sustainability. I now return to those documents to examine if and how, through that demonstrated focus on sustainability, the documents may also be seen to correspond to the three pillars and thus the process of institutionalization. As previously explained, because project documents do not directly address institutions or institutionalization, this analysis involves a tiered process of interpretation, examining documents for, and elaborating theoretical and linguistic links to themes within institutional theory (specifically Scott's institutional pillars). Thus, following illustrative discursive samples from each project, I identify and 
explain the links between project objectives and institutional concepts. (Due to confidentiality concerns I am unable to include project documents in the Appendices, or cite them directly.)

\section{Community Building Project}

As described in the previous chapter, because NZAID was not involved in the design of the Community Building Project (CBP), but stepped in later as funder, the CBP has no NZAID Project Design Document (PDD). In order to secure ongoing NZAID funding, the CBP must meet objectives established in a Work Plan (outlining key activities and targets), and assessed in a Monitoring and Evaluation (M\&E) Framework. These documents are by nature less detailed than a PDD, and feature bullet points and tables rather than descriptions and narrative. Nonetheless, even in these abbreviated documents, conceptual links to institutionalization are still evident. Within the M\&E Framework appear the following training objectives (with my interpretive comments following each quote):

The COEs [Councils of Elders] gain knowledge of good governance and how to affect [sic] change.

The M\&E Framework here identifies the objective of situating governance and activity regulation with communities' Councils of Elders, the traditional seat of village authority. This correlates strongly with the regulative pillar, wherein a recognized authority enforces compliance with established objectives. The CBP situates that role with the COEs, already imbued with powers of governance, as the CBP organization is itself unable to enforce project activities.

Next,

Workshops and training are recognised as relevant to their needs. The message and information is found to be credible and believed.

Such an outcome corresponds to the normative pillar, wherein a behaviour is judged to be the most appropriate way of acting in a given situation in order to produce a valued outcome. In the case of the CBP, normative support would be achieved by behaviours learned in training being recognized as the best way to address community needs. Community members would thus feel obliged to 
implement project activities due to the outcomes of that activity or set of activities being so highly valued and so obviously suited to meeting their needs. The objective also relates to the cultural-cognitive pillar, with training being carried out in such a way as to be meaningful and credible within existing cultural frameworks of understanding.

Finally,

They [communities] feel confident that they can develop and run their own projects.

This outcome relates to the degree to which communities feel comfortable with training, have taken it on board, and have faith in their ability to implement it successfully. It indicates normative and cultural-cognitive support, with training perceived as being understandable and effective, and adequate to meet communities' needs, as well as being compatible with pre-existing community traditions, behaviours, and ways of being.

From the examples above, it can be seen how CBP documents address issues described by Scott in his descriptions of the institutional pillars. These examples aside (which were the clearest and most illustrative examples I could find), it must be said that such discursive manifestations of concepts of institutionalization (and even of sustainability) are few and far between in NZAID's CBP documents. (I must reiterate, however, that detailed project descriptions are usually the province of PDDs, which the CBP lacks.)

Rather than being explicitly addressed, either nominally or conceptually, links to institutionalization discourse can primarily be glimpsed within vocabulary used in descriptions of activities within NZAID's CBP project documents (relevant words italicized, and explanations following text):

Community requests for training and project support are assessed and prioritized by [the Community Building Project].

This quote implies that target communities are the instigators of initiatives arising from self-identified need, rather than the recipients of externally initiated projects. Community initiation signifies the likelihood that projects and their outcomes are of 
value to communities, as they are the result of concerted community requests. The quote also indicates, through its use of the phrase 'project support', that the CBP organization merely supports, rather than drives the project. This signifies the push towards community ownership of the initiative, which implies normative and cultural-cognitive alignment.

Develop the capacity of 20 x CDFs [Community Development Facilitators] through CDF [Community Development Facilitation].

This objective indicates that the skills of communities are being built up, enabling them (and specifically the 20 Community Development Facilitators) to run their projects effectively and independently, contributing to project participation and ownership, and thus the establishment of the normative pillar.

Assist the CDFs \& their groups to prepare business plans, constitutions/cooperative rules, cash flow, etc...

The choice of the word 'assist' implies that the CBP is merely lending a hand in a process already underway, owned and driven by capable, motivated partners. Also, the establishment of constitutions and rules doubtless involves the elaboration of governance structures. This activity alludes to the establishment of rules governing project activities, building regulative support.

\section{Service Project}

The objectives found in the Service Project's Project Design Document (PDD) provide a marked contrast to those of the CBP's M\&E Framework and Work Plan, requiring far less interpretation to make their theoretical links to institutionalization clear. The Service Project's PDD outlines objectives such as 'To build management competencies and practices within [the provincial service provider] with particular emphasis on corporate and operational planning, human resource management, disciplinary procedures and [facility] management'. This objective directly addresses governance and enforcement, and correlates to the regulative pillar. The PDD also identifies the goal of '... development of the [service provision] philosophy and its application...', addressing the establishment of the value structures supporting the normative pillar. The document also states that 'Interventions must be integrated within [the province]'s social and cultural 
framework...', directly addressing the cultural alignment that is at the heart of the cultural-cognitive pillar. The PDD also identifies as an objective that 'Communitybased bodies such as COEs [Councils of Elders], NGOs and community groups need to be consulted, supported and involved', setting up both the regulative support provided by local authorities' support of initiatives, and the normative support provided by activity alignment with stakeholders' values and needs.

The Service Project's PDD also identifies the areas where it is not yet operating at the levels required for project handover:

In terms of a programme of support to the [provincial service provider], the following needs were identified:

- Infrastructure: this is currently being addressed by...[confidential]

- [Provincial service providers] to practice [community service provision]; development of the philosophy and its application are being facilitated by....[confidential]

- Supporting proactive, operational [service provision]

- Strengthening the senior and middle management capacities of the [provincial service provider] and encouraging HR and succession planning.

By recognizing such key shortcomings as poor philosophical alignment of the provincial service provider with the community service provision philosophy (normative and cultural-cognitive pillar), and insufficient management and governance (regulative pillar), the document identifies areas that must be addressed if the handover is to be achieved. By identifying 'proactive' service provision as an objective, the document again relates to the normative and cultural-cognitive pillars, as in order for an activity to be proactively performed, its ethos must first be adopted and integrated with pre-existing understandings. The behaviours that proactive action requires must also be perceived as being the right behaviours demanded in order to produce a positive outcome for a given situation, thus indicating normative alignment. Thus it can be seen that project objectives going forward establish a programme of action that includes themes identified in institutional theory literature as being productive of the three institutional pillars.

\section{Comparison of the Two Projects}

By comparing my analysis of the project documents of the two case study projects, it is immediately evident that the Service Project more clearly contains themes 
relating to the three institutional pillars. Its PDD directly addresses issues of governance and authority (regulative pillar), as well as consultation and participation and the socio-cultural alignment that will ideally be their result (normative and cultural-cognitive pillars). Because its objectives are so descriptively and comprehensively articulated, little linguistic analysis is required to identify thematic links to institutionalization. Rather than count on partners' abilities to read into activity descriptions to glean an understanding of NZAID's intentions, the Service Project spells them out clearly. Thus, there are strong conceptual links to the pillars within the Service Project's guiding text, both in the use of indicative terminology and by direct reference to the key principles of each pillar.

In sharp contrast, the links to the process of institutionalization in the CBP's project documents, while present, are more subtle and require a deeper and more lengthy process of interpretation. No institutional themes more explicit than the ones presented above can be found in the M\&E Framework or the Work Plan. Neither document contains any detailed descriptions of how or why outlined tasks are to be carried out, or to what standards. Nearly all outputs, as well as many activities, are quantitative, specifying the number of communities to be assisted and the number of training exercises to be carried out, i.e. 'The capacities of approximately 10 communities and or community groups to plan and manage their own livelihood activities will be enhanced', etc. There is no mention of the quality of those initiatives, or if, and by what criteria, their effectiveness is to be evaluated. NZAID provides little guidance on 'how tos', instead addressing mainly 'whats' and 'how manys'.

Regardless of the degree of interpretation required, as illustrated above both projects' documents do indeed exhibit theoretical links to institutional theory. In its goal of establishing sustainable projects, NZAID has made use of concepts and terminology that share theoretical foundations with Scott's pillars. By their thematic presence in NZAID and its partners' development discourse, the institutional pillars stand to contribute to the institutionalization of both projects. According to Phillips' theory of institutionalization, if these documents and the ideas contained within them are widely distributed and consumed and found to be valuable, the discourse of which they form a part is likely to generate actions and 
ideas which support the objectives within. In order to examine how project texts are distributed and consumed among project stakeholders, I now apply the same methods of analysis to interview transcripts.

\section{Interviews and the Three Pillars}

As demonstrated in the previous chapter, interviews conducted with stakeholders in each project featured language that was peppered with terms and concepts ubiquitous in alternative and sustainable development discourse. There was little direct reference to institutions or the principles of institutionalization, however, mirroring my analysis of NZAID staff members' interviews at the beginning of this chapter. But as discussed in the previous paragraphs, sustainable development discourse by its nature touches upon many concepts also found in institutional theory. In this section I examine how stakeholder interviews, by virtue of their conceptual links to the three pillars, can be understood as samples of a discourse of institutionalization. (As will be demonstrated directly, because of the strong conceptual links to the three pillars in stakeholders' interview texts, it has not been necessary to undertake any further analysis of the implications of stakeholders' word choices.)

\section{The Community Building Project}

While the Community Building Project's project documents did not contain overly explicit links to institutional theory, interviews with project stakeholders did so more clearly, containing themes evoking each of the three institutional pillars. The quotes below illustrate the project's normative alignment (my interpretive comments follow each quote).

It's a project that belongs to everybody. The income generated comes back to the group. It's a community-based project. Project for the people.

This quote, spoken by one of the CBP organization's board members, relates to the concept of ownership, wherein group members take an active interest in the activities and outcomes of a project. Ownership stems from the alignment of project activities and outputs (in this case, income) with the values of a group. Ownership, and thus normative support, is also demonstrated in the quote below: 
[A successful project is o]ne where all its employees or people who are working on that project are committed to their work and there's teamwork. And also that project must not benefit just an individual, but a wider community area.

As identified in the first quote, benefits that accrue to an entire group rather than to one person are a key value (reflecting the values of the wantok system described in the Background chapter.) By producing outcomes that benefit whole communities, the CBP demonstrates value alignment with its target group, contributing to stakeholder commitment and ownership, and thus normative support of the project.

Identifying the project's links to the cultural-cognitive pillar is the following quote:

\begin{abstract}
There are always more people than we need working. People want to work. We never come up with less than the required number [of workers], always come up with more than the required number.
\end{abstract}

In this example, my observations support comments made by project stakeholders. During my CBP rural site visit I observed over 20 people at the project site, well organized, and employed at several different tasks although no 'supervisors' were present. The initiative taken by community members to show up unbidden to work at the project site indicates that project work has become a normal part of their daily routine. This degree of project ownership indicates strong cultural-cognitive alignment, with project activities being taken for granted as a part of everyday life.

While the quotes above indicate the CBP's alignment with two institutional pillars, the following quote casts doubt on the support of the regulative pillar:

...[S]ome are always jealous. Outsiders. Complainers. Elders. The ones who are jealous are the ones in authority. Because of what's now happening with the youths, they're not part of it. They don't have the knowledge that's fuelling the change.

The quote above implies that this community project has involved the capacitation of new leaders outside of traditional authority structures, to the extent of excluding traditional leaders from the project. This project is thus unlikely to be able to count on the regulative support of an authority in order to enforce behavioural alignment. 


\section{The Service Project}

Following on from the strong presence of institutional concepts in its project documents, the Service Project also exhibits conceptual alignment with the three pillars in interviews with its stakeholders. The following quotes from an NZAID contractor indicate the project's normative alignment with communities in which service providers are active:

\footnotetext{
Yeah, I think so [that people have taken ownership of the project]. I think the participation by some of the elders and groups around... And everybody knows [the community based service]. People in the street talk about [it]. Yeah. I think the majority yes, yeah they have.
}

There's a high participation. There's a high degree of respect from the community, from the average punter in the street or in the village. I think our [community service providers] are held in very high regard and I think they're workers...you hear bits and pieces and I couldn't quote you or name the time or the person that said it to me, but you hear a lot of things: "We'd much rather go to a [community service provider] than [a provincial service provider]". ... So I think there's a high level of participation and faith in the [community service providers]. ... [People are] quite quick to come in....if there's a problem with one of the [community service providers] or if they perceive there's a discipline problem or something like that. A couple of them came in a couple of weeks ago with the leaders saying that they weren't happy with the service one of their [community service providers]. ... And I think if there wasn't that participation then those sort of things wouldn't be happening.

In the first quote, ownership, indicating strong value alignment, is seen to be a result of participation. The second quote elaborates on that sense of ownership, with community members taking pride in their service providers, and seeking to correct behaviour that they don't believe to be in line with their expectations of value derived from the presence of service providers. Community members are thus demonstrated to be invested in their projects and proactive in seeing that they perform at their best. 
Cultural-cognitive alignment was strongly evident in interviews, such as in the quote below:

I think there's a fair bit of demand on the individual [community service providers]. ... I think there is a high expectation on their behaviour level. You see them. Like l've driven past [community a] quite a few times... and hardly have I ever driven the road without stopping and talking to probably at least 2 or 3 [community service providers] along the way usually out doing their work.

A Service Project community member elaborated, saying

...what the [community service providers] are doing in the villages is they're making a difference there. That shows that it's a project based at that level, not something sitting in town that gets trotted out to the villages now and then when they [NZAID] visit.

The speakers above describe the firm entrenchment of Service Project activities in the daily lives of communities and their service providers, with those service providers proactively and independently going about their duties with no prompting from NZAID contractors. NZAID contractors are welcome in communities though, as was evidenced during my observations with the Service Project. I made two site visits in the time that I spent with the Service Project, each time travelling with NZAID contractors to remote village locations where monthly training and refresher courses were taking place. Throughout the drive to and from locations, community members regularly went out of their way to greet the NZAID contractors, who responded to their greetings in Tok Pisin or the local language. It was clear from the familiarity that NZAID contractors displayed, and locals' reciprocal friendliness and familiarity, that NZAID was a welcome part of the scenery. Although having been present in the province for several years already, the novelty of NZAID's presence had not yet worn off. One community member described people's regard for NZAID by saying, 'NZAID and [its contractors], your record is really high [here]. When we see you people we fully respect.' This positive perception of NZAID and its work with communities stems from NZAID contractors' respect for community culture and values, as described below by one community member: 
about knowing how to greet the chiefs, and sometimes honour them by using the Maori language. That kind of involvement and interest in their culture and in their thinking and challenging the people, not assuming what their values are...lots of good things, right things, reaching the people not only at the physical level but at the emotional and spiritual level about involvement and owning a project and that the local people see it as theirs.

It is clear from the quote above that community members value how NZAID contractors have taken the time to get to understand their culture and fit the developing service to its values and meanings.

As the speaker describes, and as my observations reinforce, NZAID's attention to communities' culture, and the incorporation of observed values and practices into service provision has contributed to the cultural alignment of the service with its stakeholders, and has resulted in project ownership. The quotes above illustrate communities' capabilities and willingness to commit themselves to projects demanding new behaviours and new ways of interaction. So long as those behaviours make sense within existing cultural frameworks, or expand those frameworks in ways that harmonize with existing ones, they may quickly become part of everyday behaviours, taken for granted, and performed without a second thought.

Service Project interviewees also touched upon the regulative pillar, as seen in the quotes below:

The community members select their [service providers]. Members of the community and the council of chiefs. They select the [service providers] and provide them with a letter endorsing that person.

Their monthly reports are always signed off by the chiefs. The chiefs know what [each community service provider] has done in the previous month. The chiefs often deploy the [community service providers], which is a good thing.

From these quotes it can be seen that the Service Project has structured the community-based service to incorporate traditional authority structures into project governance systems. By investing chiefs and Councils of Elders with authority over their community service providers and their community service provision, the Service Project has succeeded in providing its community-based service with an 
established regulative authority, whose right to enforce project behaviours will not be questioned. Thus, not only must community service providers answer to NZAID, and ultimately to the provincial service provider, they must also answer to local authority figures.

\section{Comparison of the Two Projects}

As evidenced by the quotes in the sections above, both the CBP and Service Project exhibit cultural-cognitive and normative alignment. Stakeholders' spoken texts demonstrate this alignment through the use of key terms and concepts of sustainable development, such as ownership and participation. Concepts indicative of the presence of cultural-cognitive and normative support, such as value alignment and cultural understanding, are also evident in stakeholders' descriptions of project characteristics. The Service Project in particular shows clear evidence of strong cultural-cognitive support, with multiple stakeholders describing its strong alignment with cultural understandings and behaviours. Cultural-cognitive support for the CBP is evidenced both in my interview with the project leader, as well as in the behaviour of project stakeholders during my site visit. The adoption of project behaviours, described by interviewees in both projects, indicates that stakeholders have fully taken project activities on board and incorporated them into their daily routines.

Indications of regulative support are less uniform across the two projects. It is clear from objectives within both projects' documents (cited earlier) that NZAID recognizes the importance of having the support of the chiefs and elders in the implementation of their projects, and with their support, the authority that comes with it. Where NZAID and its partners may not be able to enforce the implementation of a project, indigenous authorities, if supportive of project goals, should be able to do so. Despite CBP project documents' emphasis on building governance capacities within communities' Councils of Elders, traditional authority structures were not reinforced through project training and activities, but were in a sense undermined. By situating project authority and knowledge solely with the project's leaders, elders have been alienated through the erosion of some of their traditional authority and standing within the community. In contrast to the CBP, the Service Project has made concerted efforts to incorporate the role of traditional 
community authorities into project systems, securing their support by respecting and extending their regulative authority. Where NZAID contractors may have encountered difficulty in enforcing project activities in the many widely distributed communities in which they work, the supporting regulative presence of village elders should promote behavioural alignment with project objectives, thereby producing desired outcomes and contributing to project institutionalization.

\section{Discussion}

This chapter has encompassed the analysis of the development discourse of NZAID and its partners in the two case study projects. This analysis, examining both NZAID organizational and project documents, as well as the spoken texts of NZAID members and multiple project stakeholders, has involved a multi-layered interpretive process. Such a process has enabled me to search out the presence of concepts relating to institutions and to institutionalization as they are mentioned by name, referred to descriptively, and alluded to through the presence of key words. As identified by my initial analysis of the presence of the terms 'institution' and 'institutionalization' in project stakeholders' texts, references to those terms were few and far between, and then exclusively within NZAID texts. However, those few references did positively indicate the organization's awareness of the importance of institutions to sustainable development. This, along with the strong presence of concepts of sustainable development already identified in NZAID and its partners' texts, boded well for similarly robust links to institutional concepts.

Within the two projects there were strong thematic correlations to institutional concepts, and evidence of the establishment of the institutional pillars. This conceptual presence required more analytic work to uncover in the Community Building Project than it did in the Service Project. Where the Service Project demonstrated strong conceptual alignment with all institutional pillars, both in project objectives and in descriptions of project realities, the CBP's conceptual links were occasionally only discernible through interpretation of individual words and phrases. As previously mentioned, this may be due in part to the CBP's lack of a Project Design Document. Nonetheless, considering that NZAID has only its Work Plan and Monitoring and Evaluation Framework to use as platforms to share its development philosophy and objectives with its partners in the CBP, it is my 
opinion that the organization ought to more conscientiously infuse its documents with the principles of its sustainable development discourse, using every available opportunity to reinforce the whys and hows of its sustainability goals.

While both projects display evidence of institutionalization through the establishment of institutional pillars, it is the Service Project that most clearly demonstrates strong institutional support of its services. Consultation with community stakeholders has evidently resulted in strong value alignment, with community members recognizing the value of the service to their communities and supporting service provision through participation and project ownership. The incorporation of local governance structures has also built strong regulative support for the project, enabling local authorities to shape behaviours to project standards (there are further behavioural incentives provided by NZAID, to be described in the following chapter). And by NZAID contractors' investing time and energy in learning about and incorporating aspects of communities' cultural understandings into project design, they have contributed to the establishment of cultural-cognitive support of community-based services, with the service showing evidence of being a well-established and valued part of daily community life. It is important to note, however, that institutionalization of the Service Project was only evident in the community-based service, with the provincial service provider largely absent from the corpus. As a generation three development project, seeking to build institutions supportive of locally operating services, the Service Project does not yet demonstrate the establishment of that vital higher-level institutional support. This shortcoming will be discussed in the concluding chapter.

Within the Community Building Project there was evidence of normative and cultural-cognitive alignment, most strongly glimpsed through community ownership of the project, and through the proactive participation of community members in project activities expected to produce valued outputs accruing to the community as a whole. As described earlier, the project's lack of regulative support is a concern. Without the support of chiefs and elders, community project managers may struggle to enforce project behaviours. Furthermore, while it was not clear whether the Council of Elders' relationship with the youths running the project was oppositional, it had evidently created tension in the community. 
Thus it may be seen how in pursuing project sustainability, NZAID's development discourse simultaneously builds institutional support contributing to project institutionalization and durability. The textual presence of concepts relating to each of the three pillars collectively supports institutional formation by providing the means by which projects may encourage and streamline desired project behaviours, encouraging community members' engagement with the projects by generating value alignment through consultation and participation, and through that participation, insinuating that project and its behaviours into the daily routines of a given community and its members. The maintenance of these three pillars through ongoing attention to communities' socio-cultural values and needs should ensure the institutional success and sustainability of these projects.

Although NZAID's development discourse, heavily influenced by principles of sustainable development, is already demonstrated to be productive of institutional outcomes without any intentional infusion of institutional theory into its discourse, conceptualizing the development process as a process of institutionalization may provide additional benefits. Institutional theory, being an aspect of organization studies, provides a new way of understanding and organizing the contributions of sustainability concepts. Understanding sustainable development as an institutional process reframes the steps toward sustainability as an organizational undertaking, with inputs gradually combining to produce a stable institutional structure. Recasting sustainability concepts as building blocks in a structured process of institutionalization may result in a more orderly and predictable process of development. Furthermore, using institutionalization and the three pillars as evaluative tools may assist developers in assessing and more appropriately responding to the needs of different development environments. While the institutionalization process of both case study projects appears to be proceeding relatively well, it would doubtless improve if NZAID and its partners were to more explicitly incorporate ideas from the institutionalization process and purposely fitted the design, implementation, and evaluation of their activities to its framework. I will discuss this and other recommendations in my concluding chapter. 


\section{Conclusion and Recommendations}

\section{Introduction}

As described in the introductory chapter of this research, the genesis of this project can be located with my curiosity about how the development projects that I had been involved with would be sustained once international development assistance in the form of funding and volunteers had been withdrawn. The refinement of this personal curiosity into a workable research question for a thesis in the field of management studies did not occur until I had encountered an articulation of Nelson Phillips' discursive theory of institutionalization. This encounter not only provided a structured means by which to approach my question, it also responded to personal interests of mine (as a former French and Spanish major who had previously considered undertaking postgraduate study in linguistics) in the power of language, and its manifestations. In applying Phillips' discursive theory of institutionalization to the field of development, I have addressed my seemingly disparate interests while simultaneously demonstrating how the field of international development may benefit from the inclusion of institutional theory. I have also argued that aspects of institutional theory may be practically applied to real world situations to create deeper understandings as well as positive outcomes. In this chapter I return to my research questions in order to rearticulate and summarize this project's contributions. I also address the generalizability of this project, as well as identifying avenues for future research.

\section{Theoretical Research Questions}

The initial research question that drove this project (and the one that I became adept at reciting in response to people asking me what my thesis was about) was 'how do international development organizations plan for the long term sustainability of their projects?'. Presuming that NZAID is representative of other development organizations, this research has shown that development organizations' practice is strongly influenced by the principles and discourse of international agreements such as the Paris Principles and the Accra Agenda, and the UN's Millennium Development Goals. As I argued in the 'Modern Development' section of the Literature Review, these agreements are the products 
of both principles of alternative development, emphasizing the importance of people-focused strategies, as well as of international development's return to strategies which recognize the state as the legitimate driver of development. In addressing my research question I have identified themes within development discourse that carry through from alternative development texts and international agreements to NZAID's development discourse as manifested within organizational documents and within NZAID employees' texts. These themes are the same ones that I have used to link to institutionalization discourse and Scott's pillars of institutions.

The next question that this research answers is 'how are the processes of sustainable development and institutionalization similar?'. Having become acquainted with Nelson Phillips' discursive theory of institutionalization prior to beginning the thesis process, I had already developed an inkling of the similarity of the product of the institutionalization process (an institution), and the desired outcome of the sustainable development process (an activity or organization capable of sustaining itself independently and indefinitely, beyond the period of involvement of the instigating organization). As described in the 'Requirements for Sustainability' section of the Literature Review, institutions and sustainable development projects display very similar characteristics. At their simplest, they are durable structures which, through incentives, and alignment with socio-cultural values, direct the actions of their adherents in order to produce desired outcomes. Thus the process of sustainable development may be conceptualized as a process of institutional formation, or institutionalization. While the principles guiding the practice of sustainable development are clearly outlined in international development literature, debate within the field of institutional theory continues as to how institutionalization occurs. I have suggested that combining Phillips' discursive theory of institutionalization with Scott's theory of the institutional pillars provides a credible and comprehensive vision of the process. This combination of theories describes how a successful process of institutionalization depends on discourse and the actions it prompts to establish the regulative, normative and cultural-cognitive pillars upon which institutions depend.

The adoption of this theoretical premise then begs the question 'what possible practical benefits could result from conceptualizing the process of sustainable 
development as a discursive process of institutionalization?'. As described in the 'Requirements for Sustainability' section of the Literature Review, the record of international development organizations producing sustainable projects has been poor. While development literature frequently emphasizes the importance of institution building, records of success would indicate that the process is poorly understood. As demonstrated in the previous chapter, case study organization NZAID, while identifying institutions as being important to sustainability, provided inconsistent and incomplete definitions of institutions and institutionalization. Thus a reconceptualization of sustainable development as a process of institutionalization stands to organize development organizations' understandings of, and approaches to, sustainable development. By identifying what concepts development discourse must address, and the theoretical framework into which those concepts fit, this institutional understanding of development offers the potential for a more focused approach to sustainable development. Furthermore, this approach has the advantage of being easily implementable. It does not demand a financial investment, or a return to the theoretical drawing board. Instead, it seeks to complement organizations' current approaches to sustainability, offering a more holistic and organized framework for implementation.

\section{Analytic Process}

In order to practically demonstrate how sustainable development may be conceptualized as a discursive process of institutionalization, I have examined texts within NZAID and its partners in two projects in Papua New Guinea. Texts, compiled through document collection, interviews and observations, served as the site of comparison of sustainability discourse and institutionalization discourse. In my Sustainability chapter I have identified how sustainability discourse, as glimpsed within alternative development literature and documents such as the Paris Principles, is prevalent in NZAID and its partners' texts. Terminology pertinent to concepts such as participation, consultation, empowerment and ownership is prominent, primarily within NZAID, but also within its partners' texts. This indicates that the flow of ideas between NZAID and its partners and stakeholders is good, with key ideas being adequately communicated through documents and speech events. I have thus explored how such features of 
sustainability discourse can be alternatively understood as contributing to each of the institutional pillars, and as fitting into an institutional paradigm. The presence of such cross-discourse terminology within NZAID and its partners' sustainable development discourse signifies that even without the conscious inclusion of institutionalization discourse in project plans, sustainable development discourse can be understood as inherently addressing principles of institutional theory, thus contributing to institutionalization.

\section{Theoretical Contributions}

One of the objectives of this project is to integrate aspects of organization studies with aspects of international development. I hope to identify how organization studies can communicate with, and contribute to positive outcomes within international development. In the course of my research I have highlighted how concepts from organization studies interweave with principles of sustainable development. Specifically, I have demonstrated how concepts from within institutional theory are present within development texts, as evidenced through analysis of those collected within case study organization NZAID and its partners in Papua New Guinea. I have contributed to organization theory by demonstrating how institutional theory can be understood as providing the underlying structural framework for principles of sustainability widely employed within international development. By searching out and identifying the presence of institutional concepts within international development, I have demonstrated the support that organizational concepts may provide to this field and its endeavours.

Another key theoretical contribution of my research is my integration of different theories within the field of institutional theory. Beginning this project with a firm footing within Nelson Phillips' discursive theory of institutionalization, my explorations of the field of institutional theory soon led me to W. Richard Scott's institutional pillars. Although Phillips credibly champions his theory of institutionalization, I felt that he failed to provide a sufficient explanation of what components a discourse needed to contain in order to produce an institution. In other words, why doesn't every discourse produce an institution? Phillips states that 'The greater the number of texts and the more well structured the discourse, the more "institutionalized" the institution becomes' (Phillips, 2003, p228). I have 
found that Scott's institutional pillars provide that needed structure to the discourse, identifying how institutional foundations can be understood to lie in the conceptual realm of values, and socio-cultural frameworks of meaning. Together, Phillips' and Scott's theories illuminate the seemingly alchemical process by which institutions are formed: they arise through the generation of discourse which adequately addresses and produces the three fundamental supports upon which institutions rest. By examining how a given discourse addresses each of the three pillars, it is possible to gain an understanding of how that discourse is producing institutionalization. In integrating these two theories I believe that I have helped to illuminate the workings of the still poorly understood and often neglected concept of institutionalization. I hope that I have demonstrated how concepts within the field of organization studies may be combined to produce new theoretical and practical insights.

This research also contributes theoretically to the field of international development, demonstrating how the organizational framework of Scott's institutional pillars can re-frame the concepts of sustainable development. Where the principles of sustainable development seemed to me to be haphazardly implemented-a slapdash combination of best practice techniques-the institutional pillars demonstrate how each principle contributes to the establishment of support vital to institutional creation and stability. Furthermore, Phillips' theory of institutionalization prompts international development workers to reconsider the nature of their work. Rather than seeing it as practical, actionoriented, on the ground work, development workers may begin to look at it as being equally dependent upon the thorough formulation and equally thorough communication of development plans and their ideological foundations. By reemphasizing the importance of discursive clarity, institutional theory provides developers with a new way of understanding and organizing their work.

Phillips' discursive theory of institutionalization indicates that the more clearly and strongly an idea is expressed in a widely distributed and consumed discourse, the more likely that idea is to take root and produce material effects in the real world. I have identified Scott's pillars as providing the ideal framework for development discourse, as it provides a strongly supportive structure to which development workers may fit their plans. The promise of institutional stability would encourage 
developers to more consciously align their development plans to the conceptual framework of the institutional pillars, more strongly emphasizing and more clearly laying out the principles of sustainable development proven to contribute to the establishment of individual pillars. It may even be worthwhile to present institutional concepts in development plans, explaining how each project objective contributes to institution formation, stability, and long term sustainability.

\section{Practical Contributions and Recommendations}

I hope that I have illustrated through my examinations of NZAID and its partners' development texts that within its treatment of development principles, there can also be seen conceptual and linguistic links to Scott's institutional pillars. However, these traces are not explicit, and should be more clearly elaborated in order to reinforce the principles driving NZAID's involvement in its projects, and to begin setting in place the pillars required to support the nascent institution. Project stakeholders should not have to undertake the degree of interpretive analysis that I did in order to understand the development philosophy driving project activities and behaviours, particularly in NZAID's Community Building Project documents. While NZAID has laid out a clear 'plan of attack' in its CBP documents, it may wish to revise its Work Plan, and Monitoring and Evaluation Framework to emphasize and rearticulate the principles guiding project implementation, simply to fortify those principles' presence in discourse. And as ideas must be clearly understood to be communicated and reproduced, it may also be worthwhile to ensure that NZAID's project documents are translated into Pidgin, as my experience interviewing project workers indicated that levels of fluency in English were variable, and occasionally proved to be an obstacle to understanding.

While each of the two case study projects has demonstrated facets of institutionalization, each project still faces challenges going forward. My analysis of the presence in development discourse of concepts fuelling institutionalization thus invites a number of practical recommendations. As discussed in the previous chapter, the presence of such concepts in the Community Building Project's discourse was rather weak, evident more frequently through the use of indicative vocabulary, rather than through direct references to, or descriptions of key concepts. While there was evidence of normative and cultural-cognitive support 
for the project, regulative support in particular was lacking, thus endangering the institutionalization and sustainability of the project. Considering the fragility of community-based projects, regulative support may be especially crucial.

As mentioned in the Introduction, this research does not purport to address concerns of resourcing for projects going forward. Nonetheless, questions of resource stability have the potential to destabilize even well-established institutions and thus are worthy of some attention. Where the Service Project may count on provincial government support going forward, the future success of the CBP's community projects is heavily dependent upon provincial economic conditions. Even if projects succeed in being institutionalized within communities, should rural or provincial economic conditions be insufficient to support community economic endeavours (i.e. if no one is able to buy a brick making project's bricks), and community efforts do not produce valued outcomes, normative support may erode (Scott, 1991). Lacking normative support, and without the presence of an authority to enforce the continued enactment of project activities, projects risk being abandoned. In order to strengthen the governance of projects within communities, it is my suggestion that the CBP attempt to align itself more effectively with village governance structures. Where the Service Project has experienced success through its integration of village elders and chiefs into project systems, and then piggybacking on their authority, the CBP should seek to do the same.

The Service Project, while demonstrating strong institutionalization of its services in the communities where it works, has inadequately addressed the institutionalization of the project within the provincial service provider. The Service Project has successfully accomplished its generation two development work, establishing services within communities (Korten, 1990). It must now turn its attention to addressing the demands of its nature as a generation three project, establishing institutional support for those community-based services (Korten, 1990). As the provincial service provider is destined to assume the management of the entire community service provision programme upon NZAID's eventual withdrawal, the current state of affairs is unacceptable. It was clear from my interviews and observations that in the absence of support and leadership from the provincial service provider, local service providers and community members have 
become dependent on NZAID's contractors, their organizational abilities, and their resources. They don't like to think what would happen if and when NZAID pulls out. As one NZAID contractor stated, 'they believe that [the provincial service provider] can never be in a position to run them.' The same contractor then stated that the community based service providers 'could survive without the [provincial service provider], but not without us.' In this instance, institutionalization has occurred around a resource that will, in the not too distant future, disappear. While it is to be commended that NZAID has been able to make their service such a vital fixture of communities' lives, unfortunately they themselves have become bound up in it. Upon their departure, the institution that they leave behind will need to undergo a reorientation process to adjust itself to the new institutional environment, which, unless a comprehensive process of capacity building and philosophical realignment is successfully implemented, would be an environment with a 'leaderless, rudderless' management and support system.

Wellington NZAID staff as well as NZAID's contractors have demonstrated their awareness of this issue by stating both in the current phase's Project Design Document and in stakeholder interviews that project handover is impossible until the capacity and alignment of the provincial service provider has improved. This task is the project's primary focus going forward. I suggest that using an institutional evaluative framework (such as the one that I will present shortly) would assist NZAID in identifying the institutional shortcomings of the provincial service provider, and would also help in conceptualizing and structuring an effective programme of response. By bringing the provincial service provider up to a level at which they are consistently capable of providing the level of support that communities have, through their involvement with NZAID's contractors, come to expect, NZAID may establish the institutional conditions through which they may withdraw without endangering the project's sustainability.

\section{Using the Institutional Pillars as an Evaluative Tool}

In addition to being applicable to the design and implementation process of sustainable development, development practitioners may find institutional theory helpful in the examination and analysis of current systems of behaviour in place within given communities. Institutional theory has the potential to assist 
development planners in understanding the environments into which they intend to introduce new behaviours and new institutions. By using Scott's institutional pillars as a framework for analysis, development planners may identify where and how existing community institutions derive their regulative, normative and culturalcognitive support. Understanding precursor institutions and their structures and functions stands to provide project planners with knowledge of how existing community systems operate, and may provide viable blueprints for modelling new institutional structures.

In order to address how the development process is proceeding, I believe that international development organizations would benefit from evaluating project progress through evidence of the establishment of the three institutional pillars. I provide a sample evaluation below, which I use to assess the progress of the two case study projects towards institutionalization. This table demonstrates that the pillars can be useful not only in guiding and evaluating development discourse, but also as tools to understand and evaluate the progress of projects themselves. The table encourages practitioners to examine their project objectives and activities in order to understand which pillar an activity or objective goes to establish, and thus why that activity or objective is important. The table may clarify which support a project activity is helping to establish, and, depending on imbalances in support, where developers should focus their energies going forward. From the starting point of this evaluative table, it would be a simple process for development organizations to delve further into the requirements for each specific project to suitably address each pillar. This could provide an effective and insightful framework for project design and implementation. The table forcibly integrates development and institutional theory and encourages development practitioners to reconceptualize their projects within the bounds of an institutional framework.

Each project is broken down to look at both the projects currently being operated at the community level (the Service Project's community-based services, and the community income-generating project that I observed with the CBP), and their operator organizations (the provincial service provider, and the CBP organization $^{2}$ ). In the case of the Service Project, the operator organization has

\footnotetext{
${ }^{2}$ I have not yet addressed the CBP organization in this paper in relation to its sustainability. Because the CBP organization has a capable management and staff, its sustainability is largely
} 
not yet assumed control, but its present status can be evaluated in order to identify appropriate courses of action to bring it up to speed.

The first column addresses the regulative pillar, examining what incentives and disincentives for behaviour are present in each aspect of each project. It also looks at the governance support present in each project. The second column examines the value alignment of the aspects of each project, identifying the steps each project has taken to establish that alignment and how that alignment is or is not presently evidenced. The third column looks at each project's culturalcognitive support by examining how project behaviours are present in communities or operator organizations, and how each is seen in the eyes of their target populations.

Upon reading the chart, it is evident that (as discussed earlier) the Service Project's community-based service is well institutionalized, with evident support in all areas. The provincial service provider, however, is poorly prepared to take over the operation of the service, not having the support of any of the institutional pillars. And the CBP's community project is seemingly well established normatively and cultural-cognitively but lacks regulative support. By engaging in such a process of evaluation, NZAID may identify where its projects currently need work and may design the appropriate texts and actions to address those critical areas.

dependent upon its developing viable revenue streams in anticipation of NZAID withdrawing its funding. As previously stated, this research does not address resourcing concerns. I have included it in this table merely for the sake of example. 


\section{Using the Institutional Pillars as an Evaluative Tool - Sample Evaluation of Case Study Projects}

\begin{tabular}{|c|c|c|c|}
\hline & $\begin{array}{c}\text { Regulative Pillar - } \\
\text { Incentives and Penalties, } \\
\text { Governance }\end{array}$ & $\begin{array}{c}\text { Normative Pillar - } \\
\text { Proof of Value Alignment }\end{array}$ & $\begin{array}{l}\text { Cultural-Cognitive Pillar - } \\
\text { Proof of Cultural Alignment }\end{array}$ \\
\hline $\begin{array}{c}\text { CBP - } \\
\text { Organization }\end{array}$ & $\begin{array}{l}\text { - The incentive for exhibiting behaviour in line with } \\
\text { NZAID's expectations and Work Plan is continued } \\
\text { funding by NZAID } \\
\text { - Incentive for developing own reliable funding } \\
\text { sources is the organization's survival after NZAID } \\
\text { withdraws its financial support } \\
\text { - CBP employees may lose their jobs if they don't } \\
\text { perform as expected }\end{array}$ & $\begin{array}{l}\text { - The organization's mission statement } \\
\text { provides its guiding moral values } \\
\text { - The province's social and cultural values } \\
\text { also guide the organization } \\
\text { - The project is staffed by local workers }\end{array}$ & $\begin{array}{l}\text { - Word of the organization's services has spread and } \\
\text { more communities are requesting their help; more } \\
\text { students come to their school from farther away } \\
\text { - CBP workers describe the respect that they are held in } \\
\text { by the provincial government and the local people }\end{array}$ \\
\hline CBP - Projects & $\begin{array}{l}\text { - Incentive for communities is increased income and } \\
\text { prosperity, greater social standing } \\
\text { - No penalties for project failure or non-compliance } \\
\text { with CBP's recommendations once training has } \\
\text { been completed } \\
\text { - Elders have not been incorporated into community } \\
\text { projects }\end{array}$ & $\begin{array}{l}\text { - The good of the community/wantok } \\
\text { (over that of the individual) is the } \\
\text { primary value. Benefits must accrue to } \\
\text { all. These projects share benefits } \\
\text { among community members. }\end{array}$ & $\begin{array}{l}\text { - Evidence of alignment through project leader's } \\
\text { statement that every day more workers turn up than } \\
\text { they need, without being asked } \\
\text { - Project leader's description of CBP training being } \\
\text { regularly and productively employed by community }\end{array}$ \\
\hline
\end{tabular}

Continued... 


\begin{tabular}{|c|c|c|c|}
\hline & $\begin{array}{c}\text { Regulative Pillar - } \\
\text { Incentives and Penalties, } \\
\text { Governance }\end{array}$ & $\begin{array}{l}\text { Normative Pillar - } \\
\text { Proof of Value Alignment }\end{array}$ & $\begin{array}{l}\text { Cultural-Cognitive Pillar - } \\
\text { Proof of Cultural Alignment }\end{array}$ \\
\hline $\begin{array}{l}\text { Service Project - } \\
\text { Provincial } \\
\text { Service Provider }\end{array}$ & $\begin{array}{l}\text { - At present no penalty for their non-cooperation } \\
\text { - No incentive for them to cooperate. Town-based } \\
\text { provincial staff do not see benefits of their } \\
\text { interventions in communities. } \\
\text { - There is a disincentive for their cooperation: it } \\
\text { would result in more work for them with no greater } \\
\text { compensation. As described by one NZAID } \\
\text { contractor, 'There's never been any outward bad } \\
\text { dealings. It's just a total lack of commitment here } \\
\text { for them to do any work. So why would they help } \\
\text { the [community service providers] out, that sort of } \\
\text { thing.' }\end{array}$ & $\begin{array}{l}\text { Expanded provincial service requires } \\
\text { new behaviours and extra work with no } \\
\text { training (at the moment), and no } \\
\text { perceptible return, meaning that } \\
\text { provincial service providers are unable } \\
\text { to act as situations demand } \\
\text { - Low resource capacity for dealing with } \\
\text { outputs of new behaviours }\end{array}$ & $\begin{array}{l}\text { - The provincial service provider receives different } \\
\text { training than community service providers, and so they } \\
\text { don't operate on the same foundational value/cultural } \\
\text { system } \\
\text { - 'Leaderless, rudderless' provincial service provider } \\
\text { organization } \\
\text { - Lack of instilled values, resulting in unmotivated, } \\
\text { uninspired staff } \\
\text { - Community service providers and community } \\
\text { members do not trust provincial service providers }\end{array}$ \\
\hline $\begin{array}{l}\text { Service Project - } \\
\text { Community } \\
\text { Service Provider }\end{array}$ & $\begin{array}{l}\text { - Salary is dependent upon proof of productivity, } \\
\text { which is evaluated monthly } \\
\text { - Status in community rises with productivity and } \\
\text { effectiveness } \\
\text { - Community well-being directly affected by job } \\
\text { performance, and is easily observable } \\
\text { - Councils of Elders support and enforce the } \\
\text { enactment of project activities } \\
\text { - Because service providers live in the communities } \\
\text { they serve, they must live up to community } \\
\text { expectations }\end{array}$ & $\begin{array}{l}\text { - Service provision can be directly linked } \\
\text { to community/wantok well-being } \\
\text { - High rates of participation of not only } \\
\text { service providers, but other community } \\
\text { members as well } \\
\text { - Service integrates village authority } \\
\text { structures (i.e. chiefs and COEs choose } \\
\text { community service providers) } \\
\text { - Community members regularly attend } \\
\text { service trainings }\end{array}$ & $\begin{array}{l}\text { - The service is taken for granted and performed } \\
\text { automatically. Community members routinely go to } \\
\text { service providers for assistance } \\
\text { - NZAID contractors see service providers at work and } \\
\text { get reports of their work from providers themselves } \\
\text { and from community members } \\
\text { - Community leaders regularly speak to NZAID in order } \\
\text { to request more service providers for their villages }\end{array}$ \\
\hline
\end{tabular}




\section{Generalizability and Ideas for Future Research}

I believe that this research is highly generalizable. Although it is certainly most relevant to NZAID and the two case study projects in PNG, any organization looking to implement sustainable projects of any kind may find its contributions to be helpful. While NZAID is a unique organization with its own specially developed procedures and ideology, it is also representative of other international development organizations of its kind. Any international development organization looking to produce sustainable outcomes, and subscribing to the suggestions of the Paris Principles and the Millennium Development Goals is likely to develop and implement projects using methods similar to NZAID's. Thus this research has the potential to offer theoretical and practical insights to those organizations.

Although this research has been applied to the field of international development, this represents only one possible application of this area of institutional theory to real world situations. International development was chosen due to my interest in and prior experience with development projects, and the parallels I perceived between sustainable development and institutionalization. But the compound theory of institutionalization that I explore in this research, using both Phillips' and Scott's theoretical contributions, can and should be applied by any individual, group or organization looking to create long-lasting new behaviours, or behavioural change within a population group or organization. Institutional theory and the process of institutionalization stand to contribute to the management of any process of behavioural or ideational change. Institutions are ubiquitous in modern life, and as such, this research, which offers a way of understanding institutions and the dynamics of institutional situations, should be widely applicable.

There are a number of ways in which this research might be revisited or expanded. While my research includes multiple stakeholders of development projects, it does not include representatives of the PNG government at the national, regional or local level. Due to time and logistical constraints, I was unable to expand the scope of my research to include these stakeholders, but future research would benefit from the inclusion of stakeholders at the national, 
regional and local levels of government. In doing so it would provide a more complete picture of the development chain beyond NZAID. To further expand the 'corpus' of NZAID's development discourse, it would also be useful to interview more stakeholders at each level of the development process in order to obtain more samples of discourse, and thus provide a better and more broadbased understanding of the degree of penetration and assimilation (or alteration, or absence) of NZAID's development discourse.

Another avenue for future research would be to expand the role of critical discourse analysis. Text production, distribution and consumption are critical parts of CDA. While this research touches upon these briefly, it does not go into detail about exactly how NZAID creates and communicates its development plans to its stakeholders, particularly those stakeholders in remote areas where communication infrastructure and literacy are poor. As broad and uniform consumption of development texts contributes to shared understandings of tasks and objectives, and the achievement of those objectives, it would be useful to understand how current modes of communication are helping or hindering the successful implementation of development projects. Also, as discussed in the Background chapter, NZAID is currently undergoing a restructuring process, and moving away from a poverty reduction focus to a new focus on sustainable economic development. It would be interesting to revisit the organization in a few years' time to see if and how aspects of development discourse had changed and how those changes were evident in stakeholders' development discourse and results on the ground.

And of course, should recommendations from this research be implemented within NZAID or another similar organization, I would be very interested to explore how project design, communication and implementation might change, and how those changes might produce short and long term effects within target groups.

\section{Conclusion}

I believe that this research has succeeded in answering my research questions, and in identifying and elaborating the links between sustainability and 
institutionalization. I hope that it has also demonstrated the importance of building a development discourse whose texts work to establish the institutional pillars upon which stable institutions, and sustainable projects, depend. The three institutional pillars provide an excellent framework upon which to build project objectives and activities. The pillars organize development concepts into a readily comprehensible framework by which to achieve the too little understood outcome of institutionalization. Rather than merely 'knowing it when they see it', international development organizations must also know what makes institutionalization happen and how to achieve it, incorporating it into their plans and their discourse. They will thereby increase their likelihood of establishing development projects that will truly address the needs of target groups, both during the period of their involvement, and during the independent operation of projects far into the future. 


\section{Appendices}

\section{Appendix A : Research Project Information Sheet}

\section{Institutionalizing Sustainability in Development}

I am carrying out research on the planning and implementation of communitybased international development projects for my Master's Thesis for the Victoria University Management Studies program. I have recently carried out interviews with some of your colleagues at NZAID in Wellington. In order to further my research into dialogues of sustainability in the development process, I would like to interview you about your experience doing development work. I have obtained Human Ethics Approval from the Victoria University Ethics Committee.

Having worked abroad as a volunteer on development projects, I am interested in the design and implementation of sustainable community development initiatives. I am particularly interested in learning about the perspectives and practices of project planners and on-site project workers, and how the texts and dialogues that shape plans and practice might in turn affect the long-term sustainability of development outcomes. I will approach this research from an organization studies perspective, and research outcomes will integrate and contribute to both the fields of management studies and international development.

If you agree to participate I will ask you to fill in a consent form that, with this information sheet, describes your role in the project and your rights as a research participant. I estimate that my interview with you will take approximately 1 hour, scheduled at a time and at a location suitable to you (within the limited time that I am in your area of PNG). With your permission, I intend to digitally record the interview. You may withdraw decline to participate at any time prior to the interview, and may decline to answer particular questions. Once I have conducted your interview, you may elect to withdraw any resulting data within 7 days of the date of your interview.

Data collected in this research, including digital recordings and transcripts, will be stored in password protected files. Only I and my research supervisor will have access to research data. Digital recordings will be destroyed upon the successful completion of my thesis. Transcripts will be destroyed one year after the successful completion of my thesis. 
Should you choose to participate in my study, any information obtained through our interviews and my observations will be presented in such a way as to maintain your confidentiality. You will not be identified by name or by identifying descriptors, though I will disclose the identity of NZAID, and will state that Papua New Guinea is the country in focus. Should I publish any articles or papers based on this research, your name and the names and the locations of your projects will be kept confidential.

It is more than likely, however, that you will be identifiable by other participants in this research-by the PNG team leaders in Wellington and Port Moresby, who will know at which sites I am conducting research, and who will likely have put me in touch with you. Similarly, other workers at your project site will be aware that you have spoken with me. It is also possible that other workers within NZAID who are very familiar with PNG activities and their staff may be able to identify you.

Upon the conclusion of this research I will offer to give you a report of my findings, should you wish it. The findings are likely to be of interest, and may be of use in thinking about your work. I believe that the results of my research will contribute to development practice, and as such, I intend to publish some form of it so that it may be available as a resource to practitioners. It is also possible that I may use this research in informal presentations to aid workers. A copy of my thesis will be bound and archived at the Victoria University library.

\section{About the Researcher:}

I am the current holder of a Victoria Master's by Thesis Scholarship. While doing MMS coursework, I carried out several confidential interviews with employees of two Wellington-based organizations. I am capable of carrying out organizational research efficiently, and with minimal disruption or inconvenience to organization members. I am sincerely interested in the practical implications of this research. I recently took an upper level Development Policy and Management course in preparation for this project. Prior to undertaking my Master's studies, I was employed as a programme manager with an inner-city Philadelphia community development corporation, and also spent time working as a volunteer on education and community development projects in Peru. 


\section{Appendix B : Research Project Participant Consent Form}

\section{Institutionalizing Sustainability in Development}

$\square$ I have read the Research Project Information Sheet for this study and have had the details of the study explained to me.

My questions about the study have been answered to my satisfaction, and I understand that I may ask further questions at any time.

$\square$ I understand that I am free to decline to participate at any time prior to being interviewed, and may at any point decline to answer any particular questions.

I understand that I may withdraw data derived from my interview within 7 days of the date that it was conducted, and that all data will be destroyed.

$\square$ I agree to participate in the study and provide information to the researcher under the conditions of confidentiality set out on the Information Sheet.

I understand that while my identity will be kept confidential in write-ups of this research, I may be able to be identified by other participants in this research, and by other NZAID organization members.

I agree to be interviewed.

I agree to the interview being digitally recorded.

$\square$ I would like to receive feedback in the form of a written report from the researcher.

Other conditions?

Participant:

\section{Signed:}

Name \& Organisation:

Date: 
Appendix C : Interviewee Table

\begin{tabular}{|c|c|c|c|}
\hline Site & Number of Interviewees & $\begin{array}{c}\text { Gender of Interviewees } \\
\text { (Ratio of Male:Female) }\end{array}$ & Nationality of Interviewees \\
\hline NZAID Wellington & 5 & $4: 1$ & All New Zealanders \\
\hline NZAID Port Moresby & $\begin{array}{c}\text { (an intended third interviewee } \\
\text { was called away } \\
\text { unexpectedly) }\end{array}$ & $2: 0$ & $\begin{array}{c}\text { 1 Pacific Islander, } \\
\text { 1 PNGean }\end{array}$ \\
\hline Service Project & 6 & $2: 3$ & $\begin{array}{r}\text { 3 New Zealanders, } \\
\text { decadralian (more than 2 } \\
\text { 2 PNGean ident in PNG), }\end{array}$ \\
\hline Community Building Project & 6 & $5: 1$ & All PNGean \\
\hline
\end{tabular}




\section{Appendix D : Interview Questions}

Interview Questions

(NZAID Staff in Wellington)

1. What is your role in this organization?

2. How long have you worked in this organization?

3. Why did you seek employment here?

4. What is your educational and employment background?

5. Do you specialize in a particular region? A particular type of project?

6. What projects do you work on?

7. How would you describe NZAID's development philosophy?

8. What informs your process of planning?

9. How do you conceive of your role in project planning?

10. Did you receive any training from your organization regarding how to plan projects?

11.What is your understanding of project sustainability?

12. Is sustainability (in terms of a community's being able to sustain a project after the withdrawal of supporting funds and workers) one of NZAID's project goals?

13. How do you plan a project? How do you plan for sustainability?

14. Whom do you consult in the project-planning process? Is there consultation with the target community in the planning phase?

15. Would you describe this organization's community-based development plan as involving participatory development?

16. Does NZAID plan or provide for the scaling up of projects?

17. What would you say differentiates community-based development from other types of development?

18. How do you monitor project progress?

19. Do you communicate with project workers on the ground? How, and how often?

20. What is the time scale of the projects that you plan?

21. How would you describe a successful project?

22. How would you describe an unsuccessful project?

23. What role should community members play in their development? Do you think that they perform these roles?

24. What are the conditions necessary for sustainable development?

25. What are some of the obstacles to sustainable community-based development? 
Interview Questions

(NZAID Staff in Port Moresby)

1. Please state your name and role in NZAID, and describe what that role entails.

2. How would you describe NZAID's development philosophy?

3. How would you describe a successful project?

4. How would you describe an unsuccessful project?

5. Please describe the project planning process and how it works. Whom do you consult?

6. How does your role differ from that of NZAID project team members in Wellington?

7. How is NZAID involved in community-based projects? Does NZAID have an active role in project design, or do they primarily give money to NGOs?

8. What does your presence in PNG contribute to your work and your performance?

9. Would you describe NZAID's community-based projects as involving community participation?

10.What role should community members play in their development? What role do they play?

11. What is the benefit of participatory development?

12. How do NZAID's programmes resemble partnerships?

13. How do you define sustainability? How do you plan for sustainability?

14.What are the conditions necessary for sustainable development?

15. What are some obstacles to sustainable community-based development in this province?

16. How do you work around those obstacles?

17. When and where does the sustainability dialogue start and end? (How far down the development chain does the sustainability dialogue travel?)

18. Where do you situate yourself in the development process?

19. How do you interact with Wellington? Is it a two-way relationship, or is it more that you enact the strategies that they send through?

20. How would you conceptualize your office's relationship with Wellington, with Waigani, and with field posts? A web? A chain? A discussion? A lecture?

21. How are development plans transmitted and actioned?

22. Do you consider existing community institutions and structures when elaborating project plans?

23. How do NZAID's programmes specific to this province slot in with the PNGwide development strategy?

24. The Service Project is unique in that they do have enforcing ability, but in most projects, where project practices aren't enforceable, how do you plan for communities to adopt practices? What are the signs that this is happening? 
Interview Questions

(NZAID Workers at Project Sites)

1. Please state your name and role in NZAID, and describe briefly what that role entails.

2. How would you describe NZAID's development philosophy?

3. How would you describe a successful project? An unsuccessful project?

4. Please describe your work here.

5. Please describe your interactions with community members and with community workers.

6. How often are you in touch with NZAID staff at Port Moresby and/or Wellington?

7. What does communication with the Port Moresby or Wellington office consist of?

8. Would you describe this project as involving community participation?

9. What role should community members play in their development? What role are they playing?

10.What is the benefit of participatory development?

11. How do you define sustainability?

12. How do you work to implement a sustainable project?

13. What are the conditions necessary for sustainable development?

14.What are some obstacles to this project's sustainability?

15. When and where does the sustainability dialogue start and end? (How far down the development chain does the sustainability dialogue travel?)

16. Does NZAID plan or provide for the scaling up of community projects?

17. Is this project aligned with government frameworks?

18. Is this project aligned with the community's socio-cultural frameworks?

19. How do community members interact with this project?

20. Do community members seem to be taking ownership of this project?

21. How are development plans transmitted and actioned?

22. Where do you situate yourself in the development process? 
1. I will begin with basic introductory questions as a warm-up. I will consult with project staff as to what questions are appropriate, i.e., name, family, number of children, etc.

2. What do you do here?

3. Do you like working here? Why?

4. Is it good that this project is here? Why?

5. In what ways does this project help your community?

6. What does the community think of this project?

7. How do you work with the other project workers?

8. Are you learning things here? What things?

9. Will your community be able to run this project once the NZAID contractors leave?

10. Do you and NZAID contractors talk about what will happen when they leave?

11. What is difficult about this project?

12. How do you feel when you come here each day to work?

13. How did you learn of this project?

14. How did this project come to be here?

15. How did you feel about this project at first? What about the community?

16. Did your community ask for this project? Is this project what your community wants?

17. How are development plans transmitted and actioned?

18. What must this project achieve in order for you to consider it a success? What would lead you to describe it as an unsuccessful project?

19. Please describe your relationship and interactions with community members.

20. What does communication with the Port Moresby or home office consist of?

21. How do you define sustainability?

22. How do you work to implement a sustainable project?

23. What are the conditions necessary for this project to be sustainable?

24 . What are some obstacles to this project's sustainability?

25. Is this project socially and culturally aligned with the community?

26. Do community service providers and community members seem to be taking ownership of this project?

27. What work remains to be done on this project? 
1. I will begin with basic introductory questions as a warm-up. I will consult with project staff as to what questions are appropriate, i.e., name, family, number of children, etc.

2. What do you do here?

3. Do you like working here? Why?

4. What does this project do for your community/how does it help your community?

5. Is it good that this project is here? Why?

6. What does the community think of this project?

7. How do you work with the other project workers?

8. Are you learning things here? What things?

9. Will your community be able to run this project once NZAID leaves?

10. Do you and NZAID workers talk about what will happen when this project ends?

11. What is difficult about this project?

12. What does your family/community think of your working here?

13. How do you feel when you come here each day to work?

14. How did you learn of this project?

15. How did this project come to be here?

16. How did you feel about this project at first? What about the community?

17. Did your community ask for this project? Is this project what your community wants? 


\section{Appendix E : Observation Guide}

The following list describes some of the things that I will be looking for in my observations at project sites in Papua New Guinea:

- How community members and project workers interact

- How community members interact with the project site itself

- How community members receive services

- The level of comfort and familiarity that community members display

- How many people come to the project site

- How the project site is physically situated in relation to the community itself

- How the project site is constructed and decorated

- How the project site looks in comparison to other community buildings

- Who works at the project sites (i.e. foreign workers vs. local workers)

- What community members do while they're at project sites (i.e. receive services, speak with project workers, hang around, bring their children, etc.)

- How community workers and project workers interact

- How community workers and community members interact

- What community workers' roles are at project sites

- Who uses project services

- What documents (posters, literature, etc.) if any are visible at project sites

- What is the general feel of the project site

Etc., etc.

Note: Prior to beginning observations I will consult with NZAID employees who are personally familiar with the project sites in question in order to determine the best way to carry out these observations in order to both be a non-disruptive presence at the site, and to carry out the most fruitful observations possible. 


\section{Appendix F : Paris Declaration on Aid Effectiveness}

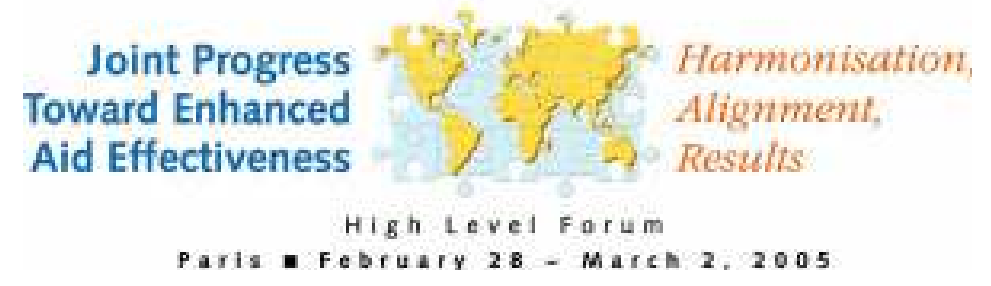

Paris Declaration On Aid EfFectiveness

\section{Ownership, Harmonisation, Alignment, Results and Mutual Accountability}

\section{Statement of Resolve}

1. We, Ministers of developed and developing countries responsible for promoting development and Heads of multilateral and bilateral development institutions, meeting in Paris on 2 March 2005, resolve to take far-reaching and monitorable actions to reform the ways we deliver and manage aid as we look ahead to the UN five-year review of the Millennium Declaration and the Millennium Development Goals (MDGs) later this year. As in Monterrey, we recognise that while the volumes of aid and other development resources must increase to achieve these goals, aid effectiveness must increase significantly as well to support partner country efforts to strengthen governance and improve development performance. This will be all the more important if existing and new bilateral and multilateral initiatives lead to significant further increases in aid.

2. At this High-Level Forum on Aid Effectiveness, we followed up on the Declaration adopted at the High-Level Forum on Harmonisation in Rome (February 2003) and the core principles put forward at the Marrakech Roundtable on Managing for Development Results (February 2004) because we believe they will increase the impact aid has in reducing poverty and inequality, increasing growth, building capacity and accelerating achievement of the MDGs.

\section{Scale up for more effective aid}

3. We reaffirm the commitments made at Rome to harmonise and align aid delivery. We are encouraged that many donors and partner countries are making aid effectiveness a high priority, and we reaffirm our commitment to accelerate progress in implementation, especially in the following areas:

i. Strengthening partner countries' national development strategies and associated operational frameworks (e.g., planning, budget, and performance assessment frameworks).

ii. Increasing alignment of aid with partner countries' priorities, systems and procedures and helping to strengthen their capacities.

iii. Enhancing donors' and partner countries' respective accountability to their citizens and parliaments for their development policies, strategies and performance.

iv. Eliminating duplication of efforts and rationalising donor activities to make them as costeffective as possible.

v. Reforming and simplifying donor policies and procedures to encourage collaborative behaviour and progressive alignment with partner countries' priorities, systems and procedures.

vi. Defining measures and standards of performance and accountability of partner country systems in public financial management, procurement, fiduciary safeguards and environmental assessments, in line with broadly accepted good practices and their quick and widespread application.

4. We commit ourselves to taking concrete and effective action to address the remaining challenges, including: 
i. Weaknesses in partner countries' institutional capacities to develop and implement resultsdriven national development strategies.

ii. Failure to provide more predictable and multi-year commitments on aid flows to committed partner countries.

iii. Insufficient delegation of authority to donors' field staff, and inadequate attention to incentives for effective development partnerships between donors and partner countries.

iv. Insufficient integration of global programmes and initiatives into partner countries' broader development agendas, including in critical areas such as HIV/AIDS.

v. Corruption and lack of transparency, which erode public support, impede effective resource mobilisation and allocation and divert resources away from activities that are vital for poverty reduction and sustainable economic development. Where corruption exists, it inhibits donors from relying on partner country systems.

5. We acknowledge that enhancing the effectiveness of aid is feasible and necessary across all aid modalities. In determining the most effective modalities of aid delivery, we will be guided by development strategies and priorities established by partner countries. Individually and collectively, we will choose and design appropriate and complementary modalities so as to maximise their combined effectiveness.

6. In following up the Declaration, we will intensify our efforts to provide and use development assistance, including the increased flows as promised at Monterrey, in ways that rationalise the often excessive fragmentation of donor activities at the country and sector levels.

\section{Adapt and apply to differing country situations}

7. Enhancing the effectiveness of aid is also necessary in challenging and complex situations, such as the tsunami disaster that struck countries of the Indian Ocean rim on December 26, 2004. In such situations, worldwide humanitarian and development assistance must be harmonised within the growth and poverty reduction agendas of partner countries. In fragile states, as we support statebuilding and delivery of basic services, we will ensure that the principles of harmonisation, alignment and managing for results are adapted to environments of weak governance and capacity. Overall, we will give increased attention to such complex situations as we work toward greater aid effectiveness.

\section{Specify indicators, timetable and targets}

8. We accept that the reforms suggested in this Declaration will require continued high-level political support, peer pressure and coordinated actions at the global, regional and country levels. We commit to accelerate the pace of change by implementing, in a spirit of mutual accountability, the Partnership Commitments presented in Section II and to measure progress against 12 specific indicators that we have agreed today and that are set out in Section III of this Declaration.

9. As a further spur to progress, we will set targets for the year 2010. These targets, which will involve action by both donors and partner countries, are designed to track and encourage progress at the global level among the countries and agencies that have agreed this Declaration. They are not intended to prejudge or substitute for any targets that individual partner countries may wish to set. We have agreed to day to set five preliminary targets against indicators as shown in Section III. We agree to review these preliminary targets before the UNGA Summit in September 2005, and to adopt targets against the remaining indicators as shown in Section III; and we ask the partnership of donors and partner countries hosted by the DAC to prepare for this urgently. Meanwhile, we welcome initiatives by partner countries and donors to establish their own targets for improved aid effectiveness within the framework of the agreed partnership commitments and indicators. For example a number of partner countries have presented action plans, and a large number of donors have announced important new commitments. We invite all participants who wish to provide information on such initiatives to submit it by 4 April 2005 for subsequent publication. 


\section{Monitor and evaluate implementation}

10. Because demonstrating real progress at country level is critical, under the leadership of the partner country we will periodically assess, qualitatively as well as quantitatively, our mutual progress at country level in implementing agreed commitments on aid effectiveness. In doing so, we will make use of appropriate country level mechanisms.

11. At the international level, we call on the partnership of donors and partner countries hosted by the DAC to broaden partner country participation and, by the end of 2005, to propose arrangements for the medium term monitoring of the commitments in this Declaration, including how frequently to assess progress. In the meantime, we ask the partnership to co-ordinate the international monitoring of the Indicators of Progress included in Section III; to refine targets as necessary; to provide appropriate guidance to establish baselines; and to enable consistent aggregation of information across a range of countries to be summed up in a periodic report. We will also use existing peer review mechanisms and regional reviews to support progress in this agenda. We will, in addition, explore independent cross-country monitoring and evaluation processes - which should be applied without imposing additional burdens on partners - to provide a more comprehensive understanding of how increased aid effectiveness contributes to meeting development objectives.

12. Consistent with the focus on implementation, we plan to meet again in 2008 in a developing country and conduct two rounds of monitoring before then to review progress in implementing this Declaration.

\section{Partnership Commitments}

13. Developed in a spirit of mutual accountability, these Partnership Commitments are based on the lessons of experience. We recognise that commitments need to be interpreted in the light of the specific situation of each partner country.

\section{OWNERSHIP}

\section{Partner countries exercise effective leadership over their development policies, and strategies and co-ordinate development actions}

\section{Partner countries commit to:}

- Exercise leadership in developing and implementing their national development strategies ${ }^{1}$ through broad consultative processes.

- Translate these national development strategies into prioritised results-oriented operational programmes as expressed in medium-term expenditure frameworks and annual budgets (Indicator 1).

- Take the lead in co-ordinating aid at all levels in conjunction with other development resources in dialogue with donors and encouraging the participation of civil society and the private sector.

15. Donors commit to:

- Respect partner country leadership and help strengthen their capacity to exercise it.

\footnotetext{
${ }^{1}$ The term 'national development strategies' includes poverty reduction and similar overarching strategies as well as sector and thematic strategies.
} 


\title{
Alignment
}

\section{Donors base their overall support on partner countries' national development strategies, institutions and procedures}

\section{Donors align with partners' strategies}

\author{
16. Donors commit to:
}

- Base their overall support - country strategies, policy dialogues and development cooperation programmes - on partners' national development strategies and periodic reviews of progress in implementing these strategies ${ }^{2}$ (Indicator 3).

- Draw conditions, whenever possible, from a partner's national development strategy or its annual review of progress in implementing this strategy. Other conditions would be included only when a sound justification exists and would be undertaken transparently and in close consultation with other donors and stakeholders.

- Link funding to a single framework of conditions and/or a manageable set of indicators derived from the national development strategy. This does not mean that all donors have identical conditions, but that each donor's conditions should be derived from a common streamlined framework aimed at achieving lasting results.

\section{Donors use strengthened country systems}

17. Using a country's own institutions and systems, where these provide assurance that aid will be used for agreed purposes, increases aid effectiveness by strengthening the partner country's sustainable capacity to develop, implement and account for its policies to its citizens and parliament. Country systems and procedures typically include, but are not restricted to, national arrangements and procedures for public financial management, accounting, auditing, procurement, results frameworks and monitoring.

18. Diagnostic reviews are an important — and growing — source of information to governments and donors on the state of country systems in partner countries. Partner countries and donors have a shared interest in being able to monitor progress over time in improving country systems. They are assisted by performance assessment frameworks, and an associated set of reform measures, that build on the information set out in diagnostic reviews and related analytical work.

19. Partner countries and donors jointly commit to:

- Work together to establish mutually agreed frameworks that provide reliable assessments of performance, transparency and accountability of country systems (Indicator 2).

- Integrate diagnostic reviews and performance assessment frameworks within country-led strategies for capacity development.

20. Partner countries commit to:

- Carry out diagnostic reviews that provide reliable assessments of country systems and procedures.

- On the basis of such diagnostic reviews, undertake reforms that may be necessary to ensure that national systems, institutions and procedures for managing aid and other development resources are effective, accountable and transparent.

- Undertake reforms, such as public management reform, that may be necessary to launch and fuel sustainable capacity development processes.

\footnotetext{
2 This includes, for example, the Annual Progress Review of the Poverty Reduction Strategies (APR).
} 
- Use country systems and procedures to the maximum extent possible. Where use of country systems is not feasible, establish additional safeguards and measures in ways that strengthen rather than undermine country systems and procedures (Indicator 5).

- Avoid, to the maximum extent possible, creating dedicated structures for day-to-day management and implementation of aid-financed projects and programmes (Indicator 6).

- Adopt harmonised performance assessment frameworks for country systems so as to avoid presenting partner countries with an excessive number of potentially conflicting targets.

\section{Partner countries strengthen development capacity with support from donors}

22. The capacity to plan, manage, implement, and account for results of policies and programmes, is critical for achieving development objectives from analysis and dialogue through implementation, monitoring and evaluation. Capacity development is the responsibility of partner countries with donors playing a support role. It needs not only to be based on sound technical analysis, but also to be responsive to the broader social, political and economic environment, including the need to strengthen human resources.

\section{Partner countries commit to:}

- Integrate specific capacity strengthening objectives in national development strategies and pursue their implementation through country-led capacity development strategies where needed.

24. Donors commit to:

- Align their analytic and financial support with partners' capacity development objectives and strategies, make effective use of existing capacities and harmonise support for capacity development accordingly (Indicator 4).

\section{Strengthen public financial management capacity}

25. Partner countries commit to:

- Intensify efforts to mobilise domestic resources, strengthen fiscal sustainability, and create an enabling environment for public and private investments.

- Publish timely, transparent and reliable reporting on budget execution.

- Take leadership of the public financial management reform process.

26. Donors commit to:

- Provide reliable indicative commitments of aid over a multi-year framework and disburse aid in a timely and predictable fashion according to agreed schedules (Indicator 7).

- Rely to the maximum extent possible on transparent partner government budget and accounting mechanisms (Indicator 5).

27. Partner countries and donors jointly commit to:

- Implement harmonised diagnostic reviews and performance assessment frameworks in public financial management. 


\section{Strengthen national procurement systems}

28. Partner countries and donors jointly commit to:

- Use mutually agreed standards and processes ${ }^{3}$ to carry out diagnostics, develop sustainable reforms and monitor implementation.

- Commit sufficient resources to support and sustain medium- and long-term procurement reforms and capacity development.

- Share feedback at the country level on recommended approaches so they can be improved over time.

29. Partner countries commit to take leadership and implement the procurement reform process.

30. Donors commit to:

- Progressively rely on partner country systems for procurement when the country has implemented mutually agreed standards and processes (Indicator 5).

- Adopt harmonised approaches when national systems do not meet mutually agreed levels of performance or donors do not use them.

\section{Untie aid: getting better value for money}

31. Untying aid generally increases aid effectiveness by reducing transaction costs for partner countries and improving country ownership and alignment. DAC Donors will continue to make progress on untying as encouraged by the 2001 DAC Recommendation on Untying Official Development Assistance to the Least Developed Countries (Indicator 8).

\section{HARMONISATION}

\section{Donors" actions are more harmonised, transparent and collectively effective}

\section{Donors implement common arrangements and simplify procedures}

32. Donors commit to:

- Implement the donor action plans that they have developed as part of the follow-up to the Rome High-Level Forum.

- Implement, where feasible, common arrangements at country level for planning, funding (e.g. joint financial arrangements), disbursement, monitoring, evaluating and reporting to government on donor activities and aid flows. Increased use of programme-based aid modalities can contribute to this effort (Indicator 9).

- Work together to reduce the number of separate, duplicative, missions to the field and diagnostic reviews (Indicator 10) and promote joint training to share lessons learned and build a community of practice.

\section{Complementarity: more effective division of labour}

33. Excessive fragmentation of aid at global, country or sector level impairs aid effectiveness. A pragmatic approach to the division of labour and burden sharing increases complementarity and can reduce transaction costs.

\footnotetext{
${ }^{3}$ Such as developed by the joint OECD/DAC - World Bank Round Table on Strengthening Procurement Capacities in Developing Countries.
} 
34. Partner countries commit to:

- Provide clear views on donors' comparative advantage and on how to achieve donor complementarity at country or sector level.

35. Donors commit to:

- Make full use of their respective comparative advantage at sector or country level by delegating, where appropriate, authority to lead donors for the execution of programmes, activities and tasks.

- Work together to harmonise separate procedures.

\section{Incentives for collaborative behaviour}

36. Donors and partner countries jointly commit to:

- Reform procedures and strengthen incentives —including for recruitment, appraisal and training - for management and staff to work towards harmonisation, alignment and results.

\section{Delivering effective aid in fragile states ${ }^{4}$}

37. The long-term vision for international engagement in fragile states is to build legitimate, effective and resilient state and other country institutions. While the guiding principles of effective aid apply equally to fragile states, they need to be adapted to environments of weak ownership and capacity and to immediate needs for basic service delivery.

\section{Partner countries commit to:}

- Make progress towards building institutions and establishing governance structures that deliver effective governance, public safety, security, and equitable access to basic social services for their citizens.

- Engage in dialogue with donors on developing simple planning tools, such as the transitional results matrix, where national development strategies are not yet in place.

- Encourage broad participation of a range of national actors in setting development priorities.

39. Donors commit to:

- Harmonise their activities. Harmonisation is all the more crucial in the absence of strong government leadership. It should focus on upstream analysis; joint assessments, joint strategies, co-ordination of political engagement; and practical initiatives such as the establishment of joint donor offices.

- Align to the maximum extent possible behind central government-led strategies or, if that is not possible, donors should make maximum use of country, regional, sector or nongovernment systems.

- Avoid activities that undermine national institution building, such as bypassing national budget processes or setting high salaries for local staff.

- Use an appropriate mix of aid instruments, including support for recurrent financing, particularly for countries in promising but high-risk transitions.

\footnotetext{
$\overline{4}$ The following section draws on the draft Principles for Good International Engagement in Fragile States, which emerged from the Senior Level Forum on Development Effectiveness in Fragile States (London, January 2005).
} 


\section{Promoting a harmonised approach to environmental assessments}

40. Donors have achieved considerable progress in harmonisation around environmental impact assessment (EIA) including relevant health and social issues at the project level. This progress needs to be deepened, including on addressing implications of global environmental issues such as climate change, desertification and loss of biodiversity.

41. Donors and partner countries jointly commit to:

- Strengthen the application of EIAs and deepen common procedures for projects, including consultations with stakeholders; and develop and apply common approaches for "strategic environmental assessment" at the sector and national levels.

- Continue to develop the specialised technical and policy capacity necessary for environmental analysis and for enforcement of legislation.

42. Similar harmonisation efforts are also needed on other cross-cutting issues, such as gender equality and other thematic issues, including those financed by dedicated funds.

\section{MANAGING FOR RESULTS Managing resources and improving decision-making for results}

43. Managing for results means managing and implementing aid in a way that focuses on the desired results and uses information to improve decision-making.

44. Partner countries commit to:

- Strengthen the linkages between national development strategies and annual and multiannual budget processes.

- Endeavour to establish results-oriented reporting and assessment frameworks that monitor progress against key dimensions of the national and sector development strategies and that these frameworks should track a manageable number of indicators for which data are costeffectively available (Indicator 11).

45. Donors commit to:

- Link country programming and resources to results and align them with effective partner country performance assessment frameworks, refraining from requesting the introduction of performance indicators that are not consistent with partners' national development strategies.

- Work with partner countries to rely, as far as possible, on partner countries' results-oriented reporting and monitoring frameworks.

- Harmonise their monitoring and reporting requirements, and, until they can rely more extensively on partner countries' statistical, monitoring and evaluation systems, with partner countries to the maximum extent possible on joint formats for periodic reporting.

46. Partner countries and donors jointly commit to:

- Work together in a participatory approach to strengthen country capacities and demand for results based management. 


\section{MUTUAL ACCOUNTABILITY \\ Donors and partners are accountable for development results}

47. A major priority for partner countries and donors is to enhance mutual accountability and transparency in the use of development resources. This also helps strengthen public support for national policies and development assistance.

\section{Partner countries commit to:}

- Strengthen as appropriate the parliamentary role in national development strategies and/or budgets.

- Reinforce participatory approaches by systematically involving a broad range of development partners when formulating and assessing progress in implementing national development strategies.

49. Donors commit to:

- Provide timely, transparent and comprehensive information on aid flows so as to enable partner authorities to present comprehensive budget reports to their legislatures and citizens.

50. Partner countries and donors commit to:

- Jointly assess through existing and increasingly objective country level mechanisms mutual progress in implementing agreed commitments on aid effectiveness, including the Partnership Commitments. (Indicator 12). 


\begin{tabular}{|c|c|c|}
\hline \multicolumn{2}{|r|}{ OWNERSHIP } & $\begin{array}{l}\text { TARGETS FOR } \\
2010\end{array}$ \\
\hline 1 & $\begin{array}{l}\text { Partners have operational development strategies - Number of } \\
\text { countries with national development strategies (including PRSs) that have } \\
\text { clear strategic priorities linked to a medium-term expenditure framework } \\
\text { and reflected in annual budgets. }\end{array}$ & $\begin{array}{l}\text { At least } \mathbf{7 5 \% *} \text { of partner } \\
\text { countries }\end{array}$ \\
\hline \multicolumn{2}{|r|}{ ALIGNMENT } & $\begin{array}{l}\text { TARGETS FOR } \\
2010\end{array}$ \\
\hline 2 & $\begin{array}{l}\text { Reliable country systems - Number of partner countries that have } \\
\text { procurement and public financial management systems that either (a) } \\
\text { adhere to broadly accepted good practices or (b) have a reform } \\
\text { programme in place to achieve these. }\end{array}$ & $\begin{array}{l}\text { Target for improvement to } \\
\text { be set by September } 2005\end{array}$ \\
\hline 3 & $\begin{array}{l}\text { Aid flows are aligned on national priorities - Percent of aid flows to the } \\
\text { government sector that is reported on partners' national budgets. }\end{array}$ & $\begin{array}{l}\mathbf{8 5 \% *} \text { of aid flows } \\
\text { reported on budgets }\end{array}$ \\
\hline 4 & $\begin{array}{l}\text { Strengthen capacity by co-ordinated support - Percent of donor } \\
\text { capacity-development support provided through co-ordinated programmes } \\
\text { consistent with partners' national development strategies. }\end{array}$ & $\begin{array}{l}\text { Target for improvement to } \\
\text { be set by September } 2005\end{array}$ \\
\hline 5 & $\begin{array}{l}\text { Use of country systems - Percent of donors and of aid flows that use } \\
\text { partner country procurement and/or public financial management systems } \\
\text { in partner countries, which either (a) adhere to broadly accepted good } \\
\text { practices or (b) have a reform programme in place to achieve these. }\end{array}$ & $\begin{array}{l}\text { Target for improvement to } \\
\text { be set by September } 2005\end{array}$ \\
\hline 6 & $\begin{array}{l}\text { Strengthen capacity by avoiding parallel implementation structures - } \\
\text { Number of parallel project implementation units (PIUs) per country. }\end{array}$ & $\begin{array}{l}\text { Target for improvement to } \\
\text { be set by September } 2005\end{array}$ \\
\hline 7 & $\begin{array}{l}\text { Aid is more predictable - Percent of aid disbursements released } \\
\text { according to agreed schedules in annual or multi-year frameworks. }\end{array}$ & $\begin{array}{l}\text { At least } 75 \% * \text { of such aid } \\
\text { released on schedule }\end{array}$ \\
\hline 8 & Aid is untied - Percent of bilateral aid that is untied. & Continued progress \\
\hline \multicolumn{2}{|r|}{ HARMONISATION } & $\begin{array}{l}\text { TARGETS FOR } \\
2010 \\
\end{array}$ \\
\hline 9 & $\begin{array}{l}\text { Use of common arrangements or procedures - Percent of aid provided } \\
\text { as programme-based approaches }\end{array}$ & At least $25 \% *$ \\
\hline 10 & $\begin{array}{l}\text { Encourage shared analysis - Percent of (a) field missions and/or (b) } \\
\text { country analytic work, including diagnostic reviews that are joint. }\end{array}$ & $\begin{array}{l}\text { Target for improvement to } \\
\text { be set by September } 2005\end{array}$ \\
\hline \multicolumn{2}{|r|}{ MANAGING FOR RESULTS } & $\begin{array}{l}\text { TARGET FOR } \\
2010 \\
\end{array}$ \\
\hline 11 & $\begin{array}{l}\text { Results-oriented frameworks - Number of countries with transparent } \\
\text { and monitorable performance assessment frameworks to assess progress } \\
\text { against (a) the national development strategies and (b) sector } \\
\text { programmes. }\end{array}$ & $75 \% *$ of partner countries \\
\hline \multicolumn{2}{|r|}{ MUTUAL ACCOUNTABILITY } & $\begin{array}{l}\text { TARGET FOR } \\
2010\end{array}$ \\
\hline 12 & $\begin{array}{l}\text { Mutual accountability - Number of partner countries that undertake } \\
\text { mutual assessments of progress in implementing agreed commitments on } \\
\text { aid effectiveness including those in this Declaration. }\end{array}$ & $\begin{array}{l}\text { Target for improvement to } \\
\text { be set by September } 2005\end{array}$ \\
\hline
\end{tabular}

* These figures will be confirmed or amended by September 2005.

${ }_{5}^{5}$ See methodological notes for a definition of programme based approaches in Appendix 


\section{Appendix A: Methodological Notes on the Indicators}

The Partnership Objectives provides a framework in which to make operational the responsibilities and accountabilities that are framed in the Paris Declaration on Aid Effectiveness. This framework draws selectively from the Partnership Commitments presented in Section II of this Declaration.

Purpose - The Partnership Objectives provide a framework in which to make operational the responsibilities and accountabilities that are framed in the Paris Declaration on Aid Effectiveness. They measure principally collective behaviour at the country level.

Country level vs. global level - The indicators are to be measured at the country level in close collaboration between partner countries and donors. Values of country level indicators can then be statistically aggregated at the regional or global level. This global aggregation would be done both for the country panel mentioned below, for purposes of statistical comparability, and more broadly for all partner countries for which relevant data are available.

Donor / partner performance - The indicators of progress also provide a benchmark against which individual donor agencies or partner countries can measure their performance at the country, regional, or global level. In measuring individual donor performance, the indicators should be applied with flexibility in the recognition that donors have different institutional mandates.

Objectives - The objectives are set at the global level. Progress against these objectives is to be measured by statistically aggregating indicators measured at the country level. In addition to global objectives, partner countries and donors in a given country might agree on country-level objectives.

Baseline - A baseline will be established for 2005 in a panel of self-selected countries. The DAC Working Party on Aid Effectiveness is asked to establish this panel.

Definitions and criteria - The DAC Working Party on Aid Effectiveness is asked to provide specific guidance on definitions, scope of application, criteria and methodologies to assure that results can be aggregated across countries and across time.

Note on Indicator 9 - Programme based approaches are defined in Volume 2 of Harmonising Donor Practices for Effective Aid Delivery (OECD, 2005) in Box 3.1 as a way of engaging in development cooperation based on the principles of co-ordinated support for a locally owned programme of development, such as a national development strategy, a sector programme, a thematic programme or a programme of a specific organisation. Programme based approaches share the following features: (a) leadership by the host country or organisation; (b) a single comprehensive programme and budget framework; (c) a formalised process for donor co-ordination and harmonisation of donor procedures for reporting, budgeting, financial management and procurement; (d) Efforts to increase the use of local systems for programme design and implementation, financial management, monitoring and evaluation. For the purpose of indicator 9 performance will be measured separately across the aid modalities that contribute to programme-based approaches. 


\section{PARTICIPATING COUNTRIES}

Albania
Australia
Austria
Bangladesh
Belgium
Benin
Bolivia
Botswana
Brazil
Burkina Faso
Burundi
Cambodia
Cameroon
Canada
China
Congo D.R.
Czech Republic
Denmark
Dominican Republic
Egypt
Ethiopia
European Commission
Fiji
Finland
France
Gambia, The
Germany
Ghana
Greece
Guatemala
Guinea
Honduras
Iceland
Indonesia
Ireland
Italy
Jamaica
Japan
Jordan
Kenya
Korea
Kuwait
Kyrgyz Republic
Lao PDR
Luxembourg
Madagascar

\author{
Malawi \\ Malaysia \\ Mali \\ Mauritania \\ Mexico \\ Mongolia \\ Morocco \\ Mozambique \\ Nepal \\ Netherlands \\ New Zealand \\ Nicaragua \\ Niger \\ Norway \\ Pakistan \\ Papua New Guinea \\ Philippines \\ Poland \\ Portugal \\ Romania \\ Russian Federation \\ Rwanda \\ Saudi Arabia \\ Senegal \\ Serbia And Montenegro \\ Slovak Republic \\ Solomon Islands \\ South Africa \\ Spain \\ Sri Lanka \\ Sweden \\ Switzerland \\ Tajikistan \\ Tanzania \\ Thailand \\ Timor-Leste \\ Tunisia \\ Turkey \\ Uganda \\ United Kingdom \\ United States of America \\ Vanuatu \\ Vietnam \\ Yemen \\ Zambia
}




\section{PARTICIPATING ORGANIZATIONS}

African Development Bank

Arab Bank for Economic Development in Africa

Asian Development Bank

Commonwealth Secretariat

Consultative Group to Assist the Poorest

Council of Europe Development Bank (CEB)

Economic Commission For Africa (ECA)

Education For All Fast Track Initiative

European Bank for Reconstruction and Development

European Investment Bank

Global Fund to Fight Aids, Tuberculosis and Malaria

G24

Inter-American Development Bank

International Fund For Agricultural Development (IFAD)

International Monetary Fund

International Organization of the Francophonie

Islamic Development Bank

Millennium Campaign

New Partnership for Africa's Development

Nordic Development Fund

Organisation for Economic Co-operation and Development (OECD)

Organisation of Eastern Caribbean States (OECS)

OPEC Fund For International Development

Pacific Islands Forum Secretariat

United Nations Development Group (UNDG)

World Bank 


\section{Works Cited}

About NZAID. (n.d.). In NZAID. Retrieved 18 January 2010 from http://nzaid.govt.nz/about/

Ainsworth, Susan and Hardy, Cynthia (2004). Discourse and identities. In Grant, David, Hardy, Cynthia, Oswick, Cliff and Putnam, Linda (Eds.), The SAGE handbook of organizational discourse (p153-73). London: SAGE Publications Ltd.

Asian Development Bank. Paris Declaration on Aid Effectiveness (2005).

Retrieved 10 April 2010 from

http://www.adb.org/media/articles/2005/7033_international_community_aid/ paris_declaration.pdf

Barley, Stephen R. and Tolbert, Pamela S. (1997). Institutionalization and structuration: Studying the links between action and institution. Organization Studies, 18(1), p93-117.

Bebbington, Anthony J. and Farrington, John (1992). NGO-government interaction in agricultural technology development. In Edwards, Michael and Hulme, David (Eds.), Making a difference: NGOs and development in a changing world (p49-59). Eastbourne, UK: Earthscan Publications Limited.

Bebbington, Anthony J. (1997). Reinventing NGOs and rethinking alternatives in the Andes. Annals of the American Academy of Political and Social Science, 554, p117-35.

Berner, Erhard and Phillips, Benedict (2005). Left to their own devices? Community self-help between alternative development and neo-liberalism. Community Development Journal, 40(1), p17-29.

Brett, E.A. (2003). Participation and accountability in development management. The Journal of Development Studies, 40(2), p1-29. 
Briggs, John (2005). The use of indigenous knowledge in development:

Problems and challenges. Progress in Development Studies, 5(2), p99-114.

Briggs, John (2008). Indigenous knowledge and development. In Desai, Vandana and Potter, Robert B. (Eds.), The companion to development studies ( $\left.2^{\text {nd }} E d.\right)(p 107-11)$. London: Hodder Education.

Brinkerhoff, Jennifer M. (2002). Partnership for international development:

Rhetoric or results? London: Lynne Rienner Publishers, Inc.

Broadfoot, Kirsten, Deetz, Stanley and Anderson, Donald (2004). Multi-levelled, multi-method approaches in organizational discourse. In Grant, David, Hardy, Cynthia, Oswick, Cliff and Putnam, Linda (Eds.), The SAGE handbook of organizational discourse(p193-211). London: Sage Publications Ltd.

Burman, Erica and Parker, lan (Eds.) (1993). Discourse analytic research: repertoires and readings of texts in action. New York: Routledge.

Calás, Marta B. and Smircich, Linda (2003). At home from Mars to Somalia: Recounting organization studies. In Tsoukas, Haridimos and Knudsen, Christian (Eds.), The Oxford handbook of organization theory (p596-606). Auckland: Oxford University Press.

Clark, John (1992). Policy influence, lobbying and advocacy. In Edwards, Michael and Hulme, David (Eds.), Making a difference: NGOs and development in a changing world (p191-202). Eastbourne, UK: Earthscan Publications Limited.

Clegg, Stewart (2003). Managing organization futures in a changing world of power/knowledge. In Tsoukas, Haridimos and Knudsen, Christian (Eds.), The Oxford handbook of organization theory (p536-67). Auckland: Oxford University Press. 
Clemens, Elisabeth S. and Cook, James M. (1999). Politics and institutionalism: Explaining durability and change. Annual Review of Sociology, 25, p44166.

Cohen, Ira J., 2004. Structuration. In Encyclopedia of social theory. SAGE Publications. Retrieved April 18 2009, from http://www.sageereference.com/socialtheory/Article_n301.html.

Collier, Paul (2007). The bottom billion. New York: Oxford University Press.

Collier, Paul and Dollar, David (2004). Development effectiveness: what have we learnt? The Economic Journal, 114(496), p244-271.

Constantino-David, Karina (1992). The Philippine experience in scaling-up. In Edwards, Michael and Hulme, David (Eds.), Making a difference: NGOs and development in a changing world (p137-47). Eastbourne, UK:

Earthscan Publications Limited.

Cornwall, Andrea (2002). Making spaces, changing places: Situating participation in development. IDS Working Paper 170. Brighton: Institute of Development Studies.

Corruption perceptions index 2009. (2009). In Transparency International. Retrieved 12 December 2009 from http://www.transparency.org/policy_research/surveys_indices/cpi/2009/cpi_ 2009_table

Davis et al.. (2005). Creating a common framework. In Davis, Gerald F., McAdam, Doug, Scott, W. Richard and Zald, Mayer N. (Eds.). Social movements and organization theory (p1-3). Melbourne: Cambridge University Press.

DiMaggio, Paul J., and Powell, Walter W. (1983). The iron cage revisited: Institutional isomorphism and collective rationality in organizational fields. American Sociological Review, 48(2), p147-60. 
DiMaggio, Paul J. and Powell, Walter W. (1991). Introduction. In Powell, Walter W. and DiMaggio, Paul J. (Eds.) (1991), The new institutionalism in organizational analysis (p232-263). Chicago: The University of Chicago Press.

Easterly, William (2006). The white man's burden. New York: The Penguin Press.

Edwards, Michael and Hulme, David (1992). Making a difference? Concluding comments. In Edwards, Michael and Hulme, David (Eds.), Making a difference: NGOs and development in a changing world (211-16). Eastbourne, UK: Earthscan Publications Limited.

Edwards, Michael (2000). Future positive: International cooperation in the $21^{\text {st }}$ century. London: Earthscan Publications, Ltd.

Fairclough, Norman (1995). Critical discourse analysis: Papers in the critical study of language. London: Longman.

FAQs: About NZAID. (n.d.). In NZAID. Retrieved 16 December 2009 from http://nzaid.govt.nz/faqs/about-nzaid.html

FAQs: Recent changes to NZAID. (n.d.). In NZAID. Retrieved 10 January 2010 from http://www.nzaid.govt.nz/faqs/recent-changes-to-nzaid.html

Fernández-Alles, Maria de la luz and Valle-Cabrera, Ramón (2006). Reconciling institutional theory with organizational theories. Journal of Organizational Change Management, 19(4), p503-17.

Flannery, Tim (1998). Throwim way leg. Melbourne: Text Publishing.

Glossary. (n.d.). In NZAID. Retrieved 18 February 2010 from http://www.nzaid.govt.nz/library/glossary.html\#s 
Glossary of Statistical Terms. (March 2003). In Organization for economic cooperation and development. Retrieved 21 January 2010 from http://stats.oecd.org/glossary/

Goal 1: Eradicate extreme poverty \& hunger. (2008). In United Nations Millennium Development Goals. Retrieved 22 February 2010 from http://www.un.org/millenniumgoals/poverty.shtml

Goldsmith, Arthur A. (1992). Institutions and planned socioeconomic change: Four approaches. Public Administration Review, 52(6), p582-7.

Grant, David, Hardy, Cynthia, Oswick, Cliff and Putnam, Linda (2004). Introduction: Organizational discourse: Exploring the field. In Grant, David, Hardy, Cynthia, Oswick, Cliff and Putnam, Linda (Eds.). The SAGE handbook of organizational discourse. London: SAGE Publications Ltd.

Green Jr., Sandy Edward, Li, Yuan and Nohria, Nitin (2009). Suspending in selfspun webs of significance: A rhetorical model of institutionalization and institutionally embedded agency. Academy of Management Journal, 52(1), p11-36.

Grindle, Merilee (2000). In Quest of the political: The political economy of development policymaking, p345-80. In Meier, G.M. and Stiglitz, J.E. (Eds.). Frontiers of development economics: The future in perspective. Washington, DC: The World Bank.

Groves, Leslie and Hinton, Rachel (Eds.)(2004). Inclusive aid. London: Earthscan.

Hardy, Cynthia and Phillips, Nelson (1999). No joking matter: Discursive struggle in the Canadian refugee system. Organization Studies, 20(1), p1-24.

Hardy, Cynthia and Phillips, Nelson (2004). Discourse and power. In Grant, David, Hardy, Cynthia, Oswick, Cliff and Putnam, Linda (Eds.), The SAGE 
handbook of organizational discourse (p299-316). London: SAGE Publications Ltd.

Harriss, John (2005). Great promise, hubris and recovery: A participant's history of development studies. In Kothari, Uma (Ed.), A radical history of development studies (p17-46). London: Zed Books Ltd.

Herfkens, Eveline and Bains, Mandeep (2007). Reaching our development goals: Why does aid effectiveness matter? In OECD. Retrieved 20 December 2009 from http://www.oecd.org/dataoecd/43/31/40987004.pdf

Holstein, James A. and Gubrium, Jaber F. (2004). The active interview. In Silverman, David (Ed.), Qualitative research (2 ${ }^{\text {nd }}$ Ed.) (p140-161). London: SAGE Publications Ltd.

Human Development Report 2009: Papua New Guinea. (2009). In Human Development Reports: United Nations Development Programme. Retrieved 16 December 2009 from http://hdrstats.undp.org/en/countries/country_fact_sheets/cty_fs_PNG.html

Institution. (1989). Oxford English dictionary online. Oxford University Press. Retrieved 21 February 2010 from http://dictionary.oed.com.helicon.vuw.ac.nz/cgi/entry/50118314?single=1\&q uery type $=$ word\&queryword=institution\&first $=1 \& \max$ to show $=10$

Jennings, P. Devereaux and Zandbergen, Paul A. (1995). Ecologically sustainable organizations: An institutional approach. Academy of Management: The Academy of Management Review, 20(4), p1015-52.

Kavieng declaration on aid effectiveness. (15 February 2008). Retrieved 1 September 2009 from http://old.developmentgateway.org/download/257013/KaviengDeclarationon AidEffectiveness.pdf 
Klinmahorn, Somthavil and Ireland, Kevin (1992). NGO-government collaboration in Bangkok. In Edwards, Michael and Hulme, David (Eds.), Making a difference: NGOs and development in a changing world (p60-9). Eastbourne, UK: Earthscan Publications Limited.

Korten, David C. (1990). Getting to the $21^{\text {st }}$ century: Voluntary action and the global agenda. West Hartford, CT: Kumarian Press, Inc.

Kothari, Uma (2005). From colonial administration to development studies. In Kothari, Uma, A radical history of development studies (p47-66). London: Zed Books Ltd.

Kramer, Ralph M. (2000). A third sector in the third millennium? Voluntas: International Journal of Voluntary and Nonprofit Organizations, 11(1), p1-23.

Lawrence, Thomas B. (1999). Institutional strategy. Journal of Management, 25(2), p161-88.

Lepenies, Philipp (2008). New institutional economics and development. In Desai, Vandana and Potter, Robert B. (Eds.), The companion to development studies (2 ${ }^{\text {nd }}$ Ed.)(p20-24). London: Hodder Education.

Lounsbury, Michael (2003). The problem of order revisited: Towards a more critical institutional perspective. In Westwood, Robert and Clegg, Stewart (Eds.), Debating Organization: Point-Counterpoint in Organization Studies (p210-19). Melbourne: Blackwell Publishing Limited.

Mackie, James (1992). Multiplying micro-level inputs to government structures. In Edwards, Michael and Hulme, David (Eds.), Making a difference: NGOs and development in a changing world (p70-77). Eastbourne, UK: Earthscan Publications Limited.

Maguire, Steve and Hardy, Cynthia (2009). Discourse and deinstitutionalization: The decline of DDT. Academy of Management Journal, 52(1), p148-78. 
McAdam, Doug and Scott, W. Richard (2005). Organizations and movements. In Davis, Gerald F., McAdam, Doug, Scott, W. Richard and Zald, Mayer N. (Eds.) (2005). Social movements and organization theory (p4-40). Melbourne: Cambridge University Press.

McKinnon, Rowan (2008). Lonely Planet Papua New Guinea \& Solomon Islands. Footscray, Victoria: Lonely Planet.

Mdee, Anna (2008). Towards a dynamic structure-agency framework: Understanding patterns of participation in community-driven development in Uchira, Tanzania. International Development Planning Review, 30(4), p399-420.

Modernity. (December 2009). In Oxford English dictionary online. Oxford University Press. Retrieved 18 December 2009 from http://dictionary.oed.com.helicon.vuw.ac.nz/cgi/entry/00313111?single=1\&q uery_type=word\&queryword=modernity\&first=1\&max_to_show $=10$

Mumby, Dennis K (2004). Discourse, power and ideology: Unpacking the critical approach. In Grant, David, Hardy, Cynthia, Oswick, Cliff and Putnam, Linda (Eds.), The SAGE handbook of organizational discourse (p237-58). London: SAGE Publications Ltd.

Nederveen Pieterse, Jan (2000). After post-development. Third World Quarterly, 21(2), p175-91.

Newman, Lenore (2007). The virtuous cycle: Incremental changes and a process-based sustainable development. Sustainable Development, 15, p267-74.

Newson, Caroline (n.d.). NZAID. NZAID making a difference in Papua New Guinea. In NZAID. Retrieved 16 December 2009 from http://nzaid.govt.nz/library/docs/factsheet-png.pdf 
North, Douglass C. (1990). Institutions, institutional change and economic performance. Melbourne: Cambridge University Press.

NZAID. (2006). NZAID activity design guideline. In NZAID. Retrieved 14 January 2010 from http://nzaidtools.nzaid.govt.nz/sites/default/files/1152926.02.pdf

NZAID. (July 2008). New Zealand Agency for International Development \& Government of Papua New Guinea Country Programme Strategy 20082018. Retrieved from http://www.nzaid.govt.nz/library/docs/nzaid-pngstrategy-2008-2018.pdf

NZAID review under fire. (12 April 2009). In Samoa Observer. Retrieved 26 March 2010 from http://samoaobserver.ws/index.php?view=article\&id=6786\%3Anzaid-reviewunder\&option=com_content\&Itemid=61

O'Leary, Zina (2004). The essential guide to doing research. London: SAGE Publications Ltd.

Oakley, Peter and Marsden, David (1984). Approaches to participation in rural development. Geneva: International Labour Office.

OECD. $(2005,2008)$. Paris declaration on aid effectiveness and Accra agenda for action. Retrieved 22 September 2009 from http://www.oecd.org/dataoecd/11/41/34428351.pdf

Organisational structure. (n.d.). In NZAID. Retrieved 10 January 2010 from http://nzaid.govt.nz/about/our-organisation.html

Ovaska, Tomi (2003). The failure of development aid. Cato Journal, 23(2), p175-188. 
Papua New Guinea. (2009). In CIA world factbook. Retrieved 1 October 2009 from https://www.cia.gov/library/publications/the-worldfactbook/geos/pp.html

Papua New Guinea. (2010). In Encyclopædia britannica online (Academic ed.). Retrieved 11 January 2010 from http://www.search.eb.com.helicon.vuw.ac.nz/eb/article-9117358

Parnwell, Michael J.G (2008). Agropolitan and bottom-up development. In Desai, Vandana and Potter, Robert B. (Eds.), The companion to development studies (2 ${ }^{\text {nd }}$ Ed.) (p111-15). London: Hodder Education.

Peet, Richard with Hartwick, Elaine (1999). Theories of development. New York: The Guildford Press.

Phillips, Louise and Jørgensen, Marianne W. (2002). Discourse analysis as theory and method. London: SAGE Publications Ltd.

Phillips, Nelson (2003). Discourse or institution? Institutional theory and the challenge of critical discourse analysis. In Westwood, Robert and Clegg, Stewart (Eds.), Debating organization: Point-counterpoint in organization studies (p220-31). Melbourne: Blackwell Publishing Limited.

Phillips, Nelson, Lawrence, Thomas B. and Hardy, Cynthia (2004). Discourse and institutions. Academy of Management Review, 29(4), p635-52.

Phillips, Nelson, Sewell, Graham and Jaynes, Steve (2008). Applying critical discourse analysis in strategic management research. Organizational Research Methods, 11(4), p770-89.

Potter, Jonathan (2004). Discourse analysis as a way of analysing naturally occurring Talk. In Silverman, David (Ed.), Qualitative research (p200-221). London: SAGE Publications Ltd. 
Prichard, Craig, Jones, Deborah and Stablein, Ralph (2004). Doing research in organizational discourse: The importance of researcher context. In Grant, David, Hardy, Cynthia, Oswick, Cliff and Putnam, Linda (Eds.), The SAGE handbook of organizational discourse (p213-36). London: SAGE Publications Ltd.

Rao, Hayagreeva, Morrill, Calvin and Zald, Mayer N. (2000). Power plays: How social movements and collective action create new organizational forms. Research in Organizational Behaviour, 22, p237-281.

Reed, Michael (2003). The agency/structure dilemma in organization theory: Open doors and brick walls. In Tsoukas, Haridimos and Knudsen, Christian (Eds.), The Oxford handbook of organization theory (p289-309). Auckland: Oxford University Press.

Robb, Caroline (2004). Changing power relations in the history of aid. In Groves, Leslie and Hinton, Rachel (Eds.). Inclusive aid (p21-41). London: Earthscan.

Robles-Morua, Agustin, Mayer, Alex S. and Durfee, Mary H. (2009). Community partnered projects: A case study of collaborative effort to improve sanitation in a marginalized community in northwest Mexico. Environment Development Sustainability, 11(1), p197-213.

Sachs, Jeffrey D. (2005). The end of poverty. New York: The Penguin Press.

Schneiberg, Marc and Soule, Sarah A. (2005). Institutionalization as a contested, multilevel process. In Davis, Gerald F., McAdam, Doug, Scott, W. Richard and Zald, Mayer N. (Eds.). Social movements and organization theory (p122-60). Melbourne: Cambridge University Press.

Scott, W. Richard (1991). Unpacking institutional arguments. In Powell, Walter W. and DiMaggio, Paul J. (Eds.) (1991), The new institutionalism in organizational analysis (p164-182). Chicago: The University of Chicago Press. 
Scott, W. Richard (September 17-18, 1999). A call for two-way traffic: Improving the connection between social movement and organization/institutional theory. Presented at Zaldfest, University of Michigan.

Scott, W. Richard (2001). Institutions and organizations ( ${ }^{\text {nd }}$ Ed.). London: SAGE Publications, Inc.

Scott, W. Richard (2004). Institutional theory. Encyclopedia of social theory. SAGE Publications. Retrieved 6 April 2009 from http://www.sageereference.com/socialtheory/Article_n155.html

Scott, W. Richard (2008). Approaching adulthood: The maturing of institutional theory. Theory and Society, 5(37), p427-442.

Stop McCully's cull of NZAID. (9 March 2009). In The Standard. Retrieved 1 February 2010 from http://www.thestandard.org.nz/stop-mccullys-cull-ofnzaid/

Suddaby, Roy (2010). Challenges for institutional theory. Journal of Management Inquiry, 19(1), p14-20.

The World Bank Group (2001). What is sustainable development. Retrieved 20 January 2010 from http://www.worldbank.org/depweb/english/sd.html

The World Bank Group (2010). Participation and civil engagement. Retrieved 12 April 2010 from http://web.worldbank.org/WBSITE/EXTERNAL/TOPICS/EXTSOCIALDEVE LOPMENT/EXTPCENG/0,,menuPK:410312 pagePK:149018 piPK:149093 theSitePK:410306,00.html

Tolbert, Pamela S. and Zucker, Lynne G. (1996). The institutionalization of institutional theory. In Clegg, Stewart R., Hardy, Cynthia and Nord, Walter R. (Eds.), The SAGE handbook of organization studies (p175-90). London: SAGE Publications Ltd. 
Trainer, Ted (2001). Development: conventional versus critical perspectives. Humanomics, 17(1/2), p29-39.

Twyford, Phil (4 January 2010). Public sector reform McCully style. In New Zealand Labour. Retrieved 26 March 2010 from http://blog.labour.org.nz/index.php/2010/01/04/public-sector-reform-mccullystyle/

Tsoukas, Haridimos (2003). New times, fresh challenges: reflections on the past and the future of organization theory. In Tsoukas, Haridimos and Knudsen, Christian (Eds.), The Oxford handbook of organization theory (p607-22). Auckland: Oxford University Press.

UNDP (2006). Participatory local development. Retrieved 12 April 2010 from http://www.undp.org/poverty/focus_local_development.shtml

UN Millennium Project (2005). Investing in development: A practical plan to achieve the Millennium Development Goals: Overview. New York: Millennium Project.

USAID. (21 July 1995). New partnerships initiative: NGO empowerment. Retrieved 14 October 2009 from http://www.usaid.gov/pubs/npi/corerept/npingo.htm

Waisbord, Silvio (2006). When training is insufficient: Reflections on capacity development in health promotion in Peru. Health Promotion International, 21(3), p230-237.

Watkins, Kevin et al. (2005). Human development report 2005. New York: United Nations Development Program.

White, Sarah C. (1996). Depoliticising development: The uses and abuses of participation. Development in Practice, 6(1), p6-15. 
Zagha, Roberto (Author), Zagha, Roberto and Nankani, Gobind T. (Eds.) (2005). Economic growth in the 1990s: Learning from a decade of reform. Washington, DC: The International Bank for Reconstruction and Development/The World Bank.

Zaidi, S. Akbar (1999). NGO failure and the need to bring back the state. Journal of International Development, 11(2), p259-71. 